\title{
Estudo do emprego do Compactador Giratório Superpave na compactação de um solo argiloso
}

Dissertação apresentada à Escola de Engenharia de São Carlos da Universidade de São Paulo, como parte dos requisitos para a obtenção do Título de Mestre em Ciências, Programa de Pós-Graduação em Engenharia de Transportes.

Área de concentração: Infraestrutura de Transportes

Orientadora: Prof. Dra. Ana Paula Furlan 


\section{AUTORIZO A REPRODUCÃO TOTAL OU PARCIAL DESTE TRABALHO, POR QUALQUER MEIO CONVENCIONAL OU ELETRÔNICO, PARA FINS DE ESTUDO E PESQUISA, DESDE QUE CITADA A FONTE.}

Dantas, Gustavo Henrique Santana

D192e

Estudo do emprego do compactador giratório

Superpave na compactação de um solo argiloso / Gustavo Henrique Santana Dantas; orientadora Ana Paula Furlan. São Carlos, 2013.

Dissertação (Mestrado) - Programa de Pós-Graduação em Engenharia de Transportes e Área de Concentração em Infra-Estrutura de Transporte -- Escola de Engenharia de São Carlos da Universidade de São Paulo, 2013.

1. Solo argiloso. 2. Compactação. 3. Método Proctor. 4. Compactador giratório Superpave. I. Título. 


\section{FOLHA DE JULGAMENTO}

Candidato: Engenheiro GUSTAVO HENRIQUE SANTANA DANTAS.

Título da dissertação: "Estudo do emprego do compactador giratório superpave nâ compactação de um solo argiloso".

Data da defesa: 06/02/2013

Comissão Julgadora:

Prof $f^{\mathrm{a}}$. Dra . Ana Paula Furlan (Orientadora)

(Escola de Engenharia de São Carlos/EESC)

Prof. Titular Alexandre Benetti Parreira

(Escola de Engenharia de São Carlos/EESC)

Prof. Dr. Erinaldo Hilário Cavalcante

(Universidade Federal de Sergipe/UFS)
Resultado:

aprouado

APROVADO

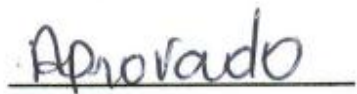

Coordenador do Programa de Pós-Graduação em Engenharia de Transportes: Prof. Associado Antônio Nélson Rodrigues da Silva

Presidente da Comissão de Pós-Graduação:

Prof. Titular Denis Vinicius Coury 



\section{DEDICATÓRIA}

Aos meus pais, Edivaldo e Sonia, exemplos de força, companheirismo e competência. 

A Deus, por ter me dado saúde para realizar esse mestrado e por cuidar da saúde dos meus entes queridos.

Aos meus pais, Edivaldo e Sonia, e meus queridos irmãos, Márcio e Marcelo, por terem me apoiado durante toda essa jornada; sem eles isso nunca seria possível.

À minha companheira, amiga e noiva, Andra, por estar sempre ao meu lado me apoiando e incentivando. Essa vitória é nossa.

Aos meus parentes em Aracaju, em especial a minha vó, Dona Zezé, por torcerem sempre por $\operatorname{mim}$.

À minha orientadora, Prof. Dra. Ana Paula Furlan, por ter a coragem de me aceitar como orientado naquela altura do campeonato, por acreditar em mim e neste trabalho e por toda paciência e dedicação.

Ao meu ex-orientador, Prof. Parreira, por acreditar no meu potencial e por ter me guiado durante quase todo este trabalho.

Aos professores do Departamento de Engenharia de Transportes da EESC-USP pelos conhecimentos transmitidos, em especial, ao Prof. Dr. Glauco Tulio Pessa Fabbri, pelos ensinamentos e contribuições feitas a este trabalho.

Aos amigos e técnicos, Paulo, João e Gigante, pelos ensinamentos, paciência e acolhimento no laboratório, proporcionando sempre momentos de descontração e alegria.

Aos funcionários do STT, Alexandre, Toco, Paulinho, Magaly, Suely, Beth, Heloisa.

À turma de 2010, pelos momentos sempre divertidos, em especial, aos amigos Jean, Andressa, Luis Miguel e Alex pela ajuda e apoio em vários momentos.

À CAPES pela bolsa de mestrado.

Ao Prof. Erinaldo e aos técnicos Washington e Willami da Universidade Federal de Sergipe que me incentivaram muito a seguir esta área.

Aos meus amigos de Aracaju pela torcida. 



\section{RESUMO}

DANTAS, G. H. S. (2012). Estudo do emprego do compactador giratório Superpave na compactação de um solo argiloso. Dissertação (Mestrado) - Escola de Engenharia de São Carlos, Universidade de São Paulo.

Esta pesquisa apresenta um estudo acerca da viabilidade do uso do Compactador Giratório Superpave (CGS) no ensaio de compactação de solos e mostra também um paralelo entre o ensaio de compactação Proctor e o ensaio de compactação no CGS. Para isso, foi selecionado um solo argiloso para ser submetido a ensaios de compactação Proctor e a ensaios de compactação com uso do compactador giratório. Nos ensaios com CGS foram utilizadas três tensões normais $(200,400$ e $600 \mathrm{kPa})$ e corpos de prova de $1000 \mathrm{~g}$ e $1800 \mathrm{~g}$. Também foi avaliado o comportamento mecânico de corpos de prova, moldados estaticamente e por amassamento, por meio dos ensaios de compressão simples, resistência a tração por compressão diametral e triaxial cíclico. No final, foi sugerido um procedimento de compactação de solos no CGS. Nos ensaios com o CGS, verificou-se que os valores de massa específica aparente seca (MEAS) (a) foram muito menores para os ensaios com $200 \mathrm{kPa}$ que aqueles apresentados nas tensões de $400 \mathrm{kPa}$ e $600 \mathrm{kPa}$; (b) apresentaram diferenças muito pequenas entre os ensaios de 400 e $600 \mathrm{kPa}$; (c) foram maiores para os CPs de $1000 \mathrm{~g}$ que para os CPs de $1800 \mathrm{~g}$ e (d) não tiveram ganho expressivo após 75 giros. A comparação entre as curvas de compactação Proctor e do CGS mostrou que os ensaios no CGS com tensão normal de $400 \mathrm{kPa}$ e $600 \mathrm{kPa}$ atingiram a massa específica seca máxima $\left(\mathrm{MEAS}_{\text {máx }}\right)$ do Proctor Intermediário, mas não a do Proctor Modificado. Quanto aos ensaios mecânicos, os corpos de prova moldados no CGS apresentaram, de maneira geral, melhores resultados de resistência à compressão simples e resistência a tração por compressão diametral, enquanto que para o MR, observou-se uma tendência de melhor desempenho dos CPs moldados estaticamente.

Palavras-chaves: Compactação de solos; método Proctor; compactador giratório Superpave; massa específica seca. 

DANTAS, G. H. S. (2012). Study of the feasibility for using the Superpave Giratory Compactor in a clayey soil compaction. Master Thesis (Mastering) - Engineering School of Sao Carlos, University of Sao Paulo.

This research presents the feasibility for using the Superpave Giratory Compactor (SGC) in soils compaction and a comparative evaluation between Proctor's and SGC's compaction processes. In order to evaluate the SGC compactor, a clayey soil was submitted SGC compaction tests at three normal stress $(200,400$ and $600 \mathrm{kPa})$ and two different weight specimens (1000 and $1800 \mathrm{~g})$. Mechanical tests to determinate the compression and tensile strength and resilient modulus were done on specimens compacted statically and by kneading. Additionally, it is suggested a compaction protocol test on SGC. About SGC's result tests indicated that dry densities values (a) at $200 \mathrm{kPa}$ were lower than those obtained at 400 and $600 \mathrm{kPa}$; (b) at 400 and $600 \mathrm{kPa}$ did not exhibit important variations (c) of $1000 \mathrm{~g}$ specimens were higher than the $1800 \mathrm{~g}$ ones and (d) did not increases after 75 number of gyrations. Regarding to mechanical properties, it can be detected that, in general, compression and tensile strength of SGC's specimens were better than the specimens compacted statically ones, and, as resilient modulus, specimens compacted statically had better perform than SGC's specimens.
\end{abstract}

Keywords: Soils compaction; Proctor Test; Superpave Gyratory Compactor; dry unit mass. 



\section{LISTA DE FIGURAS}

Figura 2.1 - Aspecto da curva de compactação de um solo qualquer 27

Figura 2.2 - Influência de diferentes níveis de energia de compactação nas curvas de compactação de um mesmo solo (adaptado do DNIT, 2006) 28

Figura 2.3 - Prensa giratória do Texas (Harman et al., 2002) 34

Figura 2.4 - Compactador giratório por amassamento do USACE (Harman et al., 2002) 35

Figura 2.5 - Exemplo de influência do número de giros sobre a curva de compactação feita no CGS (Ping et al., 2003a) 40

Figura 2.6 - Exemplo da influência da tensão normal sobre a compactação de solos (Ping et al., 2003a)

Figura 3.1 - Indicação da localização da coleta do solo 47

Figura 3.2 - Aspectos do local de coleta do solo 48

Figura 3.3 - Curva granulométrica do solo 49

Figura 3.4 - Gráfico de classificação MCT com a indicação do posicionamento do solo (Nogami; Villibor, 1995) 51

Figura 3.5 - Compactador giratório Superpave utilizado na pesquisa (Modelo SERVOPAC)

Figura 3.6 - Posição da tensão normal, do ângulo de giro e da amostra de solo numa vista em corte do molde do CGS 54

Figura 3.7 - Moldes de aço para compactação no CGS 55

Figura 3.8 - Moldagem de corpos de prova no CGS 58

Figura 3.9 - Modelo de planilha do Excel com dados de saída do CGS 59

Figura 3.10 - Esquema ilustrativo do Locking Point, segundo definição de VAVRIK e CARPENTER (1998) 61

Figura 3.11 - Prensa empregada na moldagem estática dos corpos de prova 62

Figura 3.12 - Corpo de prova colado com emulsão asfáltica 64

Figura 3.13 - Imagem do programa de aquisição de dados em plataforma LabView 67

Figura 4.1 - Curvas de compactação Proctor nas energias normal, intermediária e modificada 70

Figura 4.2 - Curvas de compactação para tensão normal de $200 \mathrm{kPa}$ e 500 giros 72

Figura 4.3 - Curvas de compactação para tensão normal de 400 kPa e 500 giros 73

Figura 4.4 - Curvas de compactação (CGS) para tensão de 600 kPa e 500 giros 74 
Figura 4.5 - Influência da massa úmida por CP na $\mathrm{MEAS}_{\text {máx }}$ no ensaio de compactação no CGS

Figura 4.6 - Curvas de compactação no CGS para as tensões de 200, 400 e 600 kPa e CPs de $1000 \mathrm{~g}$

Figura 4.7 -Curvas de compactação no CGS para as tensões de 200, 400 e 600 kPa e CPs de $1800 \mathrm{~g}$

Figura 4.8 - Influência da tensão normal na MEAS ${ }_{\text {máx }}$ no ensaio de compactação no CGS _ 79

Figura 4.9 - MEAS versus número de giros para CPs de $1000 \mathrm{~g}$ e tensão normal de $200 \mathrm{kPa} 80$ Figura 4.10 - MEAS versus número de giros para CPs de $1800 \mathrm{~g}$ e tensão normal de $200 \mathrm{kPa}$

Figura 4.11 - MEAS versus número de giros para CPs de $1000 \mathrm{~g}$ e tensão normal de 400 kPa

Figura 4.12 - MEAS versus número de giros para CPs de $1800 \mathrm{~g}$ e tensão normal de $400 \mathrm{kPa}$

Figura 4.13 - MEAS versus número de giros para CPs de $1000 \mathrm{~g}$ e tensão normal de $600 \mathrm{kPa}$

Figura 4.14 - MEAS versus número de giros para CPs de $1800 \mathrm{~g}$ e tensão normal de $600 \mathrm{kPa}$ 84

Figura 4.15 - Curvas de compactação Proctor e CGS a 500 giros (CPs de 1000g) 95

Figura 4.16 - Curvas de compactação Proctor e CGS a 500 giros (CPs de 1800g) 96

Figura 4.17 - MEAS $_{\text {máx }}$ para curvas Proctor e CGS a 500 giros 97

Figura 4.18 - Corpo de prova após ensaio de Compressão Simples 99

Figura 4.19 - RCS $_{\text {média }}$ para CPs moldados estaticamente e no CGS 102

Figura 4.20 - RTCD média para CPs moldados estaticamente e no CGS 105

Figura 4.21 - Tela do programa empregado para a calibração dos modelos matemáticos de Módulo de Resiliência 107 


\section{LISTA DE TABELAS}

Tabela 2.1 - Valores de energia do ensaio Proctor (NBR 7182/1986) 29

Tabela 2.2 - Evolução do compactador giratório (Adaptado de Harman et al., 2002) 32

Tabela 3.1 - Massa específica e limites de Atterberg do solo utilizado na pesquisa 49

Tabela 3.2 - Composição granulométrica do solo do solo utilizado na pesquisa 50

Tabela 3.3 - Parâmetros e índices obtidos nos ensaios de Mini-MCV e Perda de Massa por Imersão 50

Tabela 3.4 - Classificação do solo segundo HRB, SUCS e MCT 51

Tabela 3.5 - Intervalos de variação dos parâmetros do CGS 55

Tabela 3.6 - Configurações do CGS para ensaio de compactação 57

Tabela 3.7 -Combinações entre os parâmetros ótimos e a forma de compactar 63

Tabela 3.8 - Sequência de tensões de ensaio para base/sub-base segundo a AASHTO T 30799 66

Tabela 4.1 - Parâmetros ótimos das curvas de compactação Proctor 71

Tabela 4.2 - Porcentagens das variações dos parâmetros ótimos no ensaio Proctor 71

Tabela $4.3-w_{o}$ e MEAS $_{\text {máx }}$ para ensaio de compactação com tensão normal de $200 \mathrm{kPa}$ e 500 giros

Tabela $4.4-w_{o}$ e MEAS $_{\text {máx }}$ para ensaio de compactação com tensão normal de 400 kPa e 500 giros

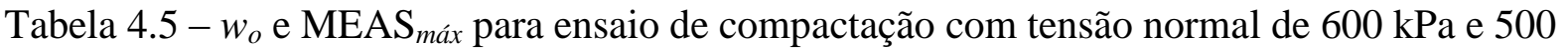
giros 75

Tabela 4.6 - Parâmetros ótimos dos ensaios de compactação com CGS 78

Tabela 4.7 - Valores de n' para ensaios de compactação com 200kPa e 500 giros 86

Tabela 4.8 - Valores de n' para ensaios de compactação com 400kPa e 500 giros 87

Tabela 4.9 - Valores de LP para ensaios de compactação com 600kPa e 500 giros 88

Tabela 4.10 - Resumo dos valores de n' médio dos ensaios de compactação 89

Tabela 4.11 - Valores de LP para ensaios de compactação com 200kPa e 500 giros 90

Tabela 4.12 - Valores de LP para ensaios de compactação com 400kPa e 500 giros 92

Tabela 4.13 - Valores de LP para ensaios de compactação com 600kPa e 500 giros 93

Tabela 4.14 - Resumo dos valores de LP dos ensaios de compactação no CGS 94

Tabela 4.15 - MEAS $_{\text {máx }}$ dos ensaios Proctor e CGS a 500 giros 97 
Tabela 4.16 - RCS para CPs moldados estaticamente e no CGS, na energia do Proctor Normal 99

Tabela 4.17 - RCS para CPs moldados estaticamente e no CGS, na energia do Proctor Normal 100

Tabela 4.18 - RCS para CPs moldados estaticamente e no CGS, na energia do Proctor Intermediário 101

Tabela 4.19 - RTCD para CPS moldados estaticamente e no CGS, na energia do Proctor Normal 103

Tabela 4.20 - RTCD para CPS moldados estaticamente e no CGS, na energia do Proctor Intermediário 104

Tabela 4.21 - Modelos avaliados na representação do MR em função do estado de tensões 106 Tabela 4.22 - Coeficientes de determinação médios $\left(\mathrm{R}^{2}\right)$ dos modelos matemáticos para o MR 108

Tabela 4.23 - MRs para o modelo composto e tensões de $\sigma_{3}=34,5 \mathrm{kPa}$ e $\sigma_{\mathrm{d}}=93,1 \mathrm{kPa} \_109$ 


\begin{tabular}{|c|c|}
\hline $\mathrm{CP}$ & Corpo de prova \\
\hline$\%$ & Porcentagem \\
\hline AASHTO & American Association of State Highway and Transportation Officials \\
\hline $\mathrm{ABNT}$ & Associação Brasileira de Normas Técnicas \\
\hline ASTM & American Society for Testing and Materials \\
\hline$c^{\prime}$ & Coeficiente de deformabilidade da classificação MCT \\
\hline CGS & Compactador Giratório Superpave \\
\hline $\mathrm{cm}$ & centímetro \\
\hline $\mathrm{CS}$ & Compressão simples \\
\hline$d^{\prime}$ & $\begin{array}{l}\text { Coeficiente que caracteriza o ramo seco da curva de compactação obtida } \\
\text { pelo método MCT }\end{array}$ \\
\hline DNER & Departamento Nacional de Estradas de Rodagem \\
\hline DNIT & Departamento Nacional de Infraestrutura de Transportes \\
\hline$e^{\prime}$ & Índice de classificação MCT, calculado em função de Pi e d' \\
\hline EUA & Estados Unidos de America \\
\hline GTM & Gyratory Testing Machine \\
\hline $\mathrm{kPa}$ & Quilopascal \\
\hline LCPC & Laboratoire Central des Ponts et Chaussées \\
\hline Locking Point & Ponto de Travamento dos Agregados \\
\hline LP & Locking point \\
\hline LVDT & Linear Variable Differencial Transducers \\
\hline MCT & Miniatura Compactado Tropical \\
\hline $\mathrm{MCV}$ & Moisture Condition Value \\
\hline MEAS & Massa específica aparente seca \\
\hline $\operatorname{MEAS}_{\text {máx }}$ & Massa específica aparente seca máxima \\
\hline $\mathrm{mm}$ & milímetro \\
\hline $\mathrm{MPa}$ & Megapascal \\
\hline MR & Módulo de resiliência \\
\hline n' & Número de giros crítico \\
\hline PCG & Prensa de Cisalhamento Giratório \\
\hline $\mathrm{R}^{2}$ & Coeficiente de determinação \\
\hline RTCD & Resistência à tração por compressão diametral \\
\hline
\end{tabular}


$\sigma_{3}$

$\sigma_{\mathrm{d}}$

SGC

SHRP

Superpave

USACE

w

$w_{o}$
Tensão de confinamento no ensaio Triaxial Cíclico

Tensão Desvio no ensaio Triaxial Cíclico

Superpave Gyratory Compactor

Strategic Highway Research Program

Superior Performing Asphalt Pavements

United States Army Corps of Engineers

teor de umidade

teor de umidade ótimo 
1. INTRODUÇÃO

1.1 CONSIDERAÇÕES INICIAIS 21

1.2 IDENTIFICAÇÃO DO PROBLEMA E JUSTIFICATIVA 23

1.3 OBJETIVOS 24

2. REVISÃO BIBLIOGRÁFICA 25

2.1 MÉTODOS DE COMPACTAÇÃO NO LABORATÓRIO 25

2.1.1 Compactação por impacto 26

2.1.2 Compactação estática __ 29

2.1.3 Compactação por amassamento _ـ 30

2.1.3.1. Considerações gerais __ 30

2.1.3.2. Compactador giratório do Texas ___ 33

2.1.3.3. Compactador giratório do USACE __ 34

2.1.3.4. Compactador giratório do LCPC __ 37

2.1.3.5. Compactador Giratório Superpave___ 38

2.1.3.6. Pesquisas com uso do compactador giratório em solos _ 39

2.1.4 Métodos de compactação menos utilizados ___ 43

3. MATERIAIS E MÉTODOS__ 45

3.1. DELINEAMENTO EXPERIMENTAL ___ 45

3.2. SOLO

3.2.1. Escolha do solo___ 46

3.2.2. Coleta do solo _ 47

3.2.3. Preparação do solo __ 48

3.2.4. Massa específica dos sólidos, limites de Atterberg e granulometria do solo __ 48

3.2.5. Ensaios da Metodologia MCT

3.2.6. Classificações geotécnicas do solo _ـ_ 51

3.3. ENSAIOS DE COMPACTAÇÃO _____________ 52

3.3.1. Ensaio de compactação Proctor ___ 52

3.3.2. Ensaio de compactação com uso do CGS _

3.3.2.1. Compactador Giratório Superpave___ 52

3.3.2.2. Escolha das configurações do CGS __ 56

3.3.2.3. Procedimento de execução do ensaio de compactação 
3.3.2.4. Análise dos dados de saída do CGS

3.3.2.5. Análise da densificação dos corpos de prova no CGS_ 60

3.4. ENSAIOS MECÂNICOS ___ 61

3.4.1. Condições para ensaio __ 62

3.4.2. Ensaio de Compressão Simples ___ 63

3.4.3. Ensaio de Compressão Diametral ___ 64

3.4.4. Ensaio Triaxial Cíclico__ 65

4. APRESENTAÇÃO E ANÁLISE DOS RESULTADOS __ 69

4.1 CONSIDERAÇÕES GERAIS ___ 69

4.2 ENSAIOS DE COMPACTAÇÃO PROCTOR _ 70

4.3 ENSAIOS DE COMPACTAÇÃO NO CGS ___ 72

4.3.1 Influência da massa úmida do corpo de prova __ 72

4.3.2 Influência da tensão normal __ 76

4.3.3 Estudo dos dados de saída do CGS___ 80

4.3.3.1 Massa específica aparente seca versus número de giros_ 80

4.3.3.2 Ajuste da curva massa específica versus número de giros

4.3.3.3 Locking Point _ 90

\subsection{CURVAS DE COMPACTAÇÃO PROCTOR VERSUS CURVAS DE}

COMPACTAÇÃO DO CGS ___ 95

4.5 ENSAIOS MECÂNICOS _ 98

4.5.1 Ensaio de Compressão Simples___ 98

4.5.2 Ensaio de Compressão Diametral ___ 102

4.5.3 Ensaio Trixial Cíclico __ 105

4.5.3.1 Calibração do modelo matemático _ 105

4.5.3.2 Módulo de resiliência para um estado de tensão específico 109

5. CONCLUSÕES E RECOMENDAÇÕES___ 111

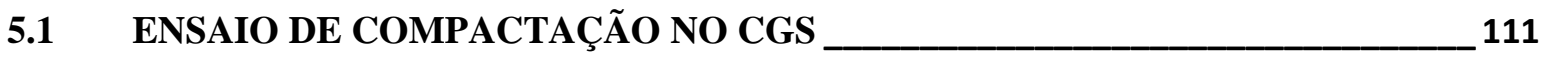

5.2 COMPACTAÇÃO PROCTOR VERSUS COMPACTAÇÃO NO CGS _ 113

5.3 PROCEDIMENTO PARA ENSAIO DE COMPACTAÇÃO NO CGS COM SOLO

ARGILOSO _ 114

5.4 SUGESTÕES PARA PESQUISAS FUTURAS 114

REFERÊECIAS — 117

ANEXO A - CÁLCULO DA ENERGIA APLICADA PELO CGS _ 121 


\section{INTRODUÇÃO}

\subsection{CONSIDERAÇÕES INICIAIS}

Nas obras com grandes movimentações de terra, como aterros, barragens e rodovias, o uso de solos encontrados na própria região como material construtivo é, na maior parte das situações, condição necessária para realização da construção, pois conduz a reduções drásticas no orçamento final, viabilizando, em muitos casos, a execução do serviço.

Todavia, na maior parte das vezes, as propriedades geotécnicas dos materiais encontrados no local não estão em níveis recomendáveis. Assim, faz-se necessário submeter os solos a processos de melhoramento geotécnico, como as estabilizações granulométricas, as estabilizações químicas por adição de cal, cimento ou ligantes asfálticos e o melhoramento do comportamento mecânico por meio da compactação de solos. Esta última sendo a forma mais empregada mundialmente como mecanismo de melhoramento das propriedades geotécnicas de um solo.

A compactação de solos é realizada com o intuito de se evitar problemas diversos, como recalques excessivos em rodovias e aterros, ruptura de taludes e de barragens, etc. No caso da pavimentação, o procedimento de compactar solos normalmente é guiado pelas especificações de projeto, que determinam as características construtivas para cada uma das camadas constituintes do pavimento. Estas especificações recomendam propriedades geotécnicas desejáveis aos solos constituintes das camadas, tais como, granulometria, índices de consistência, umidade, massa específica seca, etc; outras recomendações podem também 
serem feitas com base em propriedades mecânicas, como módulo de resiliência, resistência a compressão diametral, deformação permanente, entre outras.

Contudo, o engenheiro projetista deve ter em mente que o controle das camadas executadas de um pavimento deve ser feito no próprio local e, preferencialmente, de forma expedita. No entanto, é comum que no canteiro de obras não existam meios de se fazer ensaios geotécnicos mais complexos, como ensaios mecânicos. Portanto, métodos mais expeditos e simples devem ser utilizados no controle dos serviços de pavimentação.

O teor de umidade do solo e sua massa específica seca são os parâmetros mais empregados para controle de execução de camadas de pavimentos, pois estas duas propriedades são de simples controle para o empreiteiro. A umidade de um solo pode ser medida no campo por meio de métodos como speedy (DNER 052/94), método da frigideira mais álcool (DNER 088/94) ou estufa a vácuo ou com ventilação forçada. Quanto a massa específica seca, existem métodos como o do frasco de areia (DNER 092/94), o do balão de borracha (DNER 036/94) e o de emprego do óleo (DNER 037/94).

Sendo assim, o projetista deve especificar o teor de umidade e massa específica seca de cada uma das camadas do pavimento, além de outros parâmetros de compactação. Para obtenção destes parâmetros, o engenheiro projetista normalmente recorre ao ensaio de compactação, mais consagrado e usual no meio rodoviário, principalmente pela sua praticidade e agilidade em ser realizado, se comparado a aterros experimentais.

Internacionalmente, o ensaio de compactação mais difundido foi padronizado baseando-se nos estudos do Engenheiro Ralph R. Proctor, na década de 1930, no estado da Califórnia, sendo conhecido como Ensaio de Compactação Proctor. Por meio deste ensaio, Proctor verificou que a massa específica seca máxima $\left(M_{E A S}\right.$ máx $)$ é característica de uma determinada umidade, denominada de umidade ótima $\left(w_{o}\right)$, e um dado esforço de compactação aplicado.

No Brasil, o ensaio de compactação Proctor é normatizado pela Associação Brasileira de Normas Técnicas (NBR 7182/86), com o nome de Solo - ensaio de compactação, e pelo DNIT (DNER - ME 129/94), com o nome de Solos - compactação utilizando amostras não trabalhadas. 
No ensaio Proctor, a amostra de solo sofre um processo de compactação dinâmica ou por impacto, no qual a amostra de solo é confinada em um molde e submetida a uma série de golpes de um soquete. Porém, no campo, a compactação imprimida ao solo pelos equipamentos de terraplenagem é uma junção de diversas ações, como impacto, amassamento e vibração. Por isso, existem diversas técnicas para se fazer o ensaio de compactação em laboratório e todas idealizadas com o objetivo de representar com o maior grau de fidelidade possível a compactação realizada em campo. Dentre outras formas de realizar o ensaio de compactação, destacam-se a compactação estática, a compactação por amassamento e a compactação por vibração.

\subsection{IDENTIFICAÇÃO DO PROBLEMA E JUSTIFICATIVA}

O ensaio Proctor compacta a amostra de solo por impacto, enquanto que no campo o que se observa é uma composição de várias ações: força estática, vibração, amassamento e pisoteamento. Além disso, os equipamentos de compactação de campo, assim como as técnicas e a tecnologia empregadas, desenvolveram-se muito nos últimos anos e, em contrapartida, o principal método de compactação em laboratório, o ensaio Proctor, não evoluiu muito desde sua concepção. Esta constatação, aliada à ineficiência já comprovada da compactação por impacto com solos não-coesivos, sugere que as densidades secas alcançadas no campo podem ser maiores que aquelas obtidas do ensaio Proctor (Browne, 2006; Ping et al., 2003a).

Desta forma, pesquisas sobre métodos de compactação de solos em laboratório vêm sendo retomadas, dentre elas a compactação por amassamento com aplicação do compactador giratório. Atualmente, os compactadores giratórios são equipamentos capazes de aplicar simultaneamente uma carga vertical e uma tensão cisalhante, por meio do giro do molde de compactação sob um ângulo de inclinação. Esse mecanismo de ação do compactador giratório simula de forma mais semelhante a compactação de campo, se comparado ao Ensaio Proctor. Além disso, o compactador giratório tem apresentado um histórico positivo na compactação de misturas asfálticas (Mokwa; Cuelho; Browne; 2008; Ping et al., 2003a). 
Todavia, apesar dessas vantagens, ainda não existem normas que especifiquem o ensaio de compactação com solos utilizando o compactador giratório e poucos estudos foram realizados sobre tal tema. Dentre os estudos merecem destaque as pesquisas de Ping et al. (2003a e 2003b) e de Browne (2006).

Assim, esta pesquisa justifica-se principalmente na investigação de um método de compactação de solos alternativo ao ensaio Proctor, usando-se o compactador giratório como tentativa de melhor simular a compactação em campo, e na esperança de trazer a luz mais dados que auxiliem uma futura normatização da técnica de compactação de solos com compactador giratório.

\subsection{OBJETIVOS}

O objetivo principal desta pesquisa foi comparar os métodos de compactação por impacto e amassamento, representados, respectivamente, pelo ensaio Proctor e pelo Compactador Giratório Superpave (CGS), a partir da análise das respectivas curvas de compactação obtidas para um solo argiloso. Igualmente aos ensaios de compactação, também foram realizados ensaios de compressão simples, compressão diametral e módulo de resiliência em corpos de prova moldados na prensa estática e no CGS.

Como a compactação de solos com o CGS ainda é algo recente no Brasil, foi objetivo também desta pesquisa estudar algumas características e particularidades do processo de compactação no CGS, como tensão normal utilizada, número de giros e massa úmida por corpo de prova. Por meio dos dados fornecidos pelo CGS, avaliou-se a influência desses parâmetros, com o intuito de sugerir, ao final da pesquisa, um roteiro para compactar solos argilosos no CGS. 


\section{REVISÃO BIBLIOGRÁFICA}

Neste capítulo são abordados os métodos de compactação de solos em laboratório, dando ênfase à compactação por amassamento, aos principais compactadores giratórios desenvolvidos e às pesquisas sobre uso do compactador giratório na compactação de solos.

\subsection{MÉTODOS DE COMPACTAÇÃO NO LABORATÓRIO}

A compactação de amostras de solo em laboratório pode ser realizada através de diversos métodos, sendo que todos foram idealizados com o intuito de assemelhar-se ao máximo com a compactação executada no campo. Contudo, os mecanismos de compactação dos equipamentos de campo são de difícil reprodução em laboratório, visto que, um mesmo equipamento, em geral, executa a compactação por meio de diversas ações simultaneamente, tais como: amassamento, impacto e vibração.

Porém, mesmo assim, compactar solos em laboratório é muito importante, pois permite que se obtenham os parâmetros umidade ótima e massa específica seca máxima de forma mais rápida, precisa e econômica, se comparada, por exemplo, aos aterros experimentais.

Os métodos de compactação em laboratório podem ser categorizados em cinco tipos, a saber: 
- compactação por impacto ou dinâmica, caracterizada pela ação de queda de um soquete sobre uma amostra de solo, confinada em um molde cilíndrico;

- compactação estática ou por pressão, em que é exercida uma pressão constante (ou variável) sobre uma amostra de solo confinada em um molde em uma velocidade relativamente baixa;

- compactação por amassamento, na qual a amostra de solo é compactada pela ação de amassamento de um compactador giratório;

- compactação por pisoteamento, na qual golpes são aplicados a amostra de solo através de um pistão com mola;

- compactação por vibração, em que se aplica com ou sem uma sobrecarga a ação de vibração sobre a amostra de solo.

Nos próximos itens, serão apresentados com maiores detalhes os métodos de compactação mencionados anteriormente, dando-se um maior destaque à compactação por amassamento com uso do compactador giratório.

\subsubsection{Compactação por impacto}

A compactação de solos por impacto ou dinâmica ainda é a forma mais empregada mundialmente para realização do ensaio de compactação e consiste na aplicação de um número específico de golpes de um soquete que cai de uma altura pré-determinada, em uma amostra de solo confinada em um molde.

Não se sabe ao certo quem foi o pioneiro em compactar solos no laboratório dinamicamente. Todavia, o primeiro a publicar resultados a respeito deste assunto foi o Engenheiro Ralph R. Proctor, na década de 1930, no estado da Califórnia, EUA. Proctor publicou em 1933 uma série de artigos sobre suas observações acerca do processo de 
compactação de solos na construção de barragens e o controle de compactação em campo (Vargas, 1977).

Nesses artigos, Proctor expôs de maneira gráfica a relação existente entre o teor de umidade, a massa específica seca e o esforço de compactação imprimido a um solo. A curva proposta por Proctor relacionava o teor de umidade $(w)$ com a massa específica aparente seca (MEAS) e ficou conhecida mundialmente como de curva de compactação Proctor (Figura 2.1).

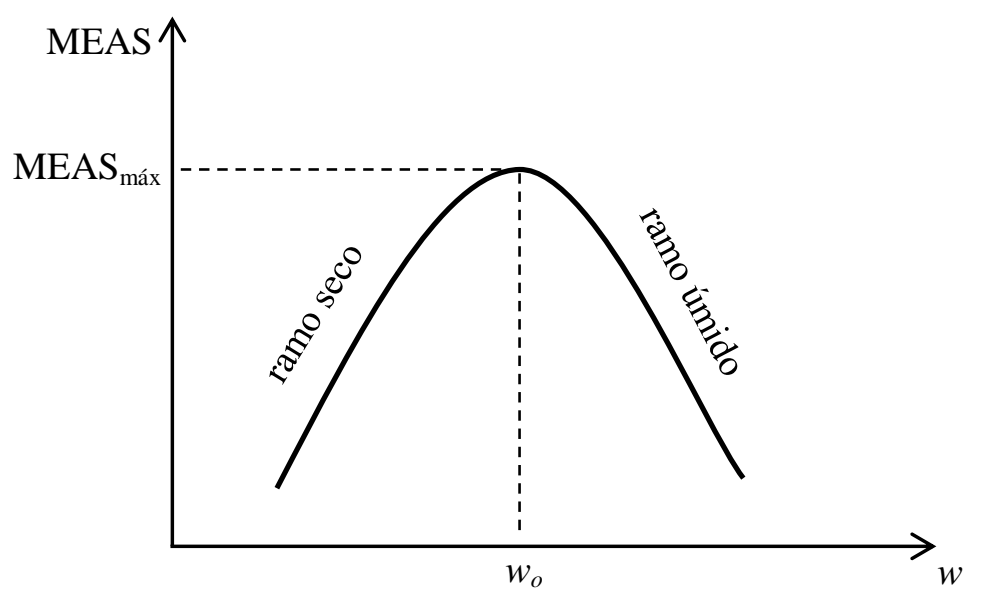

Figura 2.1 - Aspecto da curva de compactação de um solo qualquer

De maneira geral, a curva de compactação possui formato similar ao de uma parábola com concavidade voltada para baixo, onde o trecho ascendente é denominado de ramo seco e o descendente de ramo úmido.

O ponto de máximo da curva determina a umidade ótima $\left(w_{o}\right)$ e a massa específica seca máxima $\left(\mathrm{MEAS}_{\mathrm{máx}}\right)$ para o solo em questão em um determinado nível de energia aplicado. Esse ponto de máximo significa que se o solo for compactado no teor de umidade ótimo e com um nível de energia equivalente ao que foi empregado no ensaio, ele apresentará massa específica seca máxima.

Os valores do par ordenado ( $\left.w_{o}, \mathrm{MEAS}_{\text {máx }}\right)$ somente têm sentido se relacionados com a quantidade de energia aplicada no ensaio, pois de acordo com a quantidade de energia empregada um mesmo solo terá pares de valores diferentes como mostra a Figura 2.2. 


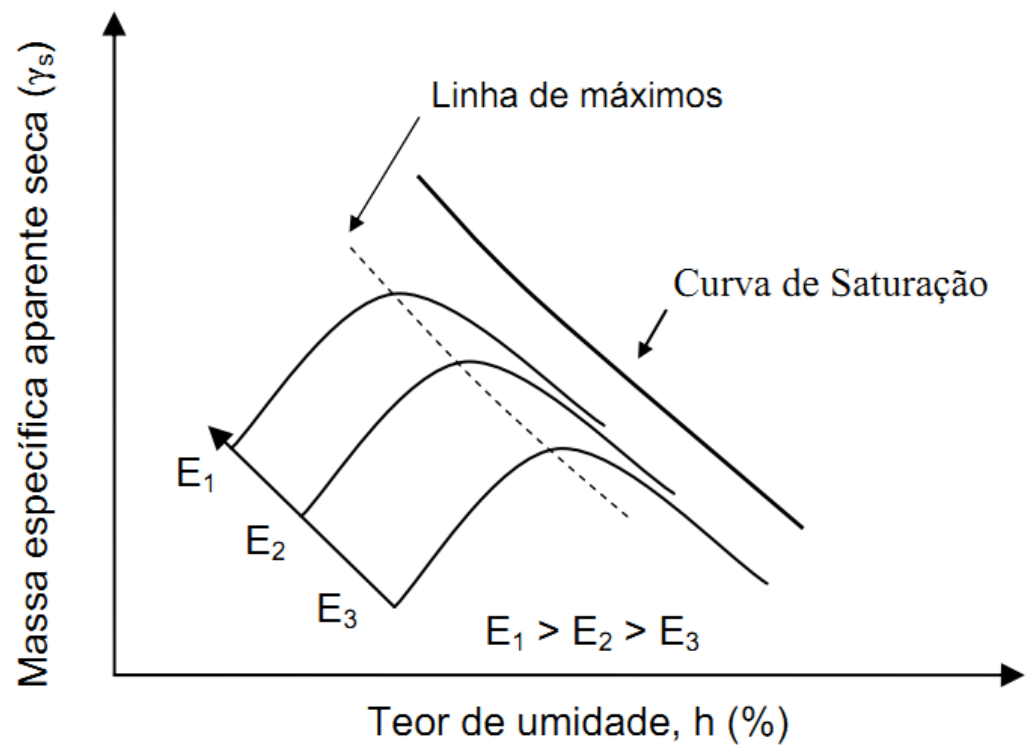

Figura 2.2 - Influência de diferentes níveis de energia de compactação nas curvas de compactação de um mesmo solo (adaptado do DNIT, 2006)

Segundo a Figura 4.2, quando maior a energia aplicada em um mesmo solo, maior será sua massa específica seca máxima e menor será a umidade ótima, isto é, a curva de compactação desloca-se para cima e para esquerda do plano cartesiano.

O ensaio de compactação idealizado por Proctor foi o primeiro a ser normatizado e talvez, por isso, seja até hoje o mais utilizado nos laboratórios. No Brasil, o ensaio de compactação Proctor é normatizado pela Associação Brasileira de Normas Técnicas (NBR 7182/86), com o nome de Solo - ensaio de compactação, e pelo DNIT (DNER - ME 129/94), com o nome de Solos - compactação utilizando amostras não trabalhadas; nas duas normas, o ensaio pode ser realizado em três níveis de energia, normal, intermediário e modificado.

A energia empregada no ensaio Proctor é calculada segundo a Equação 2.1.

$$
E c=\frac{P \cdot h \cdot N \cdot n}{V}
$$


Onde,

$\boldsymbol{E} \boldsymbol{c}$ : energia de compactação por unidade de volume $\left(\mathrm{J} / \mathrm{cm}^{3}\right)$

$P$ : peso do soquete $(\mathrm{N})$

$\boldsymbol{h}$ : altura de queda do soquete (m)

$N$ : número de golpes por camada

n: número de camadas

$V$ : volume do molde cilíndrico $\left(\mathrm{cm}^{3}\right)$

A Tabela 2.1 apresenta os valores de energia especificados pela norma NBR 7182/86, onde é possível verificar que a energia aplicada no Proctor Modificado é um pouco mais que o dobro do Proctor Intermediário e a energia deste é também um pouco mais que o dobro do Proctor Normal.

Tabela 2.1 - Valores de energia do ensaio Proctor (NBR 7182/1986)

\begin{tabular}{cc}
\hline Proctor & Energia $\left(\mathrm{J} / \mathrm{cm}^{3}\right)$ \\
\hline Normal & 0,59 \\
Intermediário & 1,30 \\
Modificado & 2,78 \\
\hline
\end{tabular}

\subsubsection{Compactação estática}

A compactação estática consiste em confinar uma amostra de solo em um molde e pressioná-la gradualmente por meio de uma carga estática, através de um pistão, geralmente hidráulico. Esta técnica de compactação é empregada principalmente quando se deseja moldar corpos de prova para ensaios mecânicos, pois ela permite repetir com maior precisão os resultados obtidos no ensaio Proctor em relação à compactação por impacto. 
Venkatarama Reddy e Jagadish (1993) classificam a compactação estática em dois tipos: tensão máxima constante - carga variável; e tensão máxima variável - carga constante. No primeiro, a amostra de solo é confinada em um molde e submetida à aplicação gradual de uma tensão que varia segundo uma (ou mais de uma) taxa, até que a tensão máxima seja atingida; a altura do corpo de prova é variável, dependendo do teor de umidade, pois o processo de compactação é encerrado quando a tensão máxima é alcançada.

No segundo tipo de compactação estática, uma carga constante é aplicada gradualmente sobre uma amostra de solo confinada em um molde até que uma altura específica seja alcançada; o critério de parada do processo de compactação é a altura determinada a ser atingida, ou seja, um determinado volume.

\subsubsection{Compactação por amassamento}

\subsubsection{Considerações gerais}

Segundo Harman et al.(2002), o primeiro serviço de pavimentação asfáltica nos Estados Unidos foi executado em 1870, na cidade de Newark, estado de New Jersey. Contudo, só após cerca de 70 anos, isto é, no período da Segunda Guerra Mundial, que houve uma intensificação no uso de materiais asfálticos, principalmente por causa da necessidade de se construir aeroportos. Como consequência direta a essa demanda, sucederam-se diversos avanços nos tipos de materiais e no projeto de misturas asfálticas.

Foi no período pós-segunda guerra mundial, fim dos anos 1950, que Bruce Marshall desenvolveu o método de dosagem de misturas asfálticas mais utilizado até hoje, conhecido como dosagem Marshall. Esse método utiliza o impacto como forma de compactação da amostra de mistura asfáltica, através de uma série de golpes de soquete sobre a amostra.

Além da dosagem Marshall, outros procedimentos desenvolvidos para dosagem de misturas asfálticas merecedores de destaque são o método Hubbard-Field, o Triaxial Smith 
e o método do compactador giratório do Texas, sendo este último o pioneiro na compactação de amostras por amassamento (Harman et al., 2002).

O compactador giratório do Texas foi idealizado com objetivo de simular mais fielmente a compactação em campo, assim como a degradação dos agregados causada pela produção, compactação e carregamento do tráfego ao longo dos anos. (Mokwa; Cuelho; Browne; 2008). Por este motivo e principalmente pelo histórico de sucessos, o compactador giratório acabou tornando-se a maneira mais eficiente de compactar misturas asfálticas em laboratório, sendo atualmente o principal método de compactação de misturas asfálticas nos Estados Unidos. Normas como a AASHTO T 312 - Standard Method of Test for Preparing and Determining the Density of Hot Mix Asphalt (HMA) Specimens by Means of the Superpave Gyratory Compactor - e a ASTM D6925 - 09 Standard Test Method for Preparation and Determination of the Relative Density of Hot Mix Asphalt (HMA) Specimens by Means of the Superpave Gyratory Compactor - são exemplos de especificações já consagradas para dosagem de misturas asfálticas usando o compactador giratório.

A AASHTO T 312, por exemplo, especifica para o procedimento de dosagem de misturas asfálticas no compactador giratório a compactação de CPs em uma frequência de 30 giros por minuto, tensão normal de $600 \mathrm{kPa} \pm 18 \mathrm{kPa}$, ângulo de giro de $1,25^{\circ} \pm 0,02^{\circ}$ e um número de giros variável, pois sua determinação está atrelada ao volume de vazios da mistura, que por sua vez depende do nível de tráfego previsto para o pavimento.

Normas como as citadas acima são exemplos da consolidação do compactador giratório como forma de compactar misturas asfálticas em laboratório. No entanto, o emprego do compactador giratório ainda se restringe a compactação de misturas asfálticas, não havendo normas que especifiquem sua utilização para compactação de solos.

Os conceitos do compactador giratório do Texas serviram de base para diversas pesquisas que resultaram no desenvolvimento de outros compactadores giratórios, como por exemplo, o GTM (Gyratory Test Machine) do Corpo de Engenheiros dos Estados Unidos (USACE) e o PCG (Prensa de Cisalhamento Giratório) do Laboratoire Central des Ponts et Chaussées (LCPC), na França.

O compactador giratório passou por muitas evoluções desde sua concepção em 1939. A Tabela 2.2 apresenta uma linha do tempo do progresso do compactador giratório e as principais agências responsáveis pelo desenvolvimento. 
Tabela 2.2 - Evolução do compactador giratório (Adaptado de Harman et al., 2002)

\begin{tabular}{|c|c|c|c|}
\hline $\begin{array}{l}\text { Linha do } \\
\text { tempo }\end{array}$ & Equipamento/Agência & $\begin{array}{l}\text { Dimensão do CP } \\
(\mathrm{mm})\end{array}$ & $\begin{array}{l}\text { Características da } \\
\text { compactação }\end{array}$ \\
\hline 1939 & $\begin{array}{l}\text { Concepção, Dep. de Transportes do } \\
\text { Texas }\end{array}$ & $\begin{array}{l}\text { D: } 101,6 \\
\text { H: } 50,8\end{array}$ & $\begin{array}{l}\text { P: desconhecida } \\
\text { A: manual } \\
\text { F: manual }\end{array}$ \\
\hline 1946 & $\begin{array}{ll}\text { Departamento de Transportes } & \text { do } \\
\text { Texas (normatização } & \text { do } \\
\text { procedimento) } & \end{array}$ & $\begin{array}{l}\text { D: } 101,6 \text { e } 152,46 \\
\text { H: } 50,8 \text { e } 76,2\end{array}$ & $\begin{array}{l}\text { P: variável } \\
\text { A: Fixado em } 6^{\circ} \\
\text { F: } 60 \mathrm{rpm}\end{array}$ \\
\hline 1957 & $\begin{array}{l}\text { GTM / Corpo de Engenheiros dos } \\
\text { EUA }\end{array}$ & $\begin{array}{l}\text { D: } 152,4 \\
\text { H: variável }\end{array}$ & $\begin{array}{l}\text { P: variável } \\
\text { A: oscilando de } 0 \text { a } 3^{\circ} \\
\text { F: variando de } 12 \text { a } 18 \\
\text { rpm }\end{array}$ \\
\hline 1960 ’s & $\begin{array}{l}\text { Primeiro protótipo do compactador } \\
\text { Texano no LCPC, França }\end{array}$ & $\begin{array}{l}\text { D: desconhecido } \\
\text { H: desconhecida }\end{array}$ & $\begin{array}{l}\text { P: variável } \\
\text { A: variável } \\
\text { F: variável }\end{array}$ \\
\hline 1968 & $\begin{array}{l}\text { Segundo protótipo do compactador } \\
\text { Texano no LCPC, França }\end{array}$ & $\begin{array}{l}\text { D: } 80 \text { ou } 120 \\
\text { H: variável }\end{array}$ & $\begin{array}{l}\text { P: Variável } \\
\text { A: Oscila de } 0,5 \text { a } 5^{\circ} \\
\text { F: Variável } \\
\text { M: Molde aquecido }\end{array}$ \\
\hline $\begin{array}{c}1974- \\
1985\end{array}$ & $\mathrm{PCG}_{1}, \mathrm{PCG}_{2} / \mathrm{LCPC}$, França & $\begin{array}{l}\text { D: } 160 \\
\text { H: Fixada de } 80 \text { a } 300\end{array}$ & $\begin{array}{l}\text { P: } 600 \mathrm{kPa} \\
\text { A: Fixado de } 1 \text { a } 4^{\circ} \\
\text { F: Fixado de } 6 \mathrm{rpm} \text { a } 30 \\
\text { rpm }\end{array}$ \\
\hline 1991 & $\begin{array}{l}\text { Equipamento de ensaio de } \\
\text { cisalhamento giratório modificado / } \\
\text { FHWA }\end{array}$ & $\begin{array}{l}\text { D: } 152,4 \\
\text { H: } 95,3\end{array}$ & $\begin{array}{l}\text { P: } 600 \mathrm{kPa} \\
\text { A: Fixada de } 0,5 \text { a } 3^{\circ} \\
\text { F: } 30 \mathrm{rpm}\end{array}$ \\
\hline 1991 & $\begin{array}{l}\text { Departamento de Transportes do } \\
\text { Texas, SHRP }\end{array}$ & $\begin{array}{l}\text { D: } 152,4 \\
\text { H: } 95,3\end{array}$ & $\begin{array}{l}\mathrm{P}: 600 \mathrm{kPa} \\
\mathrm{F}: \text { variável }\end{array}$ \\
\hline 1993 & $\begin{array}{l}\text { SHRP / Compactador Giratório } \\
\text { Superpave, EUA }\end{array}$ & $\begin{array}{l}\text { D: } 150 \\
\text { H: } 115\end{array}$ & $\begin{array}{l}\text { P: } 600 \mathrm{kPa} \\
\text { A: Fixado em } 1,25^{\circ} \\
\text { F: } 30 \mathrm{rpm}\end{array}$ \\
\hline 1996 & $\mathrm{PCG}_{3} / \mathrm{LCPC}$, França & $\begin{array}{l}\text { D: } 150 \\
\text { H: Fixada de } 100 \text { a } \\
160\end{array}$ & $\begin{array}{l}\text { P: Fixada de } 500 \text { a } 800 \\
\mathrm{kPa} \\
\text { A: Fixada de } 0,5 \text { a } 2^{\circ} \\
\text { F: Fixado de } 6 \text { a } 30 \mathrm{rpm}\end{array}$ \\
\hline
\end{tabular}

$\begin{array}{lll} & \text { D: diâmetro } & \text { A: ângulo de giro } \\ \text { Legenda } & \text { H: altura } & \text { F: frequência de giros } \\ & \text { P: tensão normal } & \end{array}$




\subsubsection{Compactador giratório do Texas}

No ano de 1939, o Departamento de Transportes do Texas inicou o desenvolvimento de uma prensa giratória manual para ensaios experimentais com solos e materiais a base de betume, referindo-se a este dispositivo como prensa giratória de solos, cuja ideia é atribuída à Philippi, Raines e Love ${ }^{1}$ (Ping et al., 2003a).

Esse departamento baseou o desenvolvimento da prensa giratória em três critérios:

i. o método deveria ser igualmente adaptável no controle de campo e no projeto de misturas asfálticas;

ii. o produto final da compactação deveria ter densidades e volume de vazios semelhantes ao pavimento finalizado exposto ao carregamento do tráfego;

iii. e, que simulasse a degradação do agregado que ocorre durante a compactação em campo (Harman et al., 2002).

Após a realização de uma série de pesquisas e procedimentos de ensaios experimentais, o Departamento de Transportes do Texas elaborou normas e procedimentos de ensaio para a prensa giratória, no ano de 1946 (Harman et al., 2002).

O processo de compactação na prensa giratória do Texas (Figura 2.3) consistia em colocar o material em um molde de aço de 1016 mm de diâmetro interno, que era colocado entre placas paralelas, sob um ângulo de 6 graus. O próximo passo era a aplicação de uma pressão de aproximadamente $345 \mathrm{kPa}$, por meio de um macaco hidráulico. A seguir, o molde era girado três vezes manualmente com o auxílio de alavancas/barras. Após os três giros, a pressão, que era de $345 \mathrm{kPa}$, apresentava a tendência em diminuir e um ciclo de carregamento era realizado, ou seja, é removido o ângulo e a pressão é reajustada para $345 \mathrm{kPa}$. O procedimento de três giros se repetia até que a pressão de $1034 \mathrm{kPa}$ fosse atingida após um

\footnotetext{
${ }^{1}$ A new Molding Press. Departamento de Estradas do Texas. Fevereiro de 1963.
} 
curso completo do macaco hidráulico; depois disso, uma carga adicional de aproximadamente 17 MPa era aplicada para finalizar a compactação (Hubber, 1996).

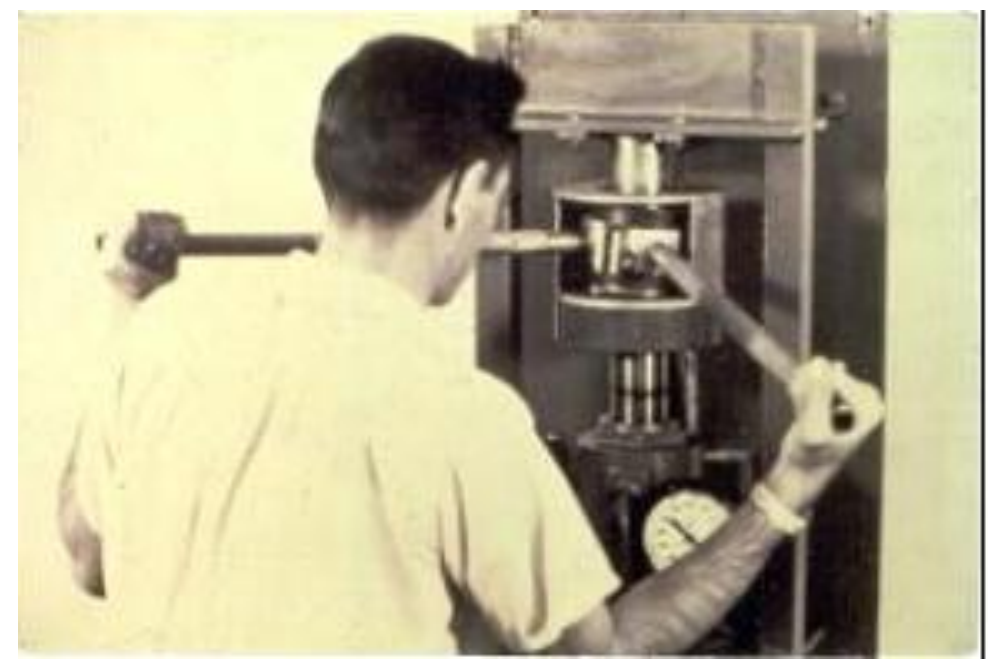

Figura 2.3 - Prensa giratória do Texas (Harman et al., 2002)

\subsubsection{Compactador giratório do USACE}

Nos anos 1950, baseando-se nos princípios do Departamento de Transportes do Texas, John L. McRae do USACE - Corpo de Engenheiros dos Estados Unidos - coordenou uma pesquisa sobre o desenvolvimento do compactador giratório por amassamento, o GTM Gyratory Testing Machine (Figura 2.4). 


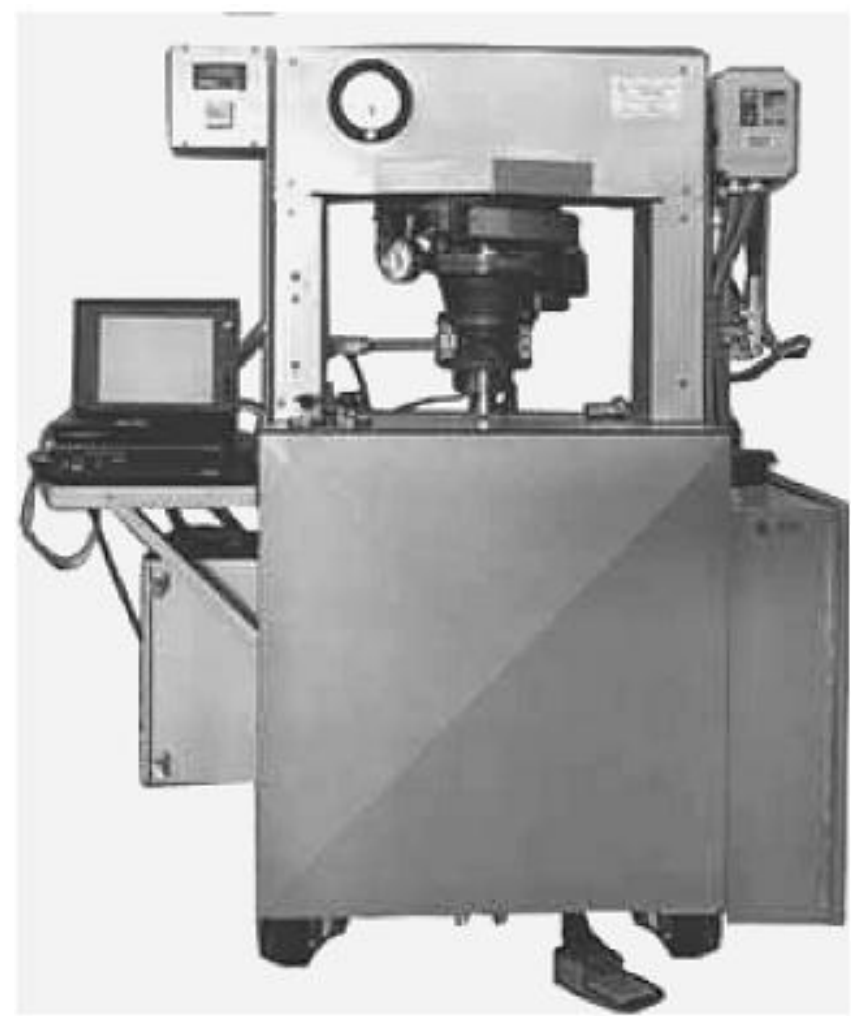

Figura 2.4 - Compactador giratório por amassamento do USACE (Harman et al., 2002)

McRae justificou seus estudos em resultados de pesquisas conduzidas pelo USACE, que indicavam que o compactador desenvolvido por Bruce Marshall, o mais utilizado na época, não simulava adequadamente as densidades das misturas asfálticas sobre o efeito de tráfego pesado, bem como suas propriedades mecânicas.

Além disso, o USACE também encontrou resultados que mostravam que os ensaios de compactação por impacto forneciam dados inadequados, visto que havia uma densificação das camadas dos pavimentos flexíveis após a abertura para o tráfego, comprovando-se que o tráfego causava uma compactação maior que aquela alcançada durante a construção da estrada.

Durante o desenvolvimento do compactador giratório, o USACE obteve resultados acerca do processo de compactação por amassamento que auxiliaram McRae e possibilitaram concluir que o número de giros por minuto tinha pouca ou até nenhuma influência na densificação, diferentemente da pressão vertical e do número de giros, que quando aumentados causavam incrementos significativos no peso específico, e que o ângulo de giro deveria estar entre um ou dois graus (Ping et al., 2003a). 
No compactador desenvolvido por McRae, o ângulo de giro era obtido por dois pontos, fazendo com que o mesmo oscilasse durante a compactação, diferentemente da prensa giratória do Texas. Os parâmetros ângulo de giro, altura da amostra e pressão aplicada eram armazenados automaticamente pelo computador e incorporados ao procedimento de projeto (Harman et al, 2002).

As pesquisas coordenadas por McRae proporcionaram que o USACE propusesse um procedimento de ensaio para compactação de solos utilizando o GTM, no qual as pressões verticais do equipamento eram baseadas nas pressões verticais teóricas produzidas pelo carregamento de roda previsto. Um resumo do procedimento sugerido pelo USACE está listado abaixo:

i. obter uma amostra representativa do solo;

ii. selecionar um teor de umidade, baseando-se na umidade prevista que estará o solo logo após a construção;

iii. admitir carregamento circular equivalente para cada área de contato do pneu, calcular a pressão vertical teórica aplicada versus a profundidade, para o carregamento de roda previsto;

iv. compactar a amostra de solo, com 500 giros, ângulo de giro de um grau e nas pressões verticais calculadas para as diversas profundidades;

v. calcular a densidade seca em todos os giros, utilizando o peso do material e o volume do molde, com altura sendo dada pela ação do êmbolo;

vi. plotar uma curva de densidade seca versus número de giros para cada uma das profundidades;

vii. nestas curvas, marcar o ponto em que os próximos 100 giros causam um aumento de $0,016 \mathrm{~g} / \mathrm{cm}^{3}$ e a densidade deste ponto será a necessária em campo para o material proposto na profundidade selecionada (Ping et al., 2003a).

Utilizando este procedimento, o USACE comparou os dados obtidos em campo no pós-tráfego àqueles obtidos em laboratório, para duas seções experimentais, construídas com solos de características arenosas. As análises comparativas mostraram que as densidades 
obtidas no CGS apresentaram uma melhor correlação com as densidades de campo póstráfego do que as densidades do Proctor Modificado.

Na literatura, há poucas referências sobre o uso do GTM na compactação de solos. Pode ser citadas as pesquisas de Womack et $a .^{2}{ }^{2}$ e do USACE ${ }^{3}$, ambas da década de 1960. Milberger e Dunlap (1966) apud Browne (2006) utilizaram o GTM para moldagem de corpos de prova de grandes dimensões para ensaio triaxial. Mais recentemente, houve uma pesquisa desenvolvida por George (1992), que calculou empiricamente o módulo de resiliência de solos com base em dados obtidos no GTM.

\subsubsection{Compactador giratório do LCPC}

Outro importante compactador desenvolvido a partir dos conceitos do compactador giratório do Texas foi a Prensa de Cisalhamento Giratório (PCG), concebida no LCPC, na França, nas décadas de 1960 e 1970. Diferentemente do compactador giratório do USACE, a primeira versão do PCG, conhecido como $\mathrm{PCG}_{1}$, possuía tensão normal constante de $600 \mathrm{kPa}$ e ângulo de giro fixo de $1^{\circ}$.

Atualmente, o PCG está na terceira geração e está preparado para atender as normas francesas, europeias e do Superpave para compactação de misturas asfálticas. Segundo HARMAN et al.(2002), a Comunidade Europeia da área de pavimentação asfáltica, num esforço de harmonização de suas especificações, adotou os conceitos de compactação de laboratório e projeto do LCPC.

\footnotetext{
${ }^{2}$ Womack, L. M., Sirr, J. F., and Webster, S. L. "Gyratory Compaction of Soil” Technical Report S-68-6, U.S. Army Engineer Waterways Experiment Station, Vicksburg, Mississippi, Novembro, 1969.

${ }^{3}$ U.S. Army Corps of Engineers. "Gyratory Compaction Method for Determining Density Requirements for Subgrade and Base of Flexible Pavements," Miscellaneous Paper No. 4-494, Waterways Experiment Station, Vicksburg, Mississippi, Maio, 1962.
} 


\subsubsection{Compactador Giratório Superpave}

O Strategic Highway Research Program (SHRP) foi um dos principais colaboradores para o desenvolvimento do Compactador Giratório Superpave (CGS), por meio do seu programa Superpave - Superior Performing Asphalt Pavements.

Assim como os outros compactadores giratórios desenvolvidos, o CGS foi projetado para simular a orientação e a degradação dos agregados, a compactação em campo e a degradação da mistura asfáltica durante a produção, compactação e carregamento do tráfego (Harman et al., 2002).

Nos Estados Unidos, existem atualmente pelo menos oito modelos de compactadores giratórios sendo produzidos, e a maior parte deles possibilita o ajuste e o controle dos quatro principais parâmetros que influenciam a compactação de misturas asfálticas em laboratório:
i) ângulo de giro;
ii) frequência de giros;
iii) tensão normal;
iv) número de giros.

Paralelamente ao desenvolvimento do CGS, o programa Superpave produziu resultados que possibilitaram a elaboração de um procedimento de compactação de misturas asfálticas com uso do compactador giratório. As especificações do procedimento são feitas basicamente com relação aos quatro parâmetros supra citados:

- o valor do ângulo de giro foi estabelecido ser $1,25^{\circ} \pm 0,02$; foram testados ângulos maiores, como $5^{\circ}$, porém, houve dificuldades na elaboração das 
curvas de densificação e depois de experimentarem o valor de $1^{\circ}$, concluiu-se que o valor de $1,25^{\circ}$ produzia os resultados mais confiáveis e mais consistentes (Huber, 1996);

- a frequência de giros foi fixada em 30 giros por minuto; pesquisas anteriores com compactadores giratórios mostraram ela tem pouca influência na densificação dos corpos de prova e o compactador giratório do Texas usava esta mesma frequência há anos, com resultados confiáveis (Browne, 2006);

- quanto à tensão normal, o programa Superpave concluiu que ela tinha pouca influência na compactação das misturas asfálticas, especificando o valor de $600 \mathrm{kPa}$ para a compactação de misturas asfálticas, o mesmo utilizado pelo PCG no LCPC (Huber, 1996; Browne, 2006);

- e finalmente o número de giros, que não foi fixado, sendo característico para cada mistura, em função do volume de tráfego previsto.

\subsubsection{Pesquisas com uso do compactador giratório em solos}

Conforme explanado neste capítulo, existem poucas pesquisas acerca da compactação de solos com uso do compactador giratório. No âmbito nacional, em que as pesquisas sobre uso do compactador giratório para misturas asfálticas são recentes, ainda não há relatos na literatura sobre uso do giratório na compactação de solos. Portanto, até o momento da elaboração desta pesquisa, dois estudos realizados nos Estados Unidos sobre uso do CGS para compactar solos merecem ser destacados: Ping, Leonard e Yang (2003a e 2003b) e Browne (2006).

No ano de 2003, no Departamento de Transportes do Estado da Florida, EUA, Ping et al. (2003a 2003b) publicaram um relatório no qual foram feitas comparações entre as densidades secas encontradas no campo no período pós-tráfego, com as densidades secas obtidas do Proctor Modificado e do compactador giratório tipo Superpave para solos com características granulares. 
Na comparação campo - Proctor Modificado, Ping et al. (2003b) encontraram resultados que mostraram grande disparidade entre as densidades secas. Contudo, na comparação campo - compactador giratório houve uma boa correlação entre as densidades secas de campo com as obtidas no compactador giratório.

Nesse mesmo estudo, os autores também fizeram análises acerca do procedimento de compactação de solos no compactador giratório, por meio da observação da influência do número de giros, do ângulo de giro, da tensão normal e da frequência de giros.

Para o número de giros, Ping et al. (2003a) concluíram que seu efeito é relevante sobre a massa específica dos solos estudados, onde um número maior de giros proporcionou um incremento na massa específica, como exemplifica a Figura 2.5.

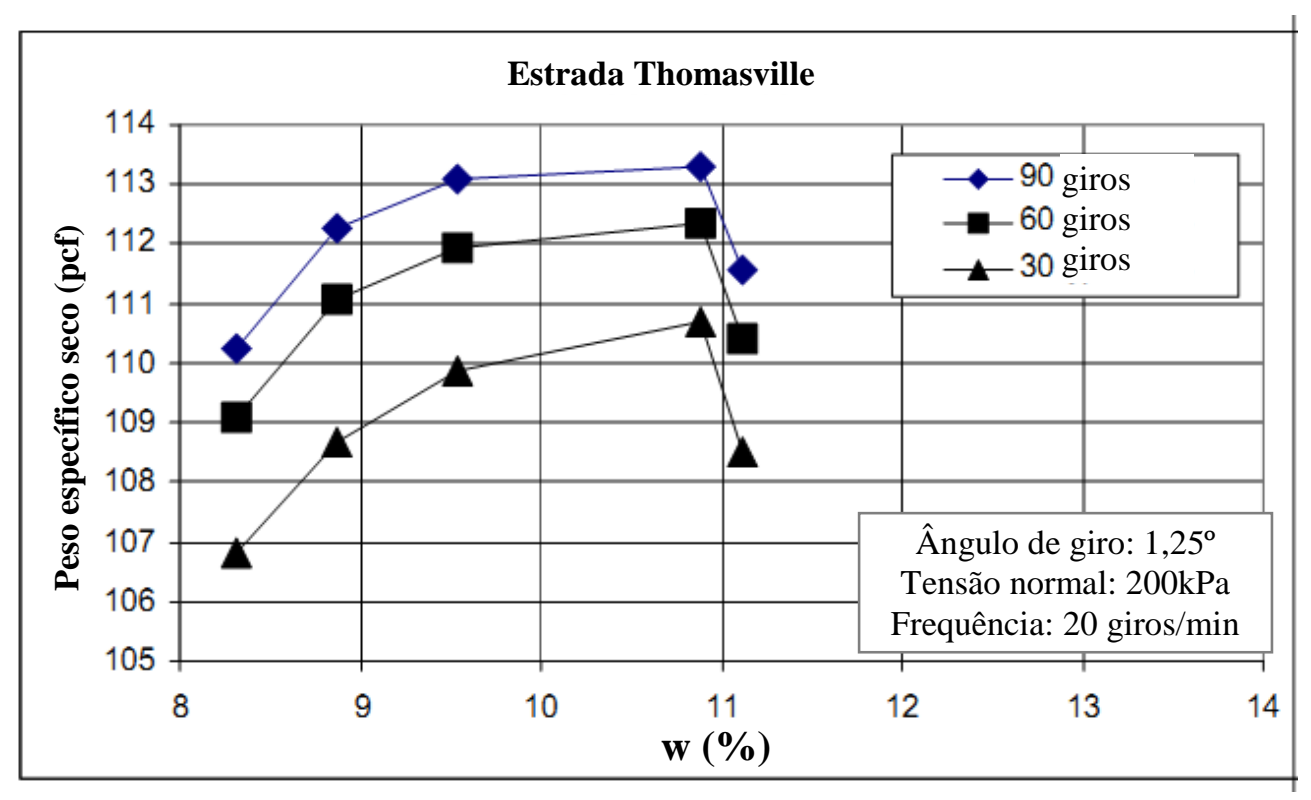

Figura 2.5 - Exemplo de influência do número de giros sobre a curva de compactação feita no CGS (Ping et al., 2003a)

Ping et al. (2003b) também concluíram que a tensão normal tem influência expressiva, desde que esteja a valores abaixo de $200 \mathrm{kPa}$, pois acima disso mostrou-se um tanto ineficaz no incremento da massa específica seca (Figura 2.6). 


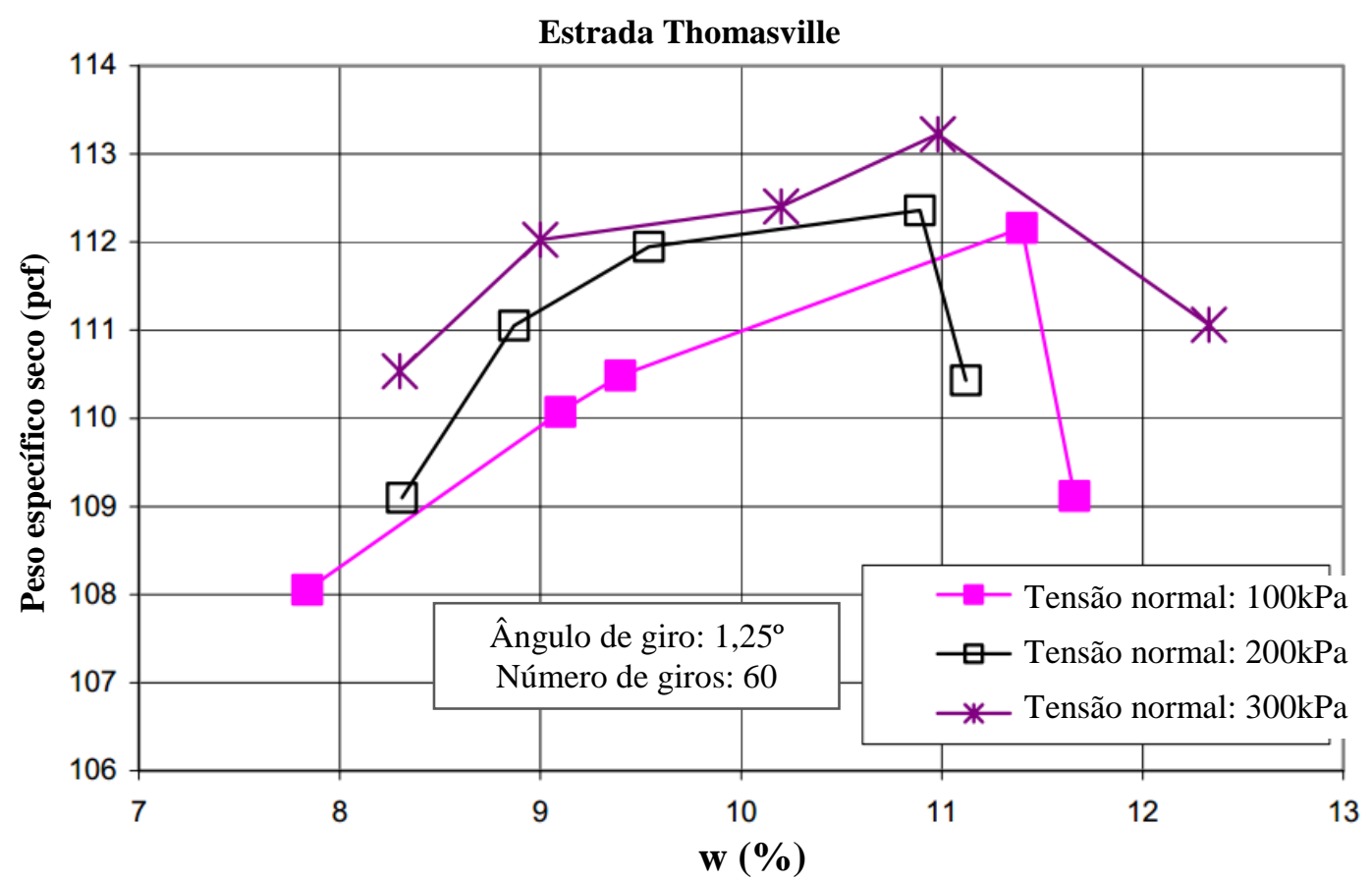

Figura 2.6 - Exemplo da influência da tensão normal sobre a compactação de solos (Ping et al., 2003a)

Ao final da pesquisa, Ping et al. (2003b) recomendaram uma configuração padrão para se executar o ensaio de compactação de solos com uso do compactador giratório:

- tensão normal de $200 \mathrm{kPa}$;

- $\quad$ ângulo de giro de $1,25^{\circ}$;

- número de giros igual a 90;

- e, frequência de 20 giros por minuto.

Ping et al. (2003b) apresentaram nos anexos do trabalho a forma de calcular a energia aplicada pelo CGS. Contudo, os autores não fizeram relação algum com as energias do Proctor. Para esta pesquisa, foi feito o cálculo da energia aplicada pelo CGS em cada ensaio de compactação, relacionando aos níveis de energia do Proctor; as fórmulas 
empregadas no cálculo da energia, juntamente com os resultados encontrado são oportunamente apresentados no Anexo A.

Por fim, é relevante ressaltar uma dificuldade que Ping et al. (2003b) encontraram na compactação de solos granulares em teores altos de umidade. Os autores relataram que nestes pontos houve exsudação de água durante a compactação, obrigando-os a fazer correções no cálculo das densidades secas, visto que a massa de material que era colocada no molde não era a mesma após a realização do ensaio.

No ano de 2006, Browne desenvolveu uma pesquisa na Universidade de Montana, EUA, onde fez comparações das curvas de compactação obtidas por meio da metodologia Proctor com aquelas obtidas por meio do compactador giratório, para solos arenosos e argilosos.

Da mesma forma que Ping et al. (2003a e 2003b), Browne, antes de comparar diretamente as curvas de compactação obtidas dos dois métodos, explorou o efeito do número de giros e da tensão normal na compactação. Para isso, Browne dividiu o estudo em duas fases: na $1^{\text {a }}$, ele compactou amostras dos solos completamente secas em várias tensões normais e usando 500 giros; e na $2^{\mathrm{a}}$, foram compactadas amostras dos solos em vários teores de umidade e várias tensões normais, na tentativa de se obter curvas de compactação de formatos equivalente àquelas obtidas no ensaio tradicional de compactação Proctor.

$\mathrm{Na} 1^{\mathrm{a}}$ fase, o autor concluiu que quanto maior o número de giros, maior é o aumento na massa específica seca, para todos os tipos de solos. Contudo, ele observou que todas as amostras atingiram 90\% da massa específica seca dos 500 giros nos primeiros 100 giros. O autor recomendou uma faixa de 200 a 350 giros para compactar solos mais finos e mais de 500 giros para solos mais granulares. O autor listou como maiores problemas do uso de 500 giros o possível desgaste do molde e degradação dos agregados e o elevado tempo de execução do ensaio.

Browne observou aumento no peso específico seco quando incrementada a tensão normal, principalmente para os solos mais finos. Browne enumerou como principais dificuldades para o uso da pressão de $600 \mathrm{kPa}$ : a) o risco de se atingir energias maiores que aquelas alcançadas em campo e, b) desgaste do molde e degradação das partículas do solo. Como vantagens, ele elencou a garantia de se atingir o peso específico seco máximo e a semelhança com o procedimento já utilizado para misturas asfálticas. 


\subsubsection{Métodos de compactação menos utilizados}

Alguns métodos de compactação são menos utilizados no meio científico, principalmente por sua especificidade para alguns materiais. Podem ser citados a compactação por pisoteamento e a compactação por vibração.

A compactação por pisoteamento é um método executado a partir da aplicação sucessiva de golpes por meio de um pistão movido por uma mola sobre pequenas áreas da amostra de solo. As pressões são aplicadas verticalmente sobre a amostra de solo, variando com o tempo de forma cíclica. Este tipo de compactação é utilizado para simular a ação em campo do rolo pé-de-carneiro, sendo por isso, recomendado principalmente para solos coesivos, pois seu mecanismo de ação faz com que haja a desagregação dos grumos do solo.

A compactação por vibração é um método que surgiu como uma alternativa a ineficiência do ensaio Proctor com solos arenosos; seu mecanismo de compactação é baseado na vibração do conjunto molde-solo. A ação de vibração geralmente é executada por uma mesa ou placa vibratória e pode ser auxiliado pela colocação de uma sobrecarga sobre a amostra de solo. 


\section{MATERIAIS E MÉTODOS}

Este capítulo inicia-se com o delineamento experimental desta pesquisa e em seguida apresenta as características do material empregado e os métodos utilizados para comparar o comportamento do solo utilizado quando compactado por impacto, estaticamente e por amassamento. Ainda destacam-se neste capítulo os procedimentos utilizados para execução do ensaio de compactação no Compactador Giratório Superpave (CGS), as análises que foram realizadas com os dados de saída do CGS e os ensaios mecânicos que foram executados, com suas respectivas formas de moldagem dos corpos de prova.

\subsection{DELINEAMENTO EXPERIMENTAL}

Para alcançar o objetivo principal desta pesquisa, a investigação experimental foi dividida em 3 fases, que são apresentadas nos itens seguintes deste capítulo.

- $\quad$ seleção e caracterização do solo;

- $\quad$ execução de ensaios de compactação do solo pelo método Proctor e com uso do CGS;

- realização de ensaios mecânicos com corpos de prova moldados no compactador estático e no CGS. 


\subsection{SOLO}

\subsubsection{Escolha do solo}

Para realização desta pesquisa, foi escolhido um solo com características argilosas, selecionado entre aqueles estudados originalmente por Takeda (2006), denominado de amostra A-34.

A opção por esse material deu-se primeiramente pela fato da presente pesquisa ser consorciada à pesquisa de doutorado em andamento do aluno David Alex Arancibia Suarez do Departamento de Engenharia de Transportes da EESC-USP sobre estabilização de solos com uso de emulsão asfáltica. Além disso, esse mesmo solo também vem sendo utilizado pelo aluno Luis Miguel Gutiérrez Klinsky em sua pesquisa de doutorado também em andamento no Departamento de Engenharia de Transportes da EESC-USP, sobre uso da areia de fundição como material componente de camadas para pavimentos.

Outra justificativa para escolha de um solo com características argilosas foi o fato de que pesquisas anteriores sobre uso do CGS na compactação de solos, como o de Ping, Leonard \& Yang (2003a e 2003b) e de Browne (2006), terem empregado solos de características predominantemente arenosas. Logo, seria de grande interesse apresentar também dados a respeito do comportamento de solos argilosos quando compactados no CGS.

Esses mesmos autores ainda suscitaram que na compactação de um solo argiloso no CGS, provavelmente não haveria exsudação de água e tal sugestão mostrou-se importante, pois excluiria uma variável de difícil controle que é a perda de água durante o ensaio. Pode-se acrescentar ainda o fato da presente pesquisa ter sido pioneira no âmbito do Departamento de Engenharia de Transportes da EESC-USP e havia uma preocupação de que a exsudação de água pudesse danificar o compactador giratório. 


\subsubsection{Coleta do solo}

O solo foi coletado em um talude na Rodovia SP-308 (km 150 - Norte), sentido Rio das Pedras - Piracicaba, na margem direita, nas coordenadas S $23^{\circ} 31^{\prime} 8,3^{\prime \prime}$ - W $46^{\circ} 56^{\prime} 52,8^{\prime}$. O material coletado foi armazenado em sacos plásticos de $30 \mathrm{~kg}$ e transportado para o Laboratório de Estradas do Departamento de Engenharia de Transportes da EESCUSP; ao total, foram feitas três coletas, perfazendo cerca de 2,5 toneladas de material.

A Figura 3.1 indica o ponto de coleta do solo situado no cruzamento da Rodovia SP-308 (rodovia do açúcar) com a Rodovia Júlio Antônio Basso, no estado de São Paulo. A Figura 3.2 apresenta imagens desse local.

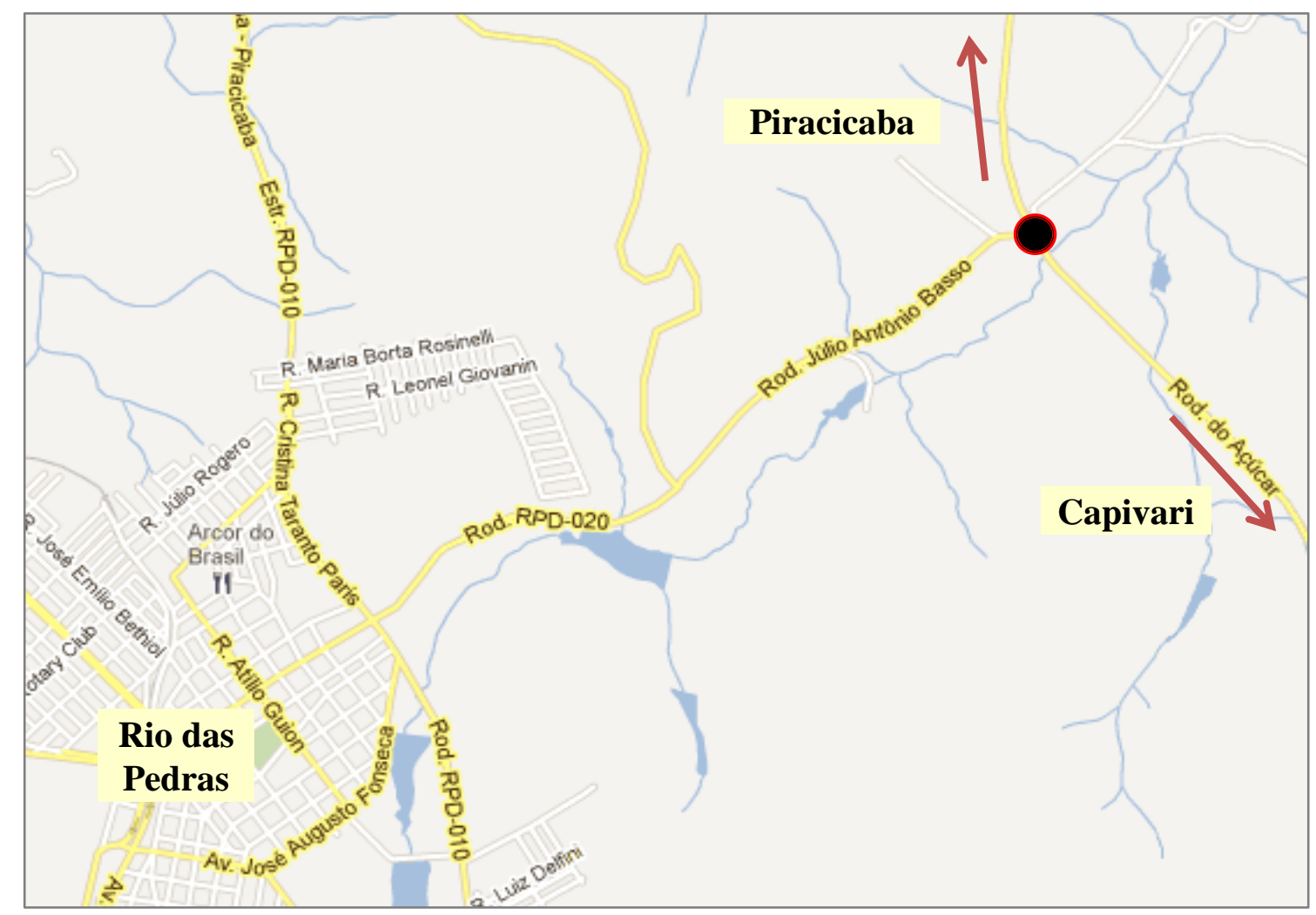

Figura 3.1 - Indicação da localização da coleta do solo 

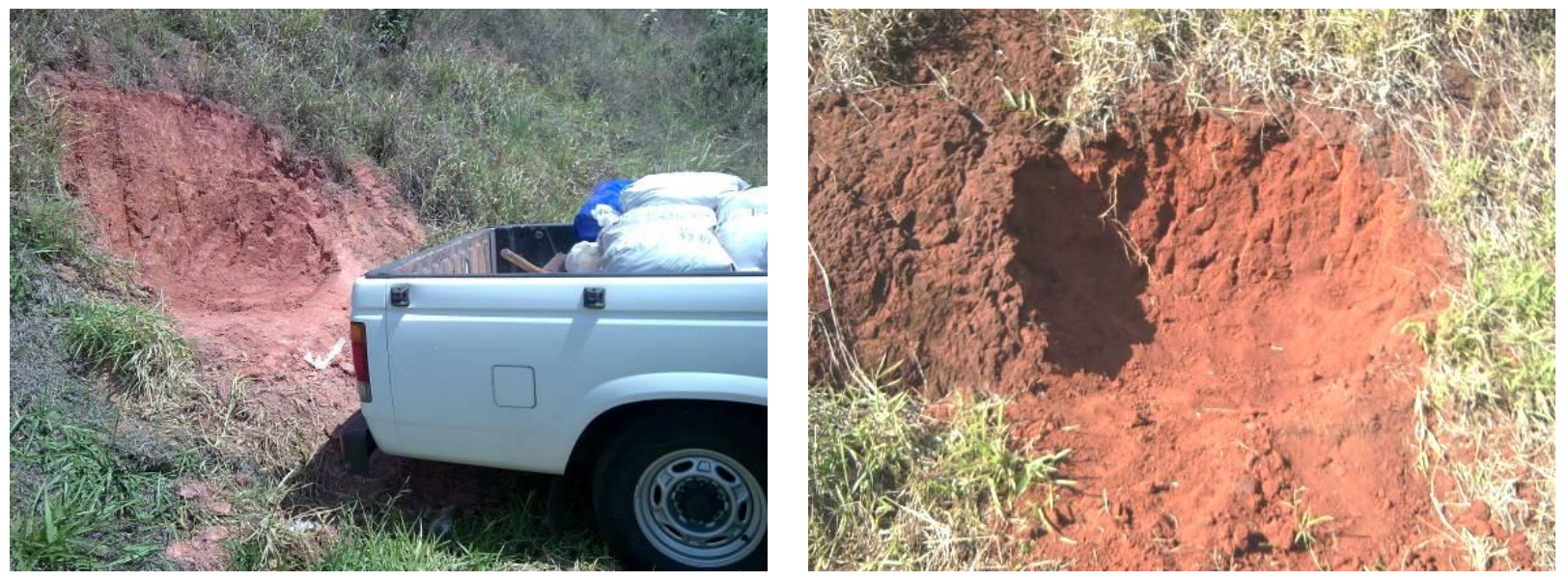

Figura 3.2 - Aspectos do local de coleta do solo

\subsubsection{Preparação do solo}

O material coletado foi destorroado e passado na peneira de número 4 (\#4,75mm); em seguida, sobre uma lona, efetuou-se sua mistura e procedeu-se sua homogeneização, com o auxílio de enxadas e pás; por fim, o solo foi armazenado em sacos plásticos de $30 \mathrm{~kg}$, devidamente identificados.

Optou-se por não secar todo material ao ar antes de armazená-lo nos sacos plásticos, devido a sua grande quantidade, fato que dificultaria em muito o processo de secagem. Desta forma, o solo foi seco ao ar, conforme a demanda de ensaios da parte experimental.

\subsubsection{Massa específica dos sólidos, limites de Atterberg e granulometria do solo}

Os ensaios de caracterização da amostra foram realizados pelo estudante de doutorado Luis Miguel Gutiérrez Klinsky do Departamento de Engenharia de Transportes da EESC-USP.

Os procedimentos utilizados na determinação da massa específica do solo estão descritos na norma NBR 6508 (1984) - Grãos de solos que passam na peneira de 4,8 mm - 
Determinação da massa específica e os procedimentos para determinação do Limite de Plasticidade e Limite de Liquidez apresentam-se, respectivamente, nas normas NBR 7180 (1984) - Solo - Determinação do limite de plasticidade- e NBR 6459 (1984) - Solo Determinação do limite de liquidez. A Tabela 3.1 apresenta os resultados obtidos nestes ensaios, onde se percebe que o solo em questão é altamente plástico, devido a seu valor de índice de plasticidade.

Tabela 3.1 - Massa específica e limites de Atterberg do solo utilizado na pesquisa

\begin{tabular}{cccc}
\hline$\rho_{\mathrm{s}}\left(\mathbf{g} / \mathbf{c m}^{3}\right)$ & $\mathbf{L L}(\boldsymbol{\%})$ & $\mathbf{L P}(\boldsymbol{\%})$ & $\mathbf{I P}(\boldsymbol{\%})$ \\
\hline 2,745 & 58 & 34 & 24 \\
\hline
\end{tabular}

A análise granulométrica foi realizada segundo os procedimentos descritos na norma NBR 7181 (1984) - Solo - Análise granulométrica, por meio de uma análise conjunta (peneiramento, seguido de sedimentação). A Figura 3.3 apresenta a curva granulométrica do solo e a Tabela 3.2 mostra sua composição granulométrica, na qual se destaca a porcentagem de $97 \%$ do solo passando na peneira de $\mathrm{n}^{\circ} 200$, mostrando trata-se de um solo muito fino.

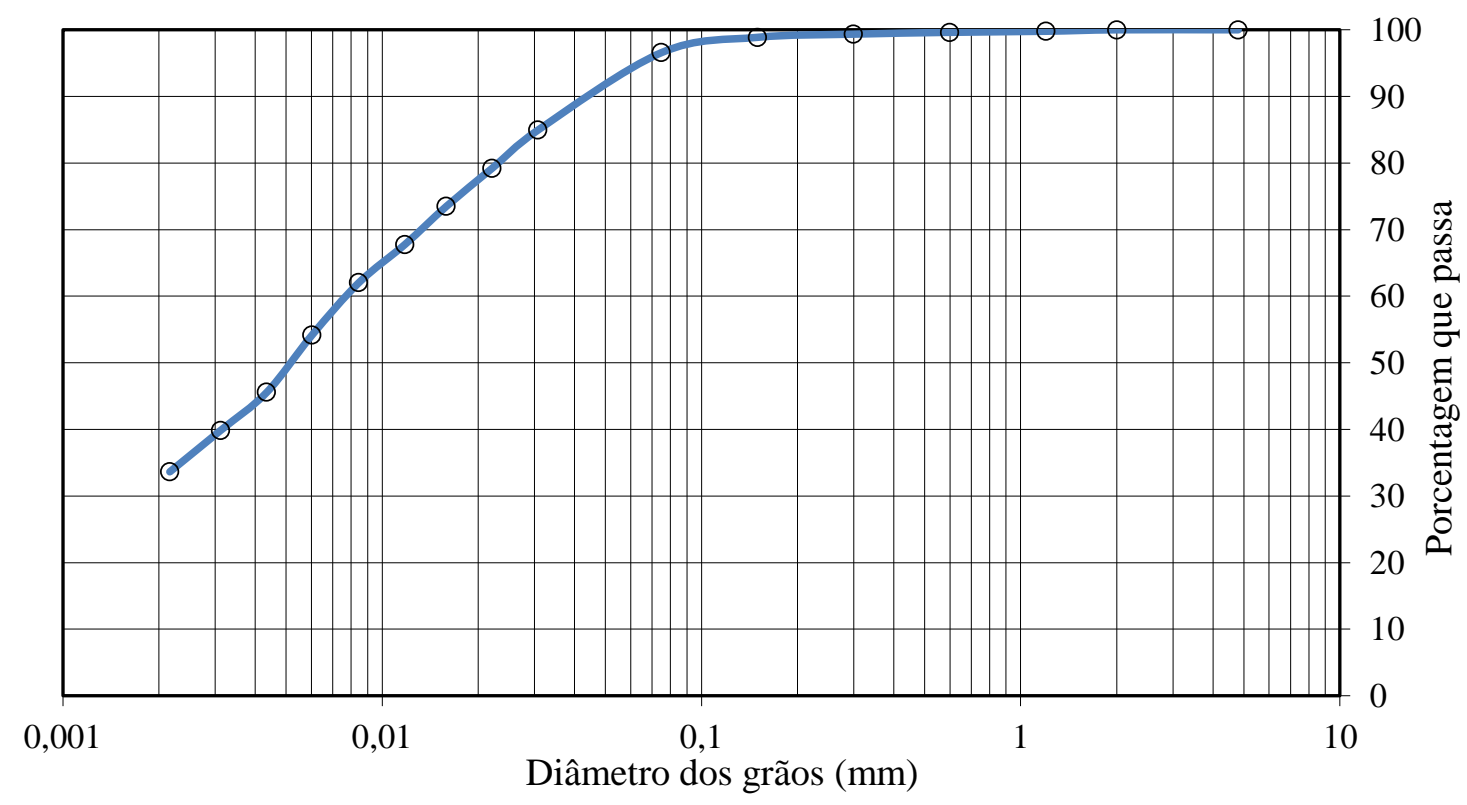

Figura 3.3 - Curva granulométrica do solo 
Tabela 3.2 - Composição granulométrica do solo do solo utilizado na pesquisa

\begin{tabular}{cc}
\hline Peneiras & $\begin{array}{c}\text { Porcentagem que } \\
\text { passa }\end{array}$ \\
\hline $\mathrm{n}^{\mathbf{o}} 4(4,75 \mathrm{~mm})$ & 100 \\
$\mathrm{n}^{\mathbf{o}} 10(2,0 \mathrm{~mm})$ & 100 \\
$\mathrm{n}^{\mathbf{o}} 40(0,42 \mathrm{~mm})$ & 99 \\
$\mathrm{n}^{\mathbf{o}} 200(0,074 \mathrm{~mm})$ & 97 \\
\hline
\end{tabular}

\subsubsection{Ensaios da Metodologia MCT}

Seguindo a metodologia MCT, amostras do solo foram submetidas aos ensaios de Mini-MCV e perda de massa por imersão. Os procedimentos para a realização desses ensaios estão explicitados nas normas: DNER - ME 228/94 - Solos - Compactação em equipamento miniatura, DNER - ME 256/94 - Solos compactados com equipamento miniatura Determinação da perda de massa por imersão, e DNER - ME 258/94 - Solos compactados em equipamento miniatura - Mini-MCV.

A Tabela 3.3 exibe os resultados dos ensaios de Mini-MCV e perda de massa por imersão; e, a Figura 3.4 apresenta o gráfico da classificação MCT do solo, isto é, um solo argiloso de comportamento não-laterítico.

Tabela 3.3 - Parâmetros e índices obtidos nos ensaios de Mini-MCV e Perda de Massa por Imersão

\begin{tabular}{cccc}
\hline $\mathbf{c}^{\prime}$ & $\mathbf{d}^{\prime}$ & $\mathbf{P i}$ & $\mathbf{e}^{\prime}$ \\
\hline 1,87 & 7,50 & $277 \%$ & 1,76 \\
\hline
\end{tabular}




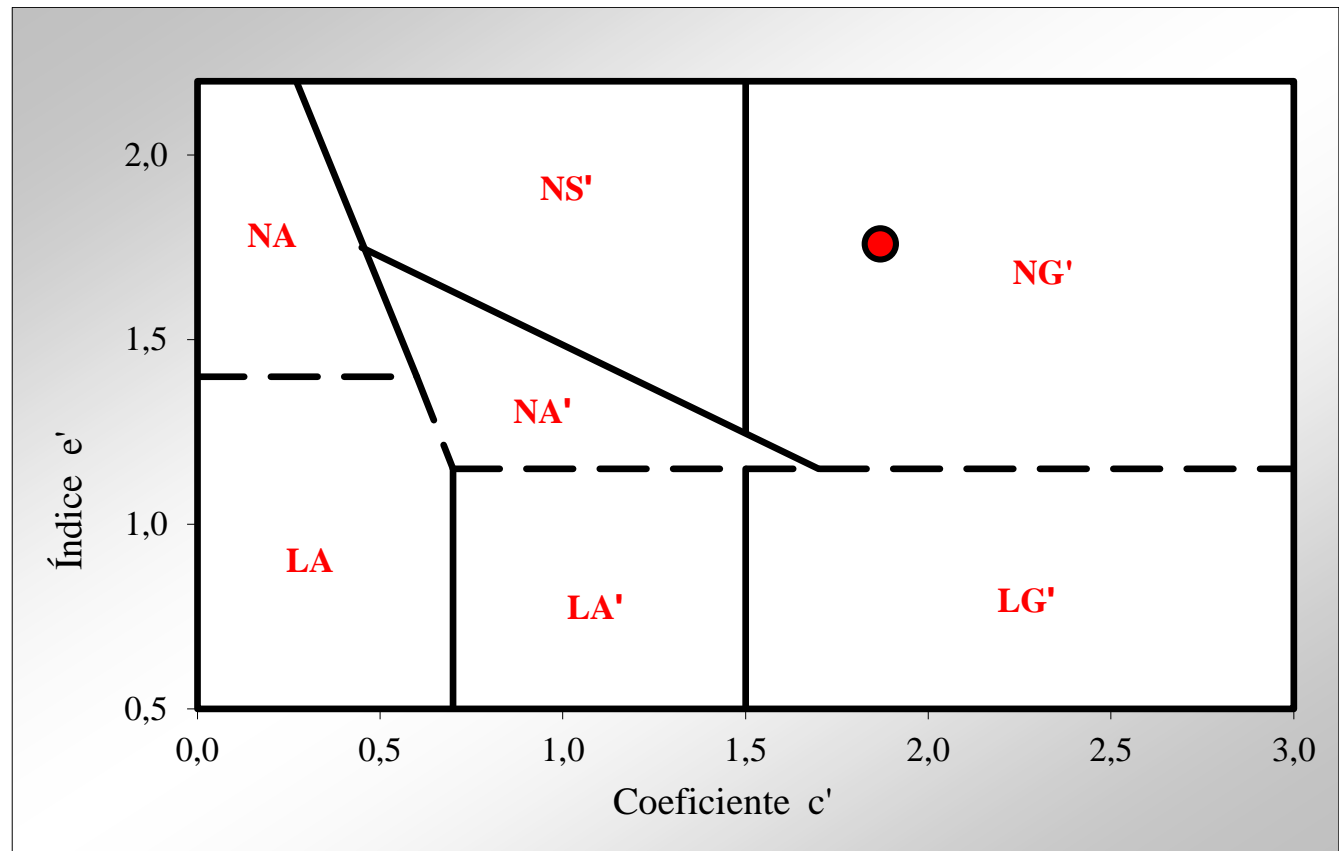

Figura 3.4 - Gráfico de classificação MCT com a indicação do posicionamento do solo (Nogami; Villibor, 1995)

\subsubsection{Classificações geotécnicas do solo}

Para a classificação do solo segundo a metodologia HRB, utilizou-se a norma AASHTO M-145-91 (2004); para a SUCS (Sistema Unificado de Classificação de Solos), a norma empregada foi a ASTM D2487 - 11; e, finalmente para a classificação segundo a Metodologia MCT, adotou-se o procedimento descrito na norma DNER-CLA 259/96.

A Tabela 3.4 expõe as classificações do solo segundo as três referências onde se verifica que o solo é predominantemente de características argilosas e comportamento nãolaterítico.

Tabela 3.4 - Classificação do solo segundo HRB, SUCS e MCT

\begin{tabular}{ccc}
\hline HRB & SUCS & MCT \\
\hline A-7-5 & MH & NG' \\
\hline
\end{tabular}




\subsection{ENSAIOS DE COMPACTAÇÃO}

Para se alcançar o objetivo principal da pesquisa, ensaios de compactação foram realizados de acordo com a metodologia Proctor e também com uso do CGS. Assim, nos itens seguintes são apresentados os procedimentos realizados nessas duas técnicas de compactação de solos em laboratório.

\subsubsection{Ensaio de compactação Proctor}

Os ensaios de compactação Proctor foram executados seguindo as recomendações da norma NBR 7182/1986 nas energias Normal, Intermediária e Modificada, com reuso de material e compactação manual.

Apesar do tipo de solo utilizado nesta pesquisa não ser normalmente recomendado para construção de bases e sub-bases de pavimentos e, portanto, não ser compactado nas energias intermediária e modificada do Proctor, optou-se pelos três níveis de energia como uma tentativa de se fazer uma análise mais abrangente entre os métodos de compactação Proctor e com uso do CGS.

\subsubsection{Ensaio de compactação com uso do CGS}

\subsubsection{Compactador Giratório Superpave}

O compactador giratório utilizado nesta pesquisa foi desenvolvido pela empresa australiana IPC Global, modelo SERVOPAC, sendo composto basicamente por computador e câmara de compactação (Figura 3.5). O SERVOPAC foi projetado originalmente para 
compactação de misturas asfálticas, em consonância às especificações do programa SUPERPAVE de projeto de misturas asfálticas do SHRP.

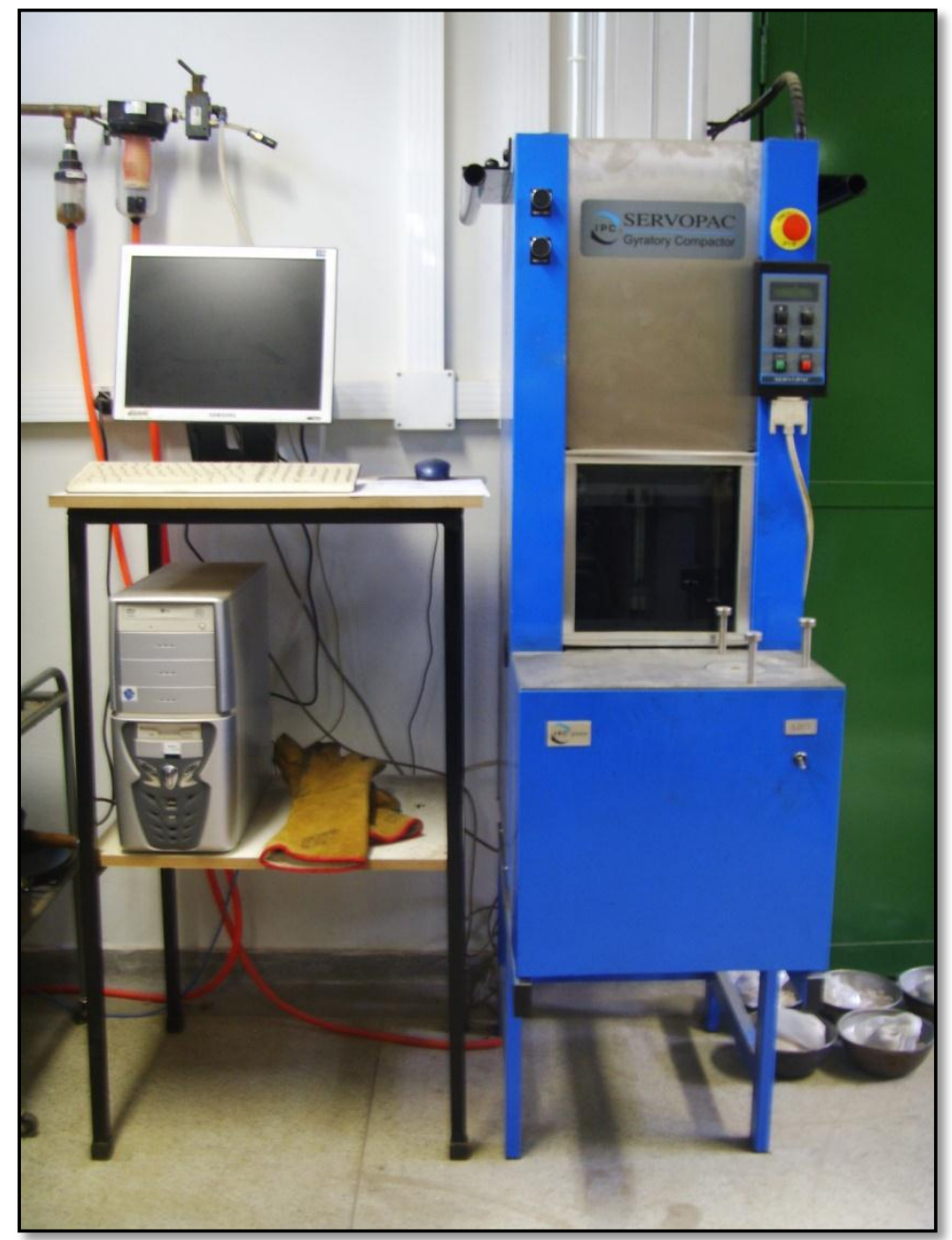

Figura 3.5 - Compactador giratório Superpave utilizado na pesquisa (Modelo SERVOPAC)

Nesse tipo de compactador giratório, o processo de compactação é realizado pela aplicação simultânea de uma tensão normal, advinda de um pistão, e de uma força de cisalhamento, decorrente do giro do molde cilíndrico em torno do seu próprio eixo sob um determinado ângulo de inclinação do próprio molde (Figura 3.6). 


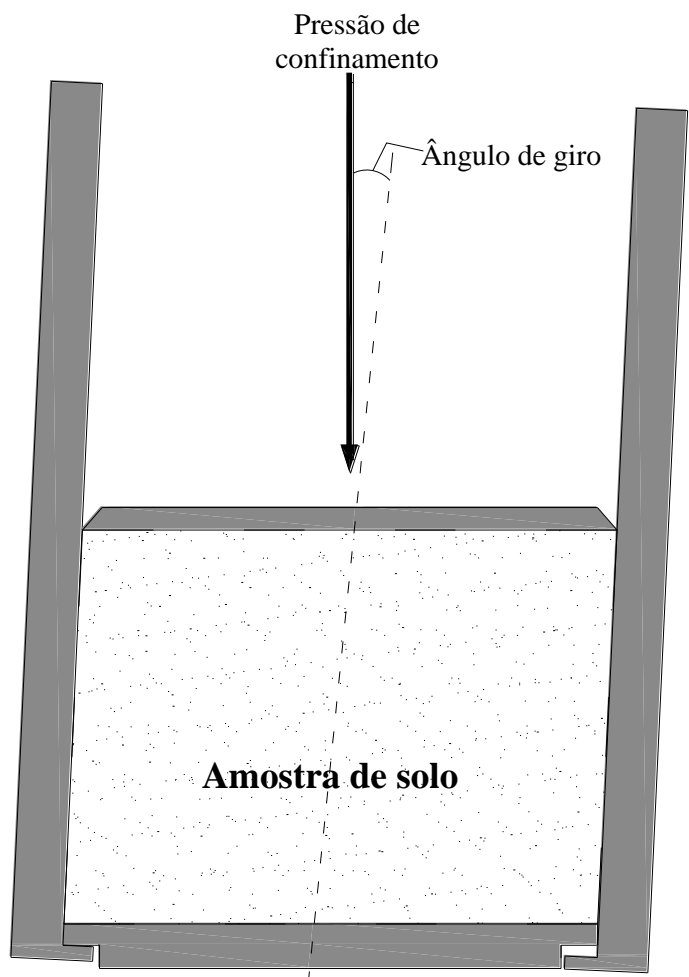

Figura 3.6 - Posição da tensão normal, do ângulo de giro e da amostra de solo numa vista em corte do molde do CGS

O compactador possibilita ao operador o ajuste automático de cinco variáveis: tensão normal, número de giros, ângulo de giro, frequência de giros e altura final do corpo de prova. Todas estas variáveis são armazenadas automaticamente pelo computador durante a compactação e podem ser exportadas em formato de planilha do Excel.

A Tabela 3.5 apresenta os valores máximos e mínimos dos parâmetros mencionados no parágrafo anterior para o compactador utilizado. 
Tabela 3.5 - Intervalos de variação dos parâmetros do CGS

\begin{tabular}{ccc}
\hline & \multicolumn{2}{c}{ LIMITES } \\
\cline { 2 - 3 } PARÂMETRO & MÍNIMO & MÁXIMO \\
\hline Tensão normal (kPa) & 0 & 600 \\
Número de giros & 0 & 999 \\
Ângulo de giro $\left({ }^{\circ}\right)$ & 0 & 3 \\
Frequência de giros $(\mathrm{rpm})$ & 3 & 60 \\
Altura final do CP $(\mathrm{mm})$ & 50 & 170 \\
\hline
\end{tabular}

No Laboratório de Estradas do Departamento de Engenharia de Transportes da EESC-USP, existem dois tipos de moldes cilíndricos de aço para compactação de misturas asfálticas e solos, sendo um com $100 \mathrm{~mm}$ de diâmetro e $270 \mathrm{~mm}$ de altura, utilizado nesta pesquisa, e outro de $150 \mathrm{~mm}$ de diâmetro e $270 \mathrm{~mm}$ de altura (Figura 3.7).

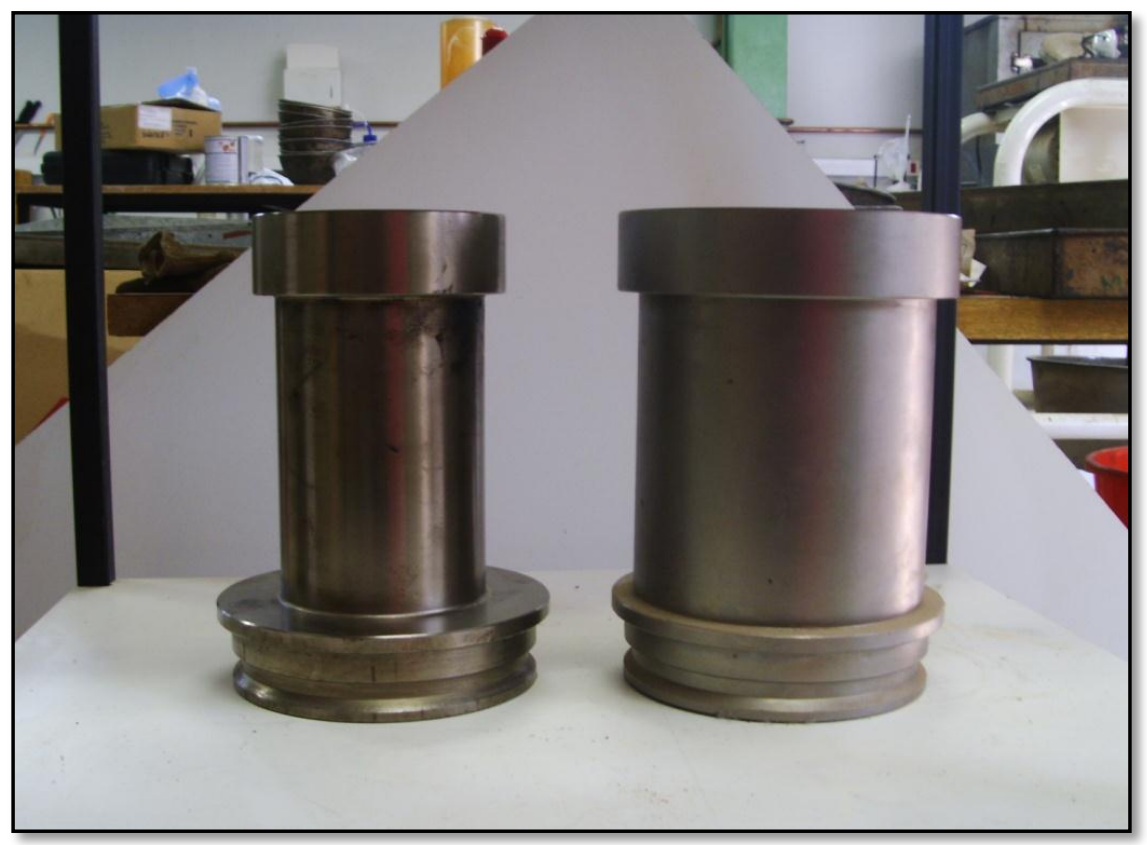

Figura 3.7 - Moldes de aço para compactação no CGS 


\subsubsection{Escolha das configurações do CGS}

O processo de compactar utilizando o CGS passa pela escolha de suas configurações de operação, isto é, tensão normal, ângulo de giro, frequência, número de giros e altura final do CP. A ausência de normas que tratem da compactação de solos no CGS fez com que a seleção dessas configurações fosse uma etapa decisiva na pesquisa.

Desta forma, para a presente pesquisa, optou-se executar os ensaios em três valores de tensões normais, 200, 400 e $600 \mathrm{kPa}$, com base em dois aspectos:

i. resultados e recomendações de pesquisas já realizadas com compactação de solos no compactador giratório (Ping et al., 2003a e 2003b; Browne, 2006; Mokwa; Cuelho; Browne, 2008);

ii. e, a hipótese de que três valores para a tensão normal mais a variação do número de giros possibilitassem a obtenção de uma série de energias de compactação.

O ângulo de giro e a frequência de giros foram fixados, respectivamente, em 1,25 e 30 giros por minuto, pois resultados de outras pesquisas sobre uso do compactador giratório na compactação de solos mostraram que ambos parâmetros não se mostraram determinantes na compactação (Ping et al., 2003a; Ping et al., 2003b; Browne, 2006; Mokwa; Cuelho; Browne, 2008; Butcher, 1998).

Com relação ao número de giros e à altura final do $\mathrm{CP}$, era necessário decidir qual desses dois parâmetros seria escolhido como critério de parada da compactação, visto que o processo de compactação é encerrado automaticamente pelo equipamento quando um desses dois parâmetros é alcançado no procedimento.

Deste modo, decidiu-se adotar o valor de 500 giros como critério de parada, na tentativa de se ter uma análise mais abrangente do comportamento do solo durante a 
compactação e garantir que houvesse estabilização da densidade seca para todos os corpos de prova compactados.

Portanto, a altura final do corpo de prova passou a ser um parâmetro variável, dependente do teor de umidade do solo. A Tabela 3.6 apresenta um resumo das configurações utilizadas no CGS para execução dos ensaios de compactação do solo.

Tabela 3.6 - Configurações do CGS para ensaio de compactação

\begin{tabular}{cccc}
\hline Tensão normal (kPa) & $\begin{array}{c}\text { Frequência de } \\
\text { giros (rpm) }\end{array}$ & $\begin{array}{c}\text { Número de } \\
\text { giros }\end{array}$ & $\begin{array}{c}\text { Ângulo de giro } \\
\text { (graus) }\end{array}$ \\
\hline 200 & 30 & 500 & 1,25 \\
400 & & & \\
600 & & & \\
\hline
\end{tabular}

\subsubsection{Procedimento de execução do ensaio de compactação}

Como já mencionado neste trabalho, não existem normas brasileiras, nem internacionais que regulamentem o ensaio de compactação de solos com uso do CGS. Logo, era necessário fixar, além das configurações de operação do CGS, a massa úmida por corpo de prova que seria empregada nos ensaios de compactação. Deste modo, fixou-se dois valores para a massa úmida de cada CP: $1800 \mathrm{~g}$ e $1000 \mathrm{~g}$.

O primeiro valor foi escolhido com base no valor médio encontrado para as massas dos corpos de prova obtidos nos ensaios de compactação Proctor para o solo em questão e o segundo, foi uma tentativa de moldar corpos de prova mais homogêneos, visto que havia uma suspeita de que os corpos de prova com $1800 \mathrm{~g}$ poderiam não estar tão bem compactados no centro como nas extremidades.

Os procedimentos adotados para o ensaio de compactação no CGS foram desenvolvidos de forma similar àqueles do ensaio Proctor. De maneira geral, as etapas do ensaio foram: 
- umidificação de cada amostra de solo, em umidades que variavam de $2 \mathrm{em}$ $2 \%$

- estocagem por $24 \mathrm{~h}$ de cada amostra em saco plástico fechado, para melhor homogeneização da umidade;

- ajuste dos parâmetros do compactador giratório;

- retirada de uma quantidade de solo para verificação de umidade, antes da compactação;

- compactação do CP;

- pesagem do CP após moldagem e;

- medição da altura do $\mathrm{CP}$ em três pontos distantes entre si por $120^{\circ}$.

A Figura 3.8 mostra a colocação do solo no molde do CGS e um corpo de prova sendo sacado após a compactação no CGS.
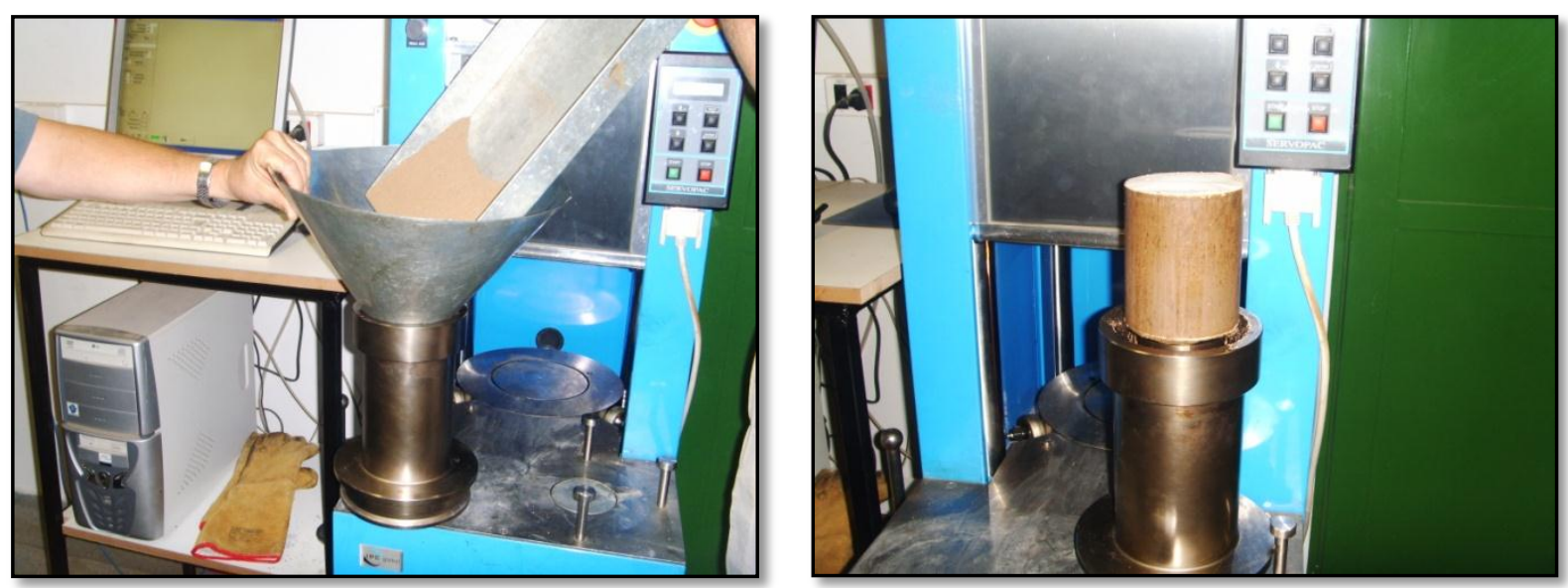

Figura 3.8 - Moldagem de corpos de prova no CGS 


\subsubsection{Análise dos dados de saída do CGS}

As curvas de compactação dos ensaios executados com o CGS foram obtidas sem grandes problemas, por meio dos valores de massa, teor de umidade e altura de cada $\mathrm{CP}$ ao final dos 500 giros. Contudo, ainda tinham os dados armazenados automaticamente pelo CGS durante a compactação de cada $\mathrm{CP}$, que são o ângulo de giro, a altura do corpo de prova e a tensão cisalhante em cada giro efetuado.

Por meio da extração desses dados para uma planilha em Excel, como mostrado na Figura 3.8, foi possível efetuar análises adicionais sobre o processo de compactação no CGS.

\begin{tabular}{|c|c|c|c|c|c|}
\hline 11 & Eyiativis-- & & & & \\
\hline 18 & density=2211 & & & & \\
\hline 19 & height $=150,0$ & no giros & altura $(\mathrm{mm})$ & ângulo de giro & $\begin{array}{c}\text { Tensão } \\
\text { cisalhante (kPa) }\end{array}$ \\
\hline 20 & data $1=599$ & 1 & 156,53 & 1,14 & 190 \\
\hline 21 & data $2=599$ & 2 & 152,96 & 1,21 & 205 \\
\hline 22 & data $3=600$ & 3 & 150,45 & 1,22 & 217 \\
\hline 23 & data $4=601$ & 4 & 148,53 & 1,23 & 228 \\
\hline 24 & data $5=603$ & 5 & 146,96 & 1,23 & 238 \\
\hline 25 & data $6=605$ & 6 & 145,71 & 1,23 & 252 \\
\hline 26 & data $7=606$ & 7 & 144,66 & 1,24 & 261 \\
\hline 27 & data $8=608$ & 8 & 143,80 & 1,24 & 267 \\
\hline 28 & data9=608 & 9 & 143,05 & 1,24 & 271 \\
\hline 29 & data $10=609$ & 10 & 142,38 & 1,24 & 279 \\
\hline 30 & data11=609 & 11 & 141,85 & 1,24 & 282 \\
\hline 31 & data $12=609$ & 12 & 141,34 & 1,24 & 285 \\
\hline 32 & data $13=609$ & 13 & 140,91 & 1,24 & 291 \\
\hline 33 & data $14=609$ & 14 & 140,52 & 1,24 & 291 \\
\hline 34 & data $15=609$ & 15 & 140,20 & 1,24 & 294 \\
\hline 35 & data $16=609$ & 16 & 139,90 & 1,24 & 295 \\
\hline 26 & data17-fana & $7^{17} 8 \mathrm{~A}$ & $\begin{array}{l}12962 \\
106\end{array}$ & $7 \quad 108^{121}$ pd $x=$ & \# \\
\hline
\end{tabular}

Figura 3.9 - Modelo de planilha do Excel com dados de saída do CGS

As avaliações foram realizadas com base na curva MEAS versus número de giros, onde foi possível verificar a influência do número de giros, assim como avaliar se a quantidade de giros utilizada para compactar os CPs estava adequada. 
Para auxiliar na análise dessas curvas, decidiu-se ajustá-las analiticamente com auxílio do software SciDAVis 0.2.4. O ajuste foi implementado com objetivo de calcular as taxas de variação da MEAS em função do número de giros e assim verificar em qual número de giros essa taxa de variação passava a ser muito discreta.

A avaliação da taxa de variação foi feita procurando-se o número de giros no qual a taxa de variação passasse a ser menor que $10^{-3} \mathrm{~g} / \mathrm{cm}^{3}$, pois este número equivale a ordem de grandeza da MEAS e assim taxas de variação menores que esse valor significam ganhos muito pequenos na MEAS.

Os dados extraídos do CGS após a compactação de cada CP também possibilitaram efetuar o cálculo da energia aplicada pelo CGS na compactação, por meio das fórmulas apresentadas por Ping et al. (2003b). Apesar de não ter sido feito análises mais conclusivas acerca da relação da energia aplicada pelo CGS com as energias Proctor, no Anexo A, são mostradas as fórmulas empregadas, assim como o número de giros necessários para o CGS alcançar os níveis de energia Proctor em cada um dos ensaios de compactação realizados.

\subsubsection{Análise da densificação dos corpos de prova no CGS}

Por meio das curvas de MEAS versus número de giros foi possível analisar a estabilização da densificação dos CPs durante a compactação, por meio do conceito de Locking Point e do cruzamento de retas aproximadas.

O Locking Point (LP) é um conceito desenvolvido pelo Departamento de Estradas do estado norte-americano de Illinois, sendo empregado no estudo da compactação de misturas asfálticas no CGS. O Locking Point é definido como o número de giros no qual a estrutura pétrea de uma mistura asfáltica começa a travar e, assim, a adição de giros além desse número pode conduzir a possíveis fraturas dos agregados e pouca densificação adicional. A degradação dos agregados de uma mistura asfáltica pode deixá-la mais suscetível à ação da água. Portanto, o Locking Point pode ser visto como um critério de parada do processo de compactação de misturas asfálticas no CGS. 
Vavrik e Carpenter (1998), definiram o Locking Point como o primeiro giro de uma sequência de 3 giros de mesma altura, antecedido por 2 pares de giros de mesma altura com diferença entre eles de $0,1 \mathrm{~mm}$ e o último par de giros $0,1 \mathrm{~mm}$ maior que a sequência de 3 giros. A Figura 3.10 ilustra o conceito de Locking Point de Vavrik e Carpenter (1998).

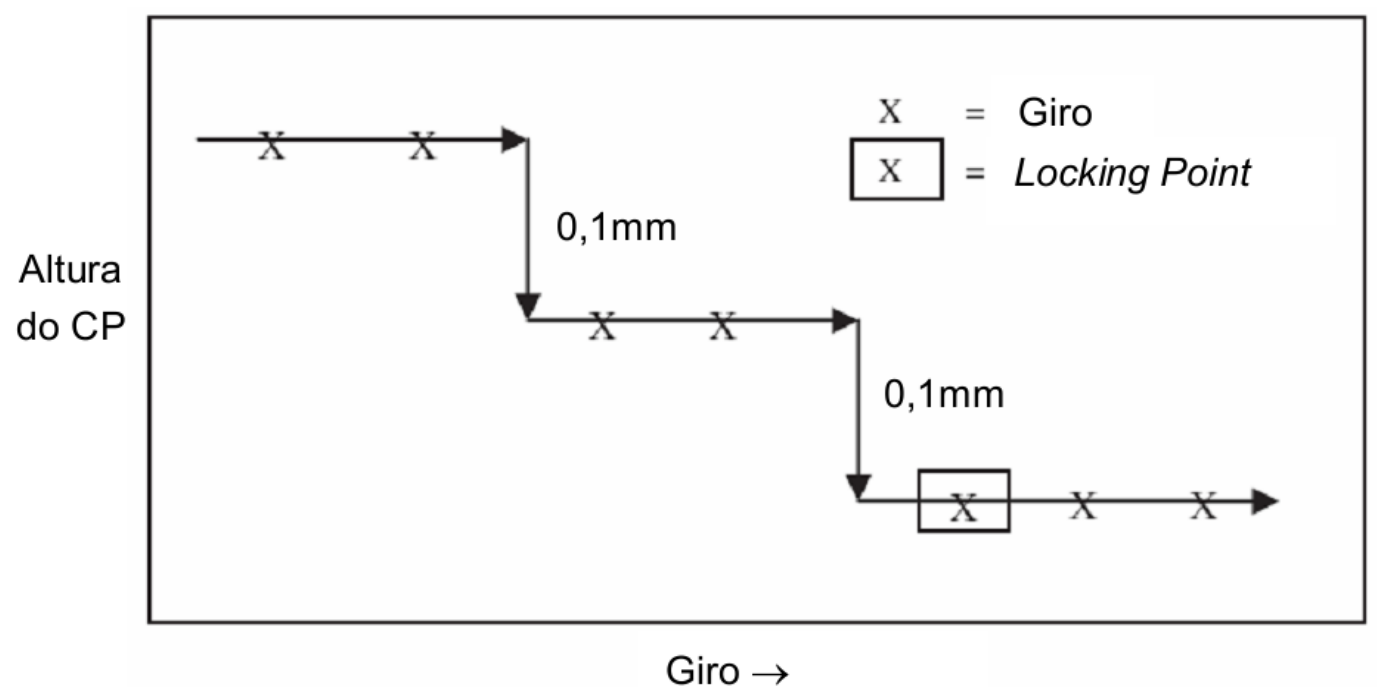

Figura 3.10 - Esquema ilustrativo do Locking Point, segundo definição de VAVRIK e CARPENTER (1998)

Nesta pesquisa, foi empregado o conceito de Locking Point de Vavrik e Carpenter (1998) como uma tentativa de se estabelecer um critério de parada do processo de compactação de solo no CGS. Haja vista os ensaios de compactação no CGS terem sido realizados com 500 giros, percebeu-se que as alturas dos CPs nas curvas de altura versus número de giros estabilizavam-se. Desta forma, no Capítulo 4, serão apresentados e analisados os resultados encontrados para Locking Point de cada um dos CPs dos ensaios de compactação.

\subsection{ENSAIOS MECÂNICOS}

Com o propósito de complementar a comparação entre os métodos de compactação Proctor e CGS, foi decidido realizar ensaios mecânicos com amostras do solo 
moldadas sob os dois métodos. Os ensaios realizados foram o de compressão simples, para determinação do valor de resistência à compressão simples, o de resistência à tração indireta e o triaxial cíclico para determinação do módulo de resiliência.

O comportamento mecânico foi avaliado entre corpos de prova moldados estaticamente e com uso do CGS. A moldagem de corpos de prova na prensa estática é uma forma já consagrada de reprodução de corpos de prova em uma determinada massa específica seca e umidade. Inclusive, a compactação estática é recomendada pela norma AASHTO T 307-99 - Standard Method of Test for Determining the Resilient Modulus of Soils and Aggregate Materials, que descreve o método de ensaio e o cálculo do módulo de resiliência de solos.

A Figura 3.11 ilustra a imagem da prensa estática utilizada para moldar os corpos de prova da presente pesquisa.

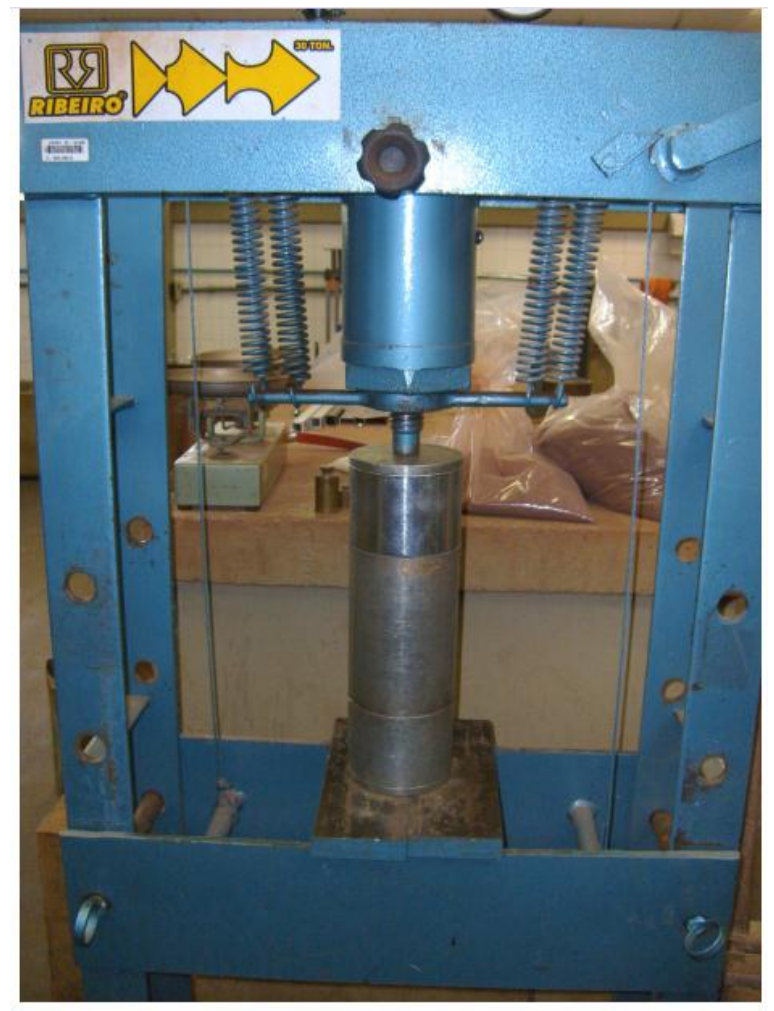

Figura 3.11 - Prensa empregada na moldagem estática dos corpos de prova

\subsubsection{Condições para ensaio}


Para se estabelecer uma análise mais ampla acerca do efeito do tipo de moldagem de CPs no seu comportamento mecânico, decidiu-se trabalhar com CPs moldados sob quatro

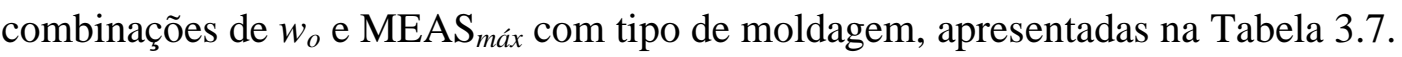

Tabela 3.7 -Combinações entre os parâmetros ótimos e a forma de compactar

\begin{tabular}{ccc}
\hline Combinações & Parâmetros ótimos $\left(w_{o}\right.$, MEAS $\left._{\text {máx }}\right)$ & Moldagem \\
\hline I & Proctor Normal & Prensa Estática \\
II & Proctor Intermediário & Prensa Estática \\
III & Proctor Normal & CGS \\
IV & Proctor Intermediário & CGS \\
\hline
\end{tabular}

As combinações I e II são modos já estabelecidos no meio acadêmico como forma de reproduzir corpos de prova para ensaios mecânicos e as combinações III e IV representam as tentativas de avaliar a influência da compactação por amassamento no comportamento mecânico dos corpos de prova.

O critério de aceitação dos corpos de prova para realização de todos os ensaios mecânicos foi de variação de $\pm 0,5 \%$ da umidade ótima e $\pm 3 \%$ da massa específica seca máxima requerida, garantindo um grau de compactação de $100 \% \pm 2 \%$.

\subsubsection{Ensaio de Compressão Simples}

Os ensaios de compressão simples foram realizados segundo os procedimentos descritos na norma NBR 12770 - Solo coesivo - Determinação da resistência à compressão não confinada. $\mathrm{O}$ objetivo da realização desse ensaio foi obter a resistência à compressão simples (RCS) de cada amostra por meio do gráfico tensão - deformação. A velocidade da 
prensa utilizada foi de $1,27 \mathrm{~mm} / \mathrm{min}$ e os deslocamentos do corpo de prova medidos por um LVDT (Linear Variable Differencial Transducer).

Os corpos de prova submetidos à compressão simples eram de $100 \mathrm{~mm}$ de diâmetro por $200 \mathrm{~mm}$ de altura, sendo que aqueles preparados na prensa estática (Figura 3.11) foram moldados em 5 camadas. Para os CPs moldados no CGS, optou-se em fazê-los com as dimensões de $100 \mathrm{~mm}$ de diâmetro e $100 \mathrm{~mm}$ de altura em uma só camada, visto que não era possível moldar diretamente espécimes com $200 \mathrm{~mm}$ de altura no CGS e, assim, logo depois da moldagem colados com auxílio de emulsão asfáltica para atingir a altura final de $200 \mathrm{~mm}$.

A Figura 3.12 ilustra a imagem de um corpo de prova de $200 \mathrm{~mm}$ de altura que foi obtido pela colagem com emulsão asfáltica de dois corpos de prova de $100 \mathrm{~mm}$ de altura.

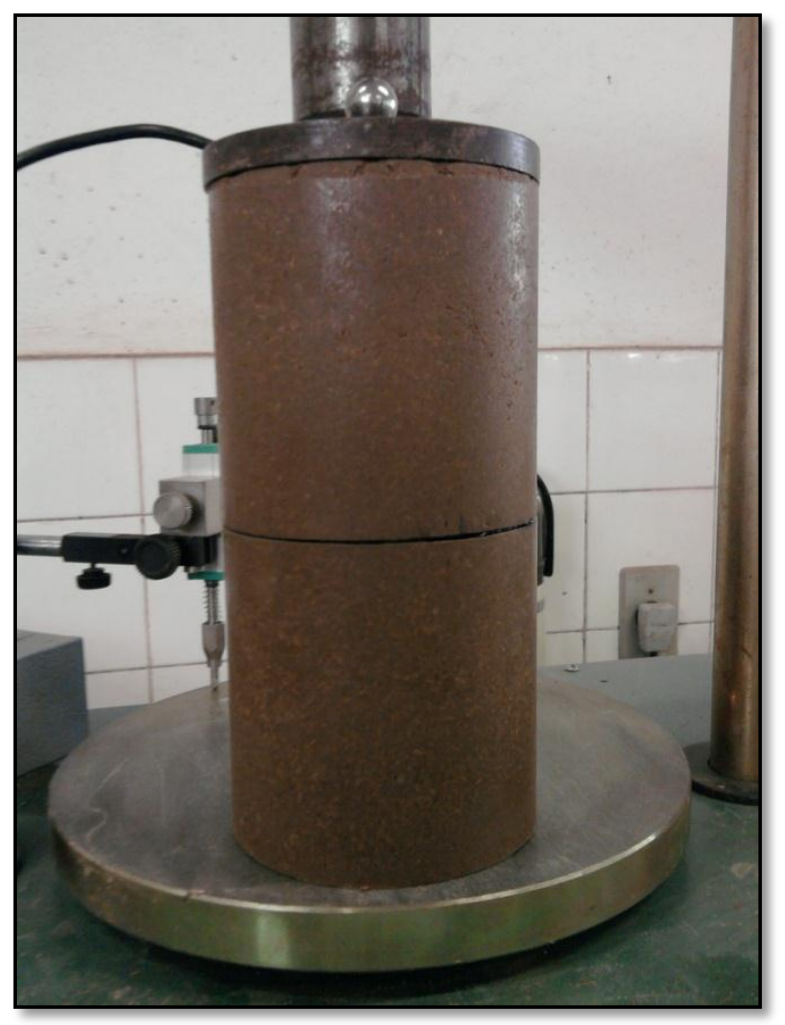

Figura 3.12 - Corpo de prova colado com emulsão asfáltica

\subsubsection{Ensaio de Compressão Diametral}


O ensaio de compressão diametral ou tração indireta foi desenvolvido por Lobo Carneiro e Barcellos, no Brasil, para determinar a resistência à tração de corpos de prova de concreto de cimento Portland. $\mathrm{O}$ ensaio consiste em submeter um corpo de prova à aplicação de uma carga de compressão sem confinamento ao longo de um plano diametral através de dois frisos de carga opostos, produzindo então uma tensão de tração ao longo do plano vertical, até que ocorra a ruptura do corpo de prova.

O valor da resistência à tração por compressão diametral (RTCD) é definido como uma relação entre a força de ruptura e as características geométricas do corpo de prova, como mostrado na Equação 3.1.

$$
R T C D=\frac{2 \times F}{\pi \times D \times H}
$$

Onde,

RTCD: resistência à tração por compressão diametral

F: carga de ruptura

D: diâmetro do corpo de prova

$\mathrm{H}$ : altura do corpo de prova

Para realização dos ensaios de compressão diametral foram moldados corpos de prova de $100 \mathrm{~mm}$ de diâmetro por $80 \mathrm{~mm}$ de altura, sendo que foram ensaiados no mínimo três corpos de prova por condição de ensaio, com a mesma velocidade de aplicação de carga utilizada para a compressão simples.

\subsubsection{Ensaio Triaxial Cíclico}


Os ensaios triaxiais cíclicos foram empregados para se obter o módulo de resiliência (MR) de corpos de prova moldados na prensa estática e no CGS. O procedimento de ensaio seguiu os preceitos da norma AASHTO T 307-99 - Standard Method of Test for Determining the Resilient Modulus of Soils and Aggregate Materials.

Segundo a norma supracitada, o ensaio é executado em duas etapas de aplicação de carga, onde a primeira corresponde a chamada fase de acondicionamento e a segunda, a fase em que os deslocamentos resilientes são efetivamente medidos para posterior cálculo do MR. A primeira fase do ensaio objetiva eliminar as deformações plásticas que ocorrem nas primeiras aplicações do carregamento e igualmente reduzir o efeito do histórico de tensões no valor do MR.

A norma AASHTO T 307-99 preconiza a execução do ensaio em 16 fases de carregamento para materiais empregados em base e sub-base de pavimentos. A primeira fase inclui a aplicação de 500 a 1000 ciclos do primeiro carregamento e a segunda, engloba a aplicação dos 15 ciclos restantes de carregamento. A Tabela 3.9 mostra os estados de tensões que são utilizados para execução do ensaio com materiais de base/sub-base.

Tabela 3.8 - Sequência de tensões de ensaio para base/sub-base segundo a AASHTO T 307-99

\begin{tabular}{|c|c|c|c|c|c|}
\hline $\begin{array}{l}\text { Sequência } \\
\text { no }^{\mathbf{0}}\end{array}$ & $\begin{array}{c}\text { Tensão } \\
\text { confinante } \\
\sigma_{3}(\mathbf{k P a})\end{array}$ & $\begin{array}{c}\text { Tensão } \\
\text { máxima } \\
\sigma_{\mathbf{a}}(\mathbf{k P a})\end{array}$ & $\begin{array}{c}\text { Tensão de } \\
\text { contato } \\
\sigma_{c}(\mathbf{k P a})\end{array}$ & $\begin{array}{c}\text { Tensão } \\
\text { desvio } \\
\sigma_{\mathbf{d}}(\mathbf{k P a})\end{array}$ & $\begin{array}{c}\text { Número de } \\
\text { aplicações } \\
\text { de carga }\end{array}$ \\
\hline 0 & 103,4 & 103,4 & 10,3 & 93,1 & $500-1000$ \\
\hline 1 & 20,7 & 20,7 & 2,1 & 78,6 & 100 \\
\hline 2 & 20,7 & 41,4 & 4,1 & 37,3 & 100 \\
\hline 3 & 20,7 & 62,1 & 6,2 & 55,9 & 100 \\
\hline 4 & 34,5 & 34,5 & 3,5 & 31,0 & 100 \\
\hline 5 & 34,5 & 68,9 & 6,9 & 62,0 & 100 \\
\hline 6 & 34,5 & 103,4 & 10,3 & 93,1 & 100 \\
\hline 7 & 68,9 & 68,9 & 6,9 & 62,2 & 100 \\
\hline 8 & 68,9 & 137,9 & 13,8 & 124,1 & 100 \\
\hline 9 & 68,9 & 206,8 & 20,7 & 186,1 & 100 \\
\hline 10 & 103,4 & 68,9 & 6,9 & 62,0 & 100 \\
\hline 11 & 103,4 & 103,4 & 10,3 & 93,1 & 100 \\
\hline 12 & 103,4 & 206,8 & 20,7 & 196,1 & 100 \\
\hline 13 & 137,9 & 103,4 & 10,3 & 93,1 & 100 \\
\hline
\end{tabular}




\begin{tabular}{llllll}
14 & 137,9 & 137,9 & 13,8 & 124,1 & 100 \\
15 & 137,9 & 275,8 & 27,6 & 248,2 & 100 \\
\hline
\end{tabular}

A prensa utilizada pertence ao Laboratório de Estradas do Departamento de Engenharia de Transportes da EESC-USP, a qual possui um sistema de carregamento pneumático, onde as tensões desvio e confinante são controladas por um computador, por meio de válvulas proporcionais. Os deslocamentos do corpo de prova são medidos com o auxílio de dois LVDTs.

Os dados do ensaio são capturados por meio de um programa desenvolvido em plataforma LabView pelo Prof. Dr. Glauco Tulio Pessa Fabbri. Uma imagem ilustrativa do programa é mostrada na Figura 3.11.

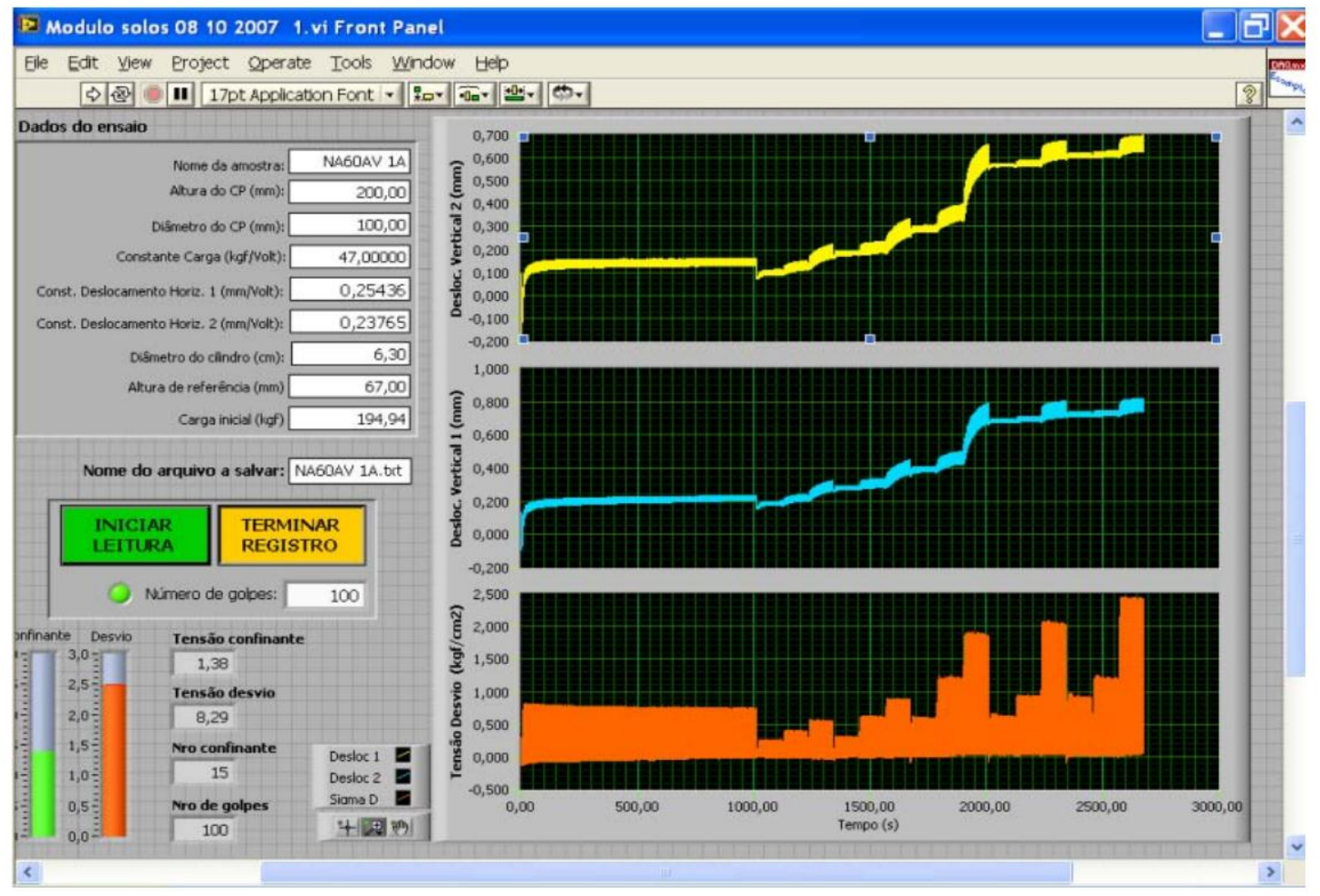

Figura 3.13 - Imagem do programa de aquisição de dados em plataforma LabView 
Para cada condição (Tabela 3.7) foram ensaiados no mínimo dois corpos de prova de $100 \mathrm{~mm}$ de diâmetro e $200 \mathrm{~mm}$ de altura. A moldagem dos corpos de prova foi feita de maneira similar ao CPs destinados ao ensaio de compressão simples (item 3.4.2). 


\section{APRESENTAÇÃO E ANÁLISE DOS RESULTADOS}

\subsection{CONSIDERAÇÕES GERAIS}

Inicialmente, este capítulo apresenta os resultados obtidos nos ensaios de compactação realizados pelo método Proctor. Em seguida, são discutidas a influência da massa úmida de cada CP e a influência da tensão normal no ensaio de compactação com emprego do CGS.

Posteriormente, são apresentadas as curvas MEAS versus número de giros dos ensaios realizados no CGS, e assim, é analisada a influência do número de giros na densificação dos CPs.

Finalizando o capítulo, serão apresentadas e analisadas as comparações entre as curvas obtidas pelos dois métodos de compactação, assim como os resultados obtidos nos ensaios mecânicos para os CPs compactados estaticamente e no CGS. 


\subsection{ENSAIOS DE COMPACTAÇÃO PROCTOR}

Amostras do solo utilizado nessa pesquisa foram submetidas aos ensaios de compactação Proctor nas energias Normal, Intermediária e Modificada. A Figura 4.1 apresenta as respectivas curvas de compactação obtidas nesses ensaios.

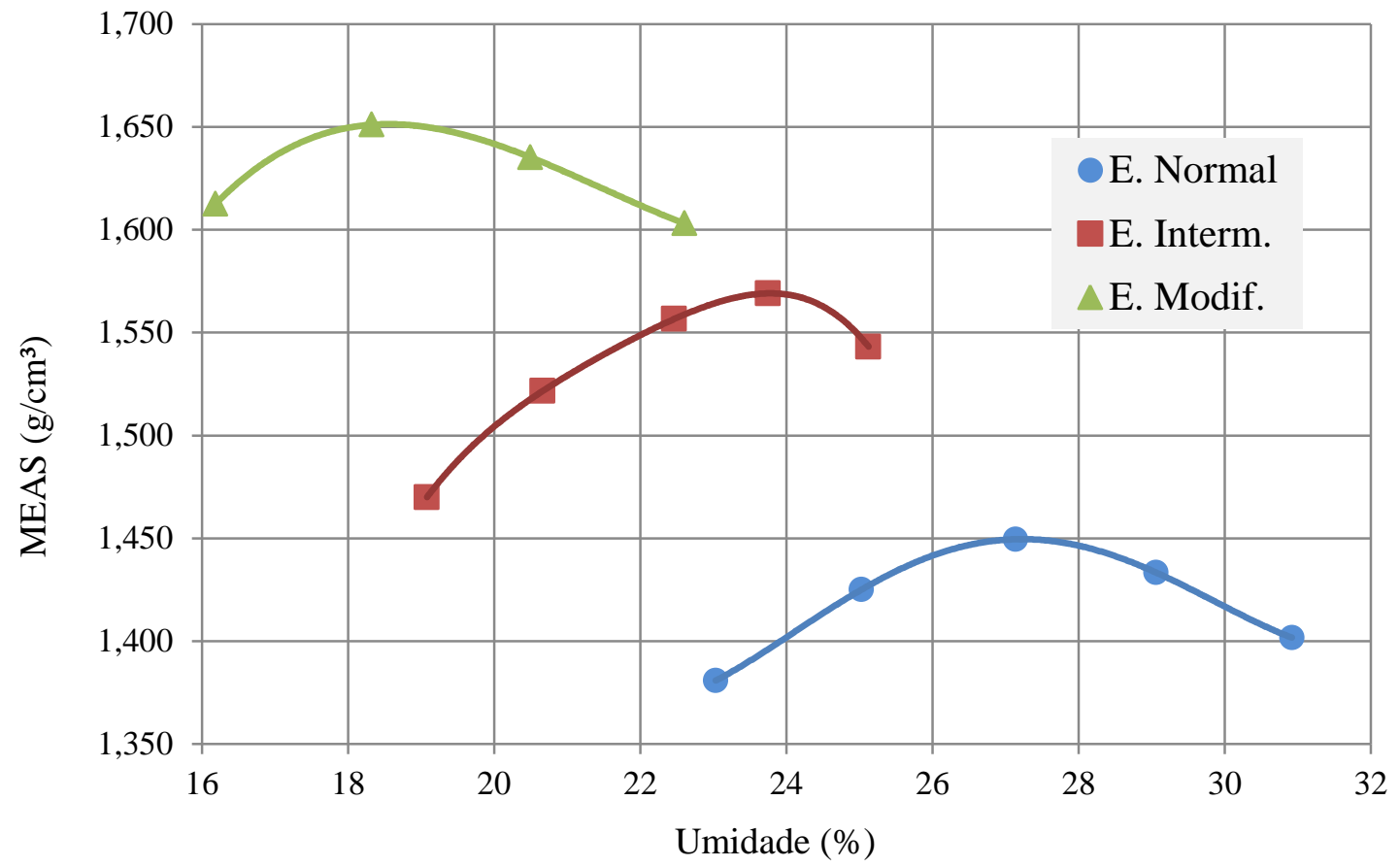

Figura 4.1 - Curvas de compactação Proctor nas energias normal, intermediária e modificada

A Figura 4.1 mostra a esperada influência da energia de compactação nos valores da umidade ótima e da massa específica seca máxima, isto é, quanto maior o nível de energia aplicado no ensaio maior é o valor da $\mathrm{MEAS}_{\text {máx }}$ e menor é a $w_{o}$. A Tabela 4.1 apresenta os valores encontrados para os parâmetros ótimos dessas curvas de compactação. 
Tabela 4.1 - Parâmetros ótimos das curvas de compactação Proctor

\begin{tabular}{ccc}
\hline ENERGIA & $w_{o}(\%)$ & $\begin{array}{c}\text { MEAS }_{\text {máx }} \\
\left(\mathrm{g} / \mathrm{cm}^{3}\right)\end{array}$ \\
\hline Normal & 27,4 & 1,450 \\
Intermediária & 23,4 & 1,575 \\
Modificada & 19,0 & 1,654 \\
\hline
\end{tabular}

Na tabela anterior, observa-se que na passagem da energia normal para energia intermediária há um incremento de cerca de $9 \%$ no valor da massa específica seca máxima e, da intermediária para a modificada cerca de 5\%. A Tabela 4.2 mostra as porcentagens representativas do aumento e da diminuição, respectivamente, para $\operatorname{MEAS}_{\text {máx }}$ e $w_{o}$.

Tabela 4.2 - Porcentagens das variações dos parâmetros ótimos no ensaio Proctor

\begin{tabular}{ccc}
\hline & \multicolumn{2}{c}{ VARIAÇÕES } \\
\cline { 2 - 3 } MUDANÇAS DE ENERGIA & $w_{o}$ & MEAS $_{\text {máx }}$ \\
\hline Normal $\rightarrow$ Intermediária & $-15,0 \%$ & $+9,0 \%$ \\
Intermediária $\rightarrow$ Modificada & $-19,0 \%$ & $+5,0 \%$ \\
\hline
\end{tabular}

A análise da Tabela 4.2 permite observar que para esse caso o aumento de energia normal para intermediária conduz a um incremento na $\mathrm{MEAS}_{\text {máx }}$ de quase o dobro daquele que é observado na mudança de energia intermediária para modificada. Essa constatação é relevante, pois, como visto no Capítulo 1, item 2.1.1, a energia aplicada no ensaio Proctor aumenta pouco mais de $100 \%$ de um tipo de ensaio para o outro, entretanto, o ganho na MEAS $_{\text {máx }}$ entre o Proctor Normal e o Intermediário foi o dobro do observado entre o Intermediário e o Modificado. 


\subsection{ENSAIOS DE COMPACTAÇÃO NO CGS}

\subsubsection{Influência da massa úmida do corpo de prova}

Conforme comentado no capítulo 3, amostras do solo foram submetidas a ensaios de compactação com uso do CGS para três valores de tensões normais, 200, 400 e 600 kPa. Para cada uma dessas tensões, dois ensaios de compactação foram executados, um com 1000g de solo úmido por corpo de prova e outro, $1800 \mathrm{~g}$.

A Figura 4.2 apresenta as duas curvas de compactação obtidas nos ensaios com tensão normal de $200 \mathrm{kPa}, 500$ giros e corpos de prova com massa úmida de 1000 e $1800 \mathrm{~g}$.

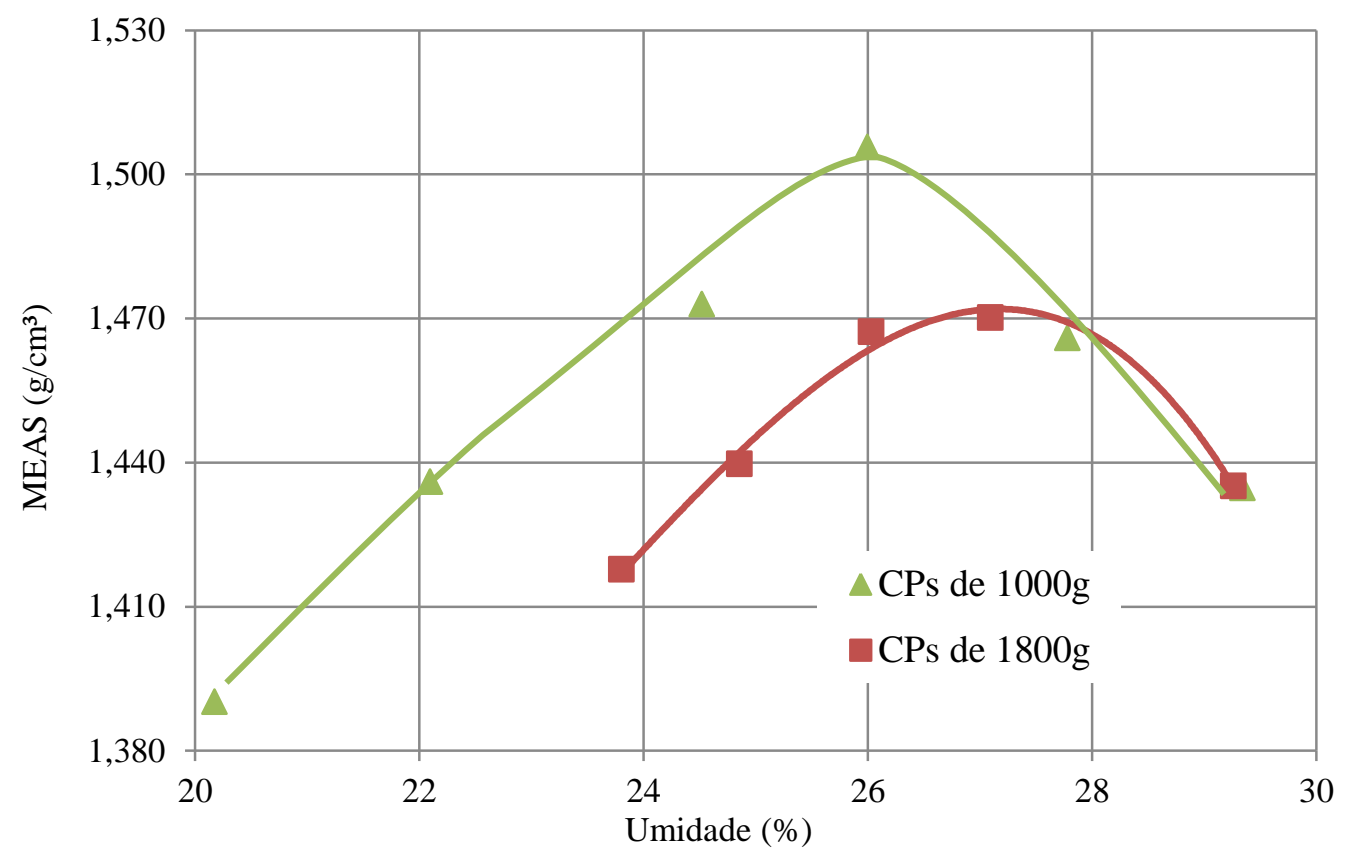

Figura 4.2 - Curvas de compactação para tensão normal de 200 kPa e 500 giros

Com base na Figura 4.2, observa-se que os valores de MEAS do ensaio com CPs de $1000 \mathrm{~g}$ foi maior que os do ensaio com CPs de $1800 \mathrm{~g}$ para o ramo seco de ambas as curvas. Para o ramo úmido, não houve grande distinção entre os valores de MEAS das duas curvas. A Tabela 4.3 apresenta os valores de umidade ótima e de MEAS $_{\text {máx }}$ para as curvas de 
compactação da Figura 4.2, onde se verifica uma diferença da ordem de 2,5\% entre os parâmetros ótimos das duas curvas.

Com base na Figura 4.2, observa-se que a curva do ensaio desenvolvido com CPs de $1000 \mathrm{~g}$ de massa úmida teve valores de MEAS maiores que os obtidos na curva com CPs de 1800g. A Tabela 4.3 apresenta os valores de umidade ótima e de $\mathrm{MEAS}_{\text {máx }}$ para as curvas de compactação da Figura 4.2, onde se verifica uma diferença da ordem de 2,5\% entre os parâmetros ótimos das duas curvas.

Tabela $4.3-w_{o}$ e MEAS $_{\text {máx }}$ para ensaio de compactação com tensão normal de $200 \mathrm{kPa}$ e 500 giros

\begin{tabular}{c|cc}
\hline Massa por CP & $w_{o}(\%)$ & MEAS $_{\text {máx }}\left(\mathrm{g} / \mathrm{cm}^{3}\right)$ \\
\hline $1000 \mathrm{~g}$ & 26,0 & 1,506 \\
$1800 \mathrm{~g}$ & 26,7 & 1,473 \\
\hline
\end{tabular}

As curvas de compactação obtidas para a tensão de $400 \mathrm{kPa}$, utilizando CPs de 1000 e 1800 gramas e 500 giros são mostradas na Figura 4.3.

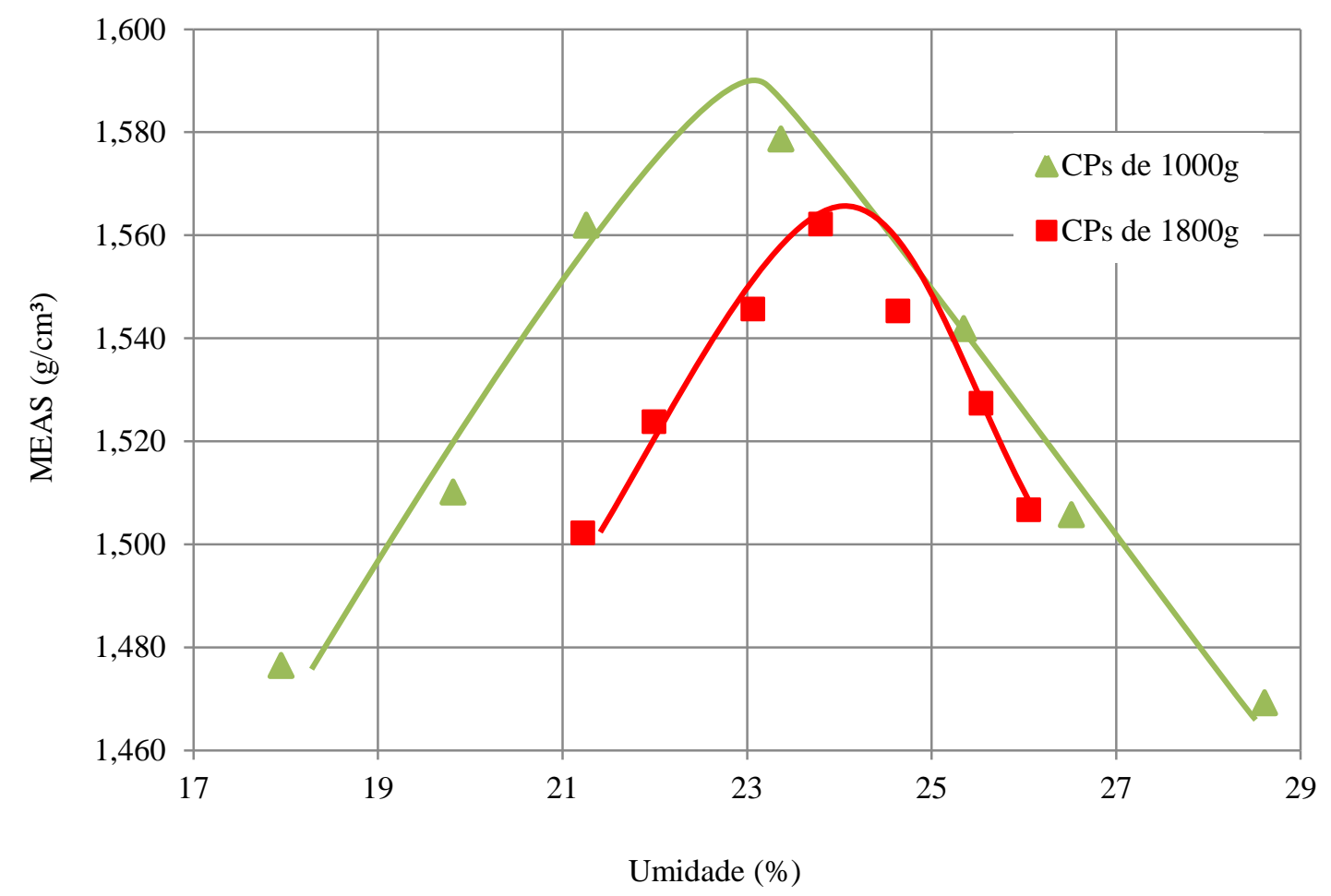

Figura 4.3 - Curvas de compactação para tensão normal de 400 kPa e 500 giros 
Analisando a Figura 4.3, observa-se mais uma vez valores de MEAS maiores para o ensaio realizado com CPs de $1000 \mathrm{~g}$ em comparação ao ensaio com CPs de $1800 \mathrm{~g}$. No caso da tensão normal de $400 \mathrm{kPa}$, o uso de massas úmidas diferentes no ensaio conduziu a uma diferença da ordem de $5 \%$ na umidade ótima, contudo na $\mathrm{MEAS}_{\text {máx }}$ a diferença ainda foi muito pequena, 1,6\%. A Tabela 4.4 ilustra os parâmetros ótimos das curvas apresentadas na Figura 4.3.

Tabela $4.4-w_{o}$ e MEAS $_{\text {máx }}$ para ensaio de compactação com tensão normal de $400 \mathrm{kPa}$ e 500 giros

\begin{tabular}{c|cc}
\hline Massa por CP & $w_{o}(\%)$ & $\begin{array}{c}\text { MEAS }_{\text {máx }} \\
\left(\mathrm{g} / \mathrm{cm}^{3}\right)\end{array}$ \\
\hline $1000 \mathrm{~g}$ & 22,9 & 1,588 \\
$1800 \mathrm{~g}$ & 24,0 & 1,563 \\
\hline
\end{tabular}

Na Figura 4.4 são mostradas as curvas de compactação resultantes dos ensaios para corpos de prova com massa de 1000g e 1800g, 500 giros e tensão normal de 600kPa.

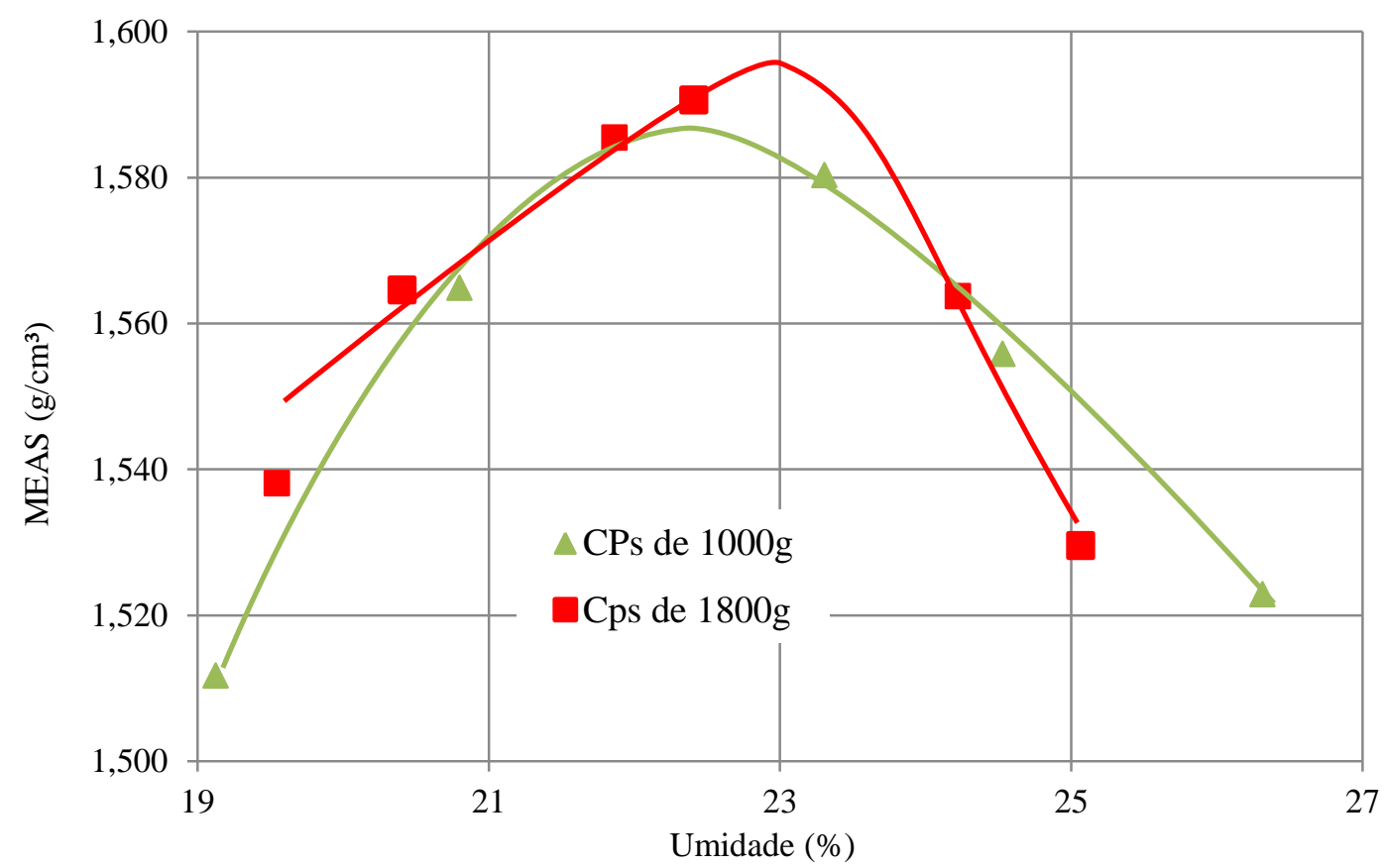

Figura 4.4 - Curvas de compactação (CGS) para tensão de 600 kPa e 500 giros 
De maneira semelhante ao observado para as tensões de 200 e $400 \mathrm{kPa}$, as curvas de compactação para tensão de $600 \mathrm{kPa}$ não tiveram grandes diferenças na umidade e na massa específica aparente seca. A Tabela 4.5 apresenta os parâmetros ótimos encontrados para os ensaios apresentados na Figura 4.4, onde se verifica que para MEASmáx pode-se dizer que não houve diferença, enquanto para a $w_{o}$ houve uma diferença de $1,8 \%$.

Tabela 4.5 - $w_{o}$ e MEAS $_{\text {máx }}$ para ensaio de compactação com tensão normal de 600 kPa e 500 giros

\begin{tabular}{c|cc}
\hline \multirow{2}{*}{ Massa por CP } & $w_{o}(\%)$ & $\operatorname{MEAS}_{\text {máx }}\left(\mathrm{g} / \mathrm{cm}^{3}\right)$ \\
\hline $1000 \mathrm{~g}$ & 22,6 & 1,587 \\
$1800 \mathrm{~g}$ & 23,0 & 1,597 \\
\hline
\end{tabular}

Um resumo das diferenças apresentadas entre os ensaios de compactação desenvolvidos com dois valores de massa úmida por CP no quesito $\mathrm{MEAS}_{\text {máx }}$ é mostrado na Figura 4.5 .

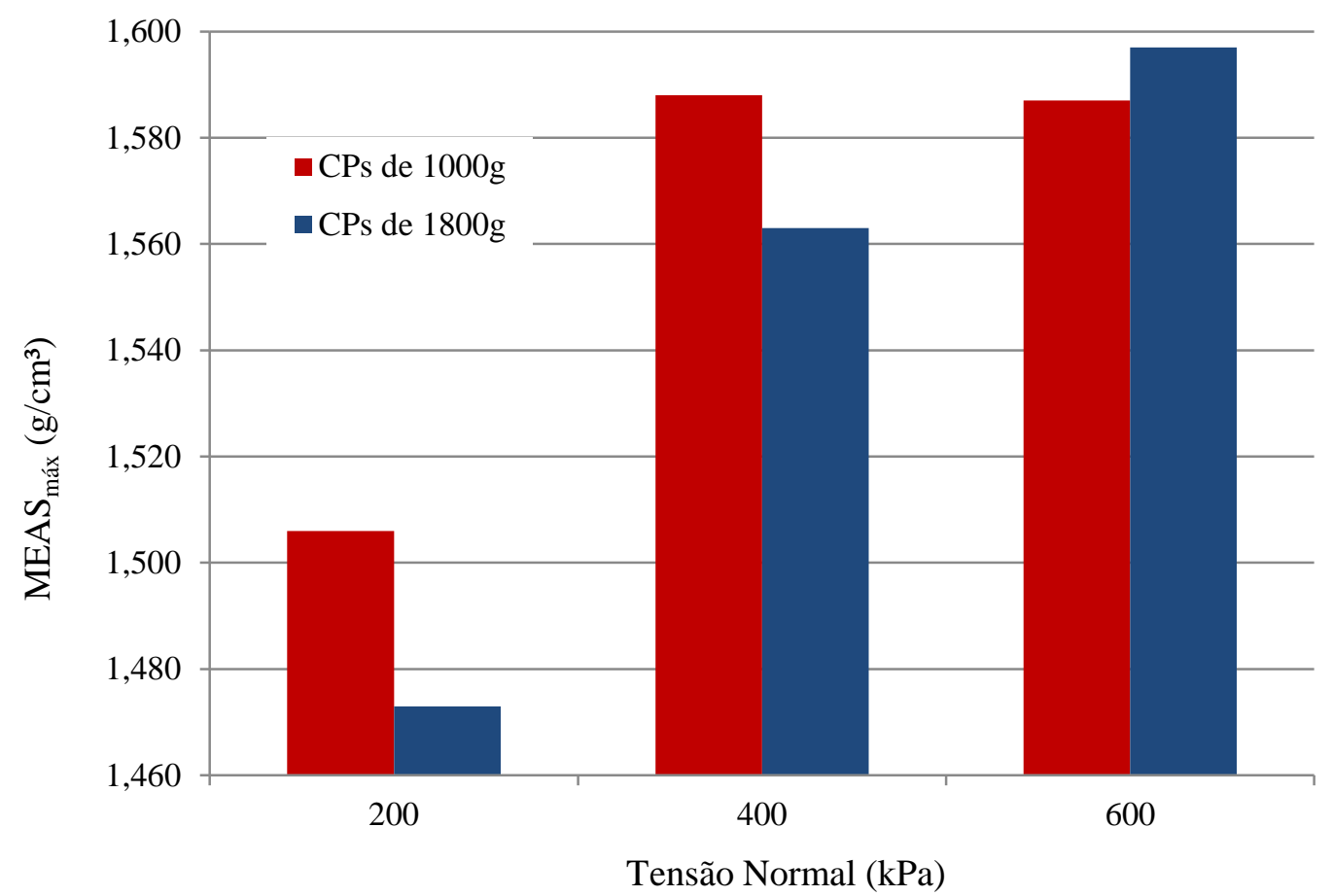

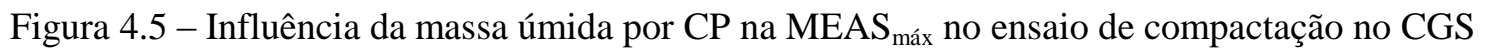


Examinando a Figura 4.5, verifica-se que nas tensões de 200 e 400kPa, os ensaios de compactação desenvolvidos com CPs de $1000 \mathrm{~g}$ de massa úmida tiveram $\mathrm{MEAS}_{\text {máx }}$ maiores que os de CPs de $1800 \mathrm{~g}$. Inclusive, os ensaios com 200kPa apresentaram a maior diferença entre si, 2,2\%, contudo não muito distante da observada com $400 \mathrm{kPa}, 1,6 \%$. Acredita-se que nos ensaios com tensão de $200 \mathrm{kPa}$, o valor da tensão tenha levado a uma maior dificuldade de compactação dos CPs com 1800g.

Nos ensaios com tensão normal de $600 \mathrm{kPa}$, apesar da $\mathrm{MEAS}_{\text {máx }}$ com CPs de $1800 \mathrm{~g}$ ter sido maior que aquela apresentada com CPs de $1000 \mathrm{~g}$, a diferença foi muito discreta, $0,6 \%$.

Os resultados encontrados nos ensaios de compactação no CGS realizados com CPs de 1000 e $1800 \mathrm{~g}$ mostraram que a massa úmida por CP apesar de ter apresentado pouca interferência no valor de $\mathrm{MEAS}_{\text {máx }}$, os ensaios realizados com $1000 \mathrm{~g}$ por CP tiveram valores de $\mathrm{MEAS}_{\text {máx }}$ maiores que aqueles apresentados pelos ensaios com $1800 \mathrm{~g}$. A exceção se fez para os ensaios com $600 \mathrm{kPa}$, que apesar ter acontecido o inverso, a diferença na $\mathrm{MEAS}_{\text {máx }}$ entre o ensaio com $1000 \mathrm{~g}$ e $1800 \mathrm{~g}$ foi muito pequena.

Possivelmente, a causa para valores mais elevados de $\mathrm{MEAS}_{\text {máx }}$ nos ensaios executados com CPs de $1000 \mathrm{~g}$ em comparação aos ensaios com CPs de $1800 \mathrm{~g}$ é a própria quantidade de massa por CP. Essa afirmação pode ser justificada olhando-se os dados da Figura 4.5 , onde se observa que justamente na tensão mais baixa, $200 \mathrm{kPa}$, houve a maior diferença entre os ensaios com massas diferentes e no ensaio com $600 \mathrm{kPa}$, a menor diferença, mostrando que a massa úmida por CP prejudicou a ação do CGS.

\subsubsection{Influência da tensão normal}

A tensão normal aplicada durante a compactação no CGS compõe uma parcela muito importante da energia aplicada no ensaio e, por isso, foi analisado o efeito da variação da tensão normal na curva de compactação. As Figuras 4.6 e 4.7 apresentam as curvas de 
compactação obtidas para os ensaios de compactação realizados no CGS, nas tensões normais de 200, 400 e $600 \mathrm{kPa}$ e, respectivamente, para corpos de prova de 1000 e $1800 \mathrm{~g}$.

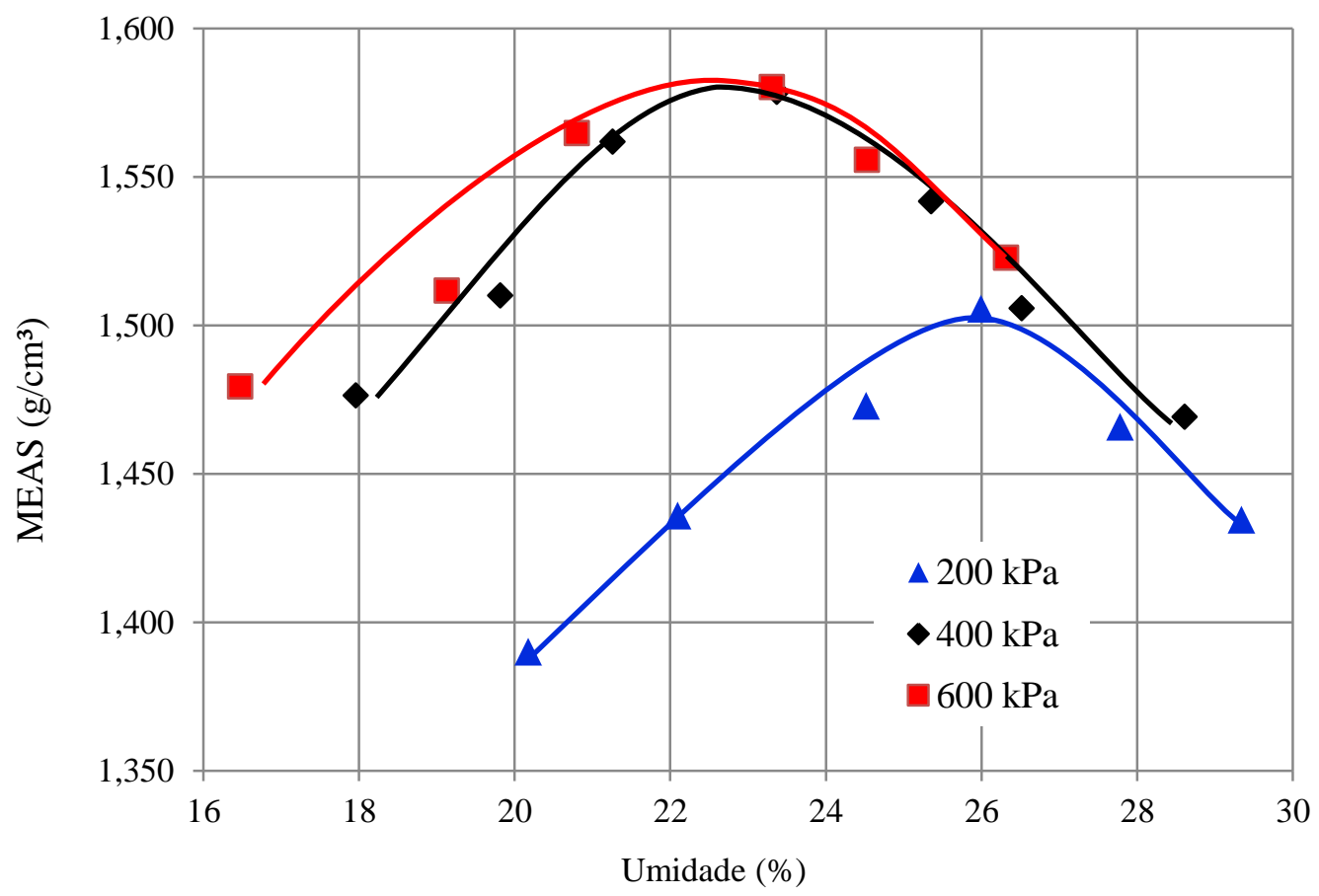

Figura 4.6 - Curvas de compactação no CGS para as tensões de 200, 400 e 600 kPa e CPs de 1000g

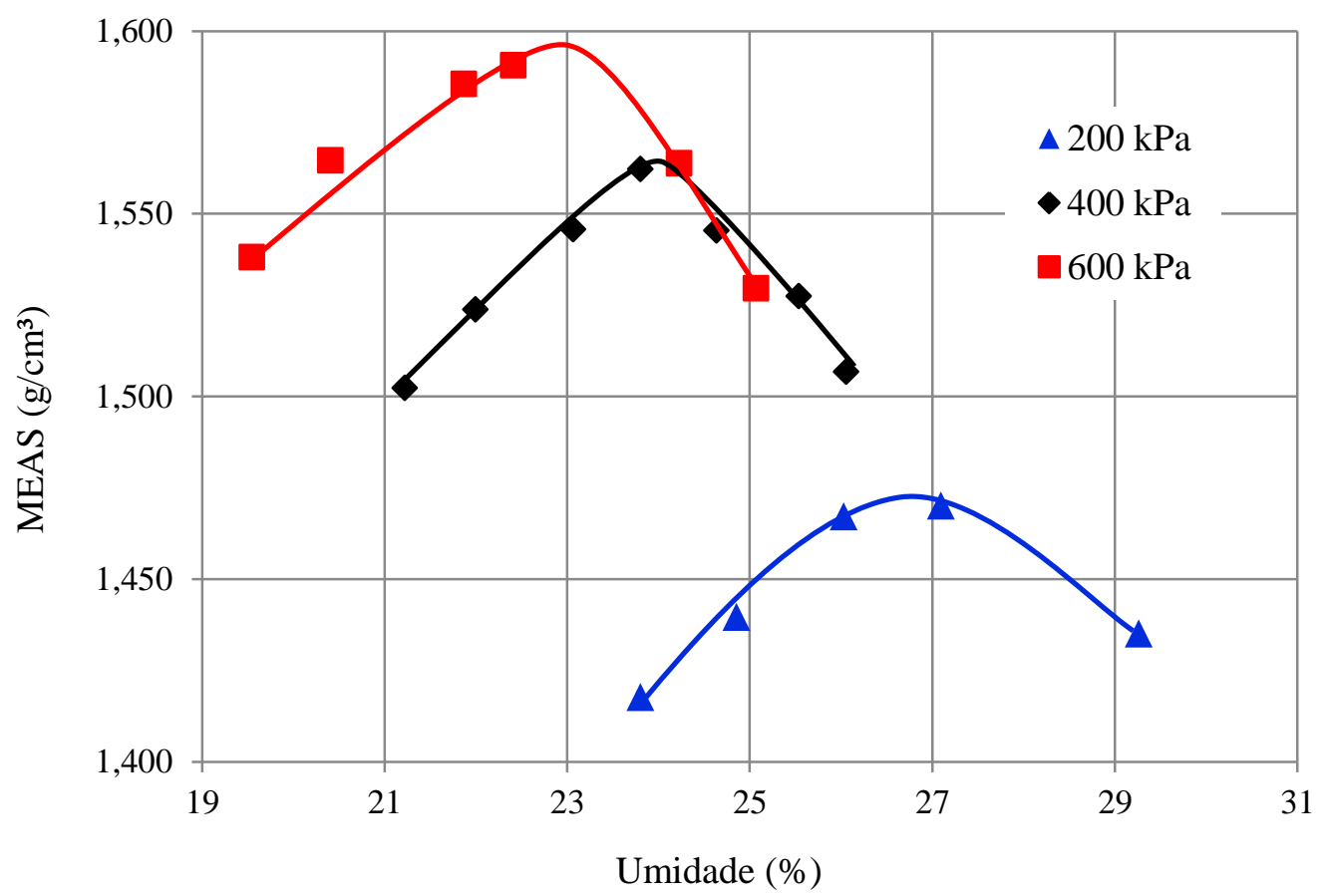

Figura 4.7 -Curvas de compactação no CGS para as tensões de 200, 400 e 600 kPa e CPs de 1800g 
O comportamento observado em relação a influência da energia aplicada nas curvas de compactação foi similar ao ocorrido com o ensaio Proctor, isto é, quanto maior a energia aplicada, maior a massa específica seca máxima e menor a úmida ótima.

Ainda analisando as Figuras 4.6 e 4.7, em ambas destaca-se o pequeno acréscimo na massa específica seca, quando houve aumento da tensão normal de 400 para $600 \mathrm{kPa}$, sobretudo quando comparado os ramos úmidos das curvas de compactação. Inclusive, na Figura 4.5, as curvas para 400 e $600 \mathrm{kPa}$ são quase coincidentes.

As distinções que ocorreram entre os parâmetros ótimos dos ensaios realizados com as três tensões normais estão resumidos na Tabela 4.6; e, a Figura 4.8 mostra a importância da tensão normal nos valores de $\mathrm{MEAS}_{\text {máx} \text {. }}$

Tabela 4.6 - Parâmetros ótimos dos ensaios de compactação com CGS

\begin{tabular}{c|ccc}
\hline Massa por CP & $\begin{array}{c}\text { Tensões } \\
\text { normais }\end{array}$ & $w_{o}(\%)$ & $\begin{array}{c}\text { MEAS } \\
\left(\mathrm{g} / \mathrm{cm}^{3}\right)\end{array}$ \\
\hline \multirow{2}{*}{$1000 \mathrm{~g}$} & $200 \mathrm{kPa}$ & 26,0 & 1,506 \\
& $400 \mathrm{kPa}$ & 22,9 & 1,588 \\
& $600 \mathrm{kPa}$ & 22,6 & 1,587 \\
\hline \multirow{2}{*}{$1800 \mathrm{~g}$} & $200 \mathrm{kPa}$ & 26,7 & 1,473 \\
& $400 \mathrm{kPa}$ & 24,0 & 1,563 \\
& $600 \mathrm{kPa}$ & 23,0 & 1,597 \\
\hline
\end{tabular}




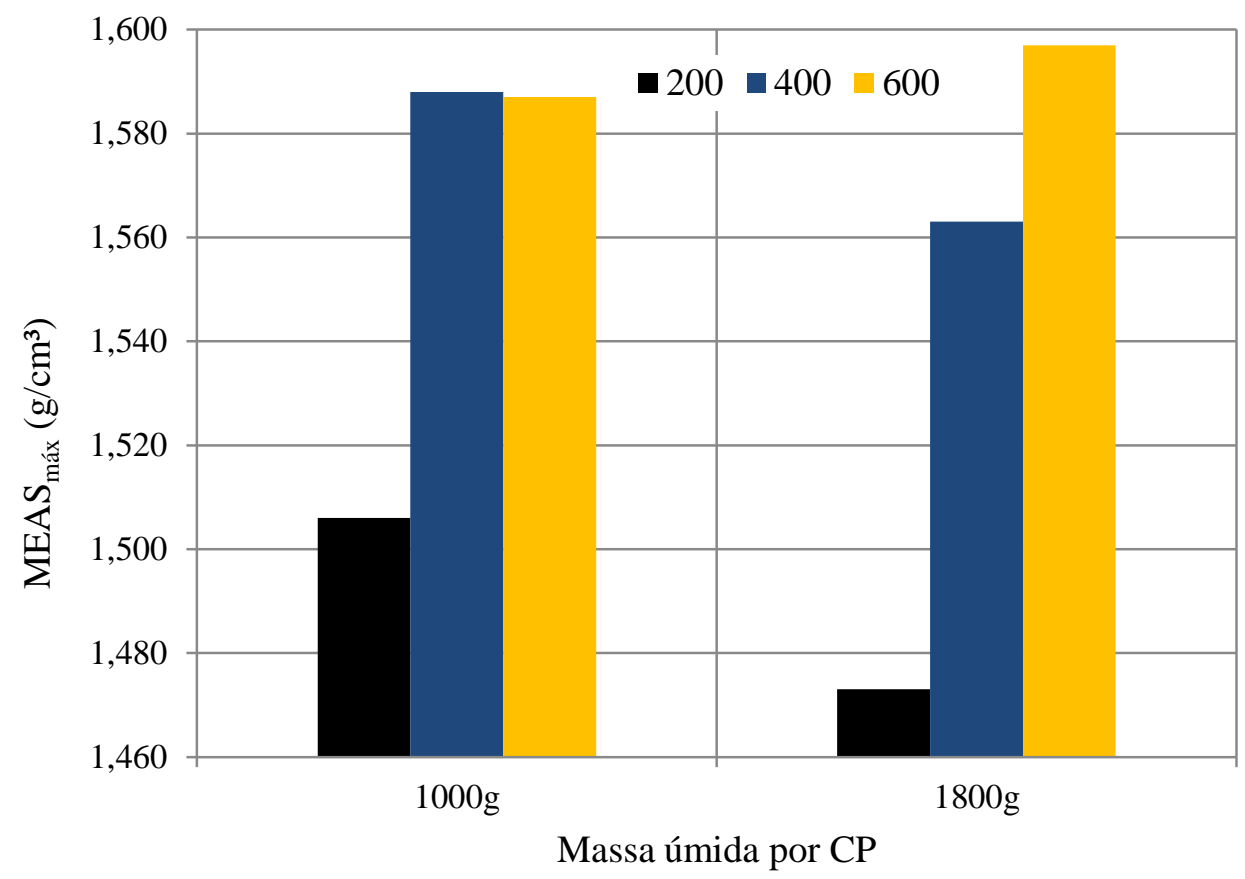

Figura 4.8 - Influência da tensão normal na $\mathrm{MEAS}_{\text {máx }}$ no ensaio de compactação no CGS

Examinando a Tabela 4.6 e a Figura 4.8, observa-se que o acréscimo na MEAS $_{\text {máx }}$ foi muito pequeno, quando aumentada a tensão de 400 para $600 \mathrm{kPa}$ principalmente para a situação dos ensaios com CPs de $1000 \mathrm{~g}$, onde foi de praticamente zero o aumento na

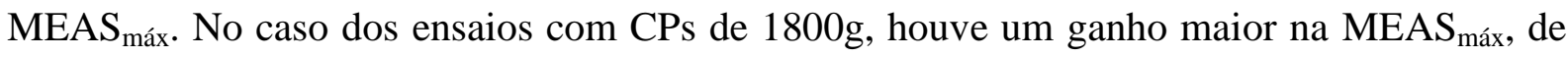
cerca de $2 \%$.

Já para a situação do aumento de tensão normal de 200 para 400 kPa, observa-se um maior incremento, onde nos ensaios com CPs de $1000 \mathrm{~g}$ o acréscimo na $\mathrm{MEAS}_{\text {máx }}$ foi cerca de $5,5 \%$ e naqueles com CPs de $1800 \mathrm{~g}, 6,0 \%$.

Com base nessas observações, pode-se concluir que apesar do pouco ganho na $\mathrm{MEAS}_{\text {máx }}$ que houve nos ensaios com CPs de $1000 \mathrm{~g}$, a compactação no CGS com tensão normal de $600 \mathrm{kPa}$ é uma condição mais favorável ao alcance de valores mais elevados de MEAS, como ocorreu nos ensaios com CPs de $1800 \mathrm{~g}$. 


\subsubsection{Estudo dos dados de saída do CGS}

\subsubsection{Massa específica aparente seca versus número de giros}

A partir da altura do corpo de prova em cada giro efetuado pelo CGS e juntamente com o valor da umidade e massa úmida do $\mathrm{CP}$, calculou-se a massa específica aparente seca em cada giro aplicado pelo CGS. Sendo assim, foi possível plotar curvas da variação da massa específica seca em função do número de giros.

As Figuras Figura 4.9 e Figura 4.10 apresentam a curva massa específica seca versus número de giros para o ensaio de compactação realizado com tensão normal de $200 \mathrm{kPa}, 500$ giros e corpos de prova de 1000 e $1800 \mathrm{~g}$, respectivamente.

Ressalta-se que em todas as figuras deste item as linhas traço-ponto representam os valores de $\mathrm{MEAS}_{\text {máx }}$ encontrados nos ensaios Proctor, mostrado no item 4.2.

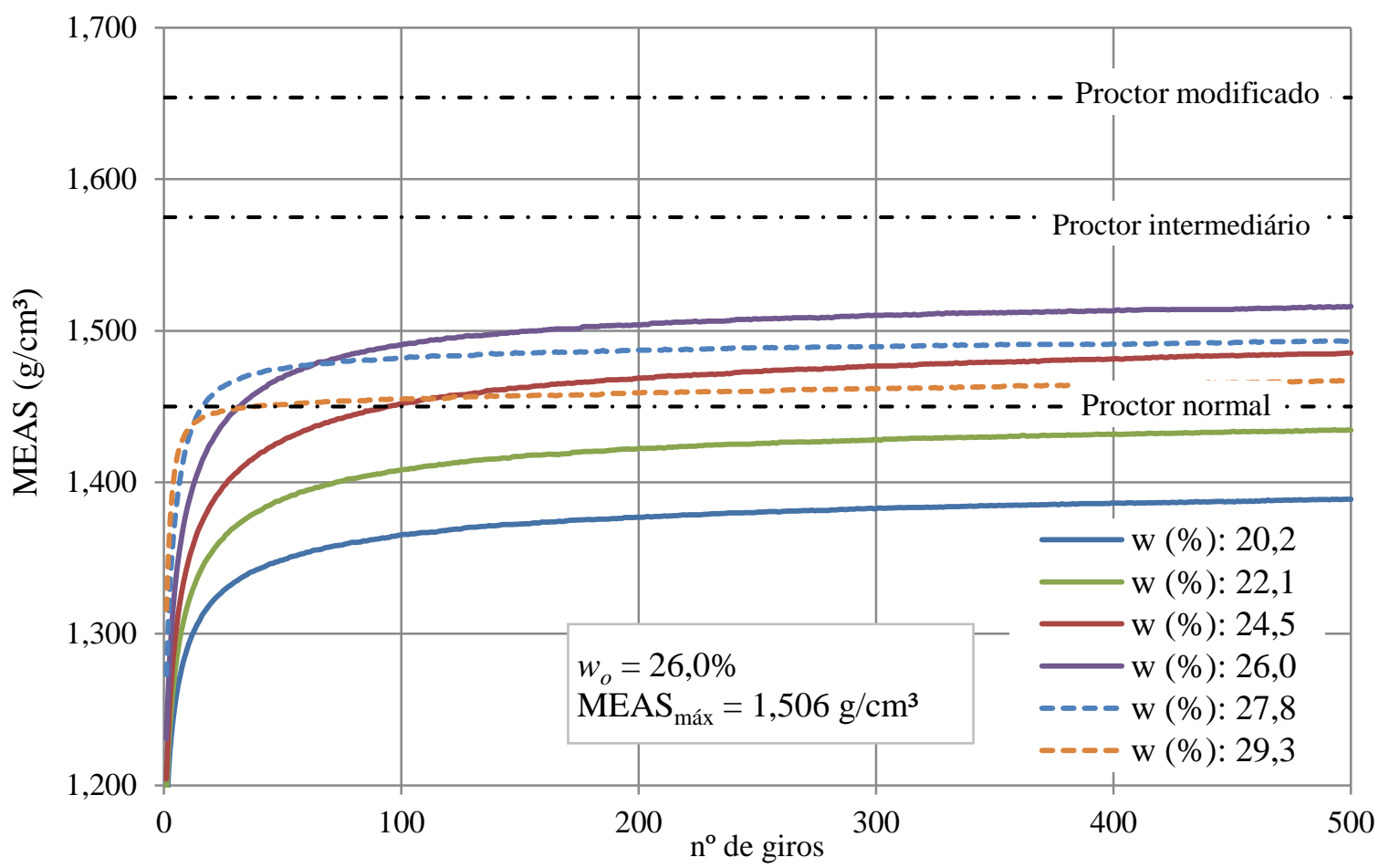

Figura 4.9 - MEAS versus número de giros para CPs de 1000g e tensão normal de $200 \mathrm{kPa}$ 


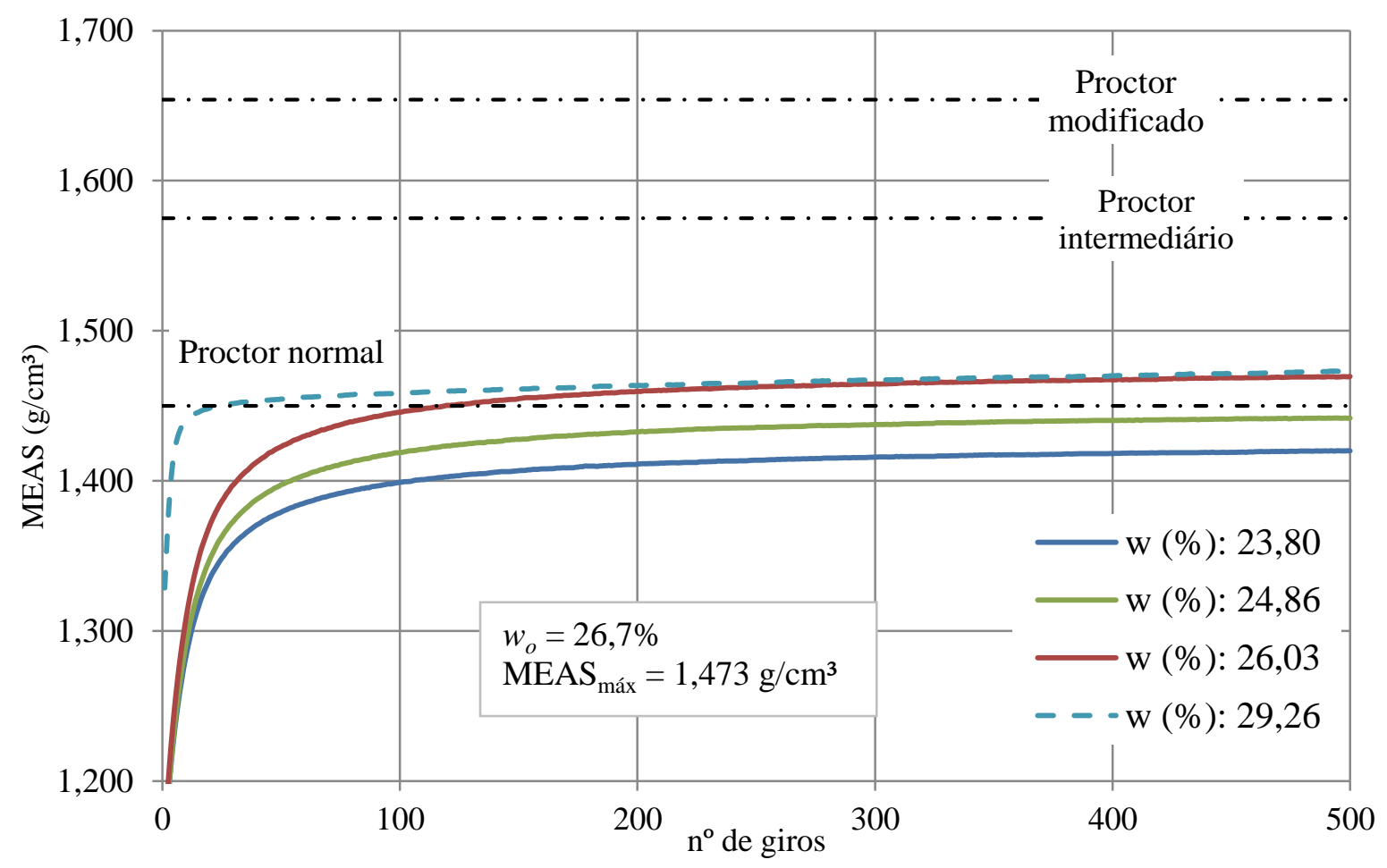

Figura 4.10 - MEAS versus número de giros para CPs de $1800 \mathrm{~g}$ e tensão normal de $200 \mathrm{kPa}$

Examinando as Figuras 4.9 e 4.10, constata-se que nas umidades mais elevadas a massa específica seca tende a se estabilizar mais rapidamente, como pode ser visualizado para as umidades de 27,8\% e 29,3\% na Figura 4.9 e para a umidade de 29,3\% na Figura 4.10.

Tal observação pode ser explicada olhando-se o valor da umidade ótima de cada ensaio de compactação. Para o ensaio apresentado na Figura 4.9, a umidade ótima foi de 26,0\%; logo, as curvas para a umidade $27,8 \%$ e $29,3 \%$ estão no ramo úmido da curva de compactação e, por conseguinte, segundo a teoria de compactação de solos (Proctor, 1933), a água existente entre as partículas do solo passa a absorver parte do esforço de compactação e, assim, a taxa de densificação do $\mathrm{CP}$ reduz-se. A mesma justificativa pode ser apresentada para a curva do CP de umidade 29,3\% na Figura 4.10, pois o mesmo já está no ramo úmido da curva de compactação.

Ainda observando as Figuras 4.9 e 4.10, observa-se que as massas específicas secas não conseguiram atingir a $\mathrm{MEAS}_{\text {máx }}$ do Proctor Intermediário, nem do Modificado, apesar do emprego de 500 giros nos ensaios. 
As Figuras 4.11 e 4.12 apresentam as curvas massa específica aparente seca versus número de giros para a tensão normal de $400 \mathrm{kPa}$ e corpos de prova de 1000 e 1800 gramas, respectivamente.

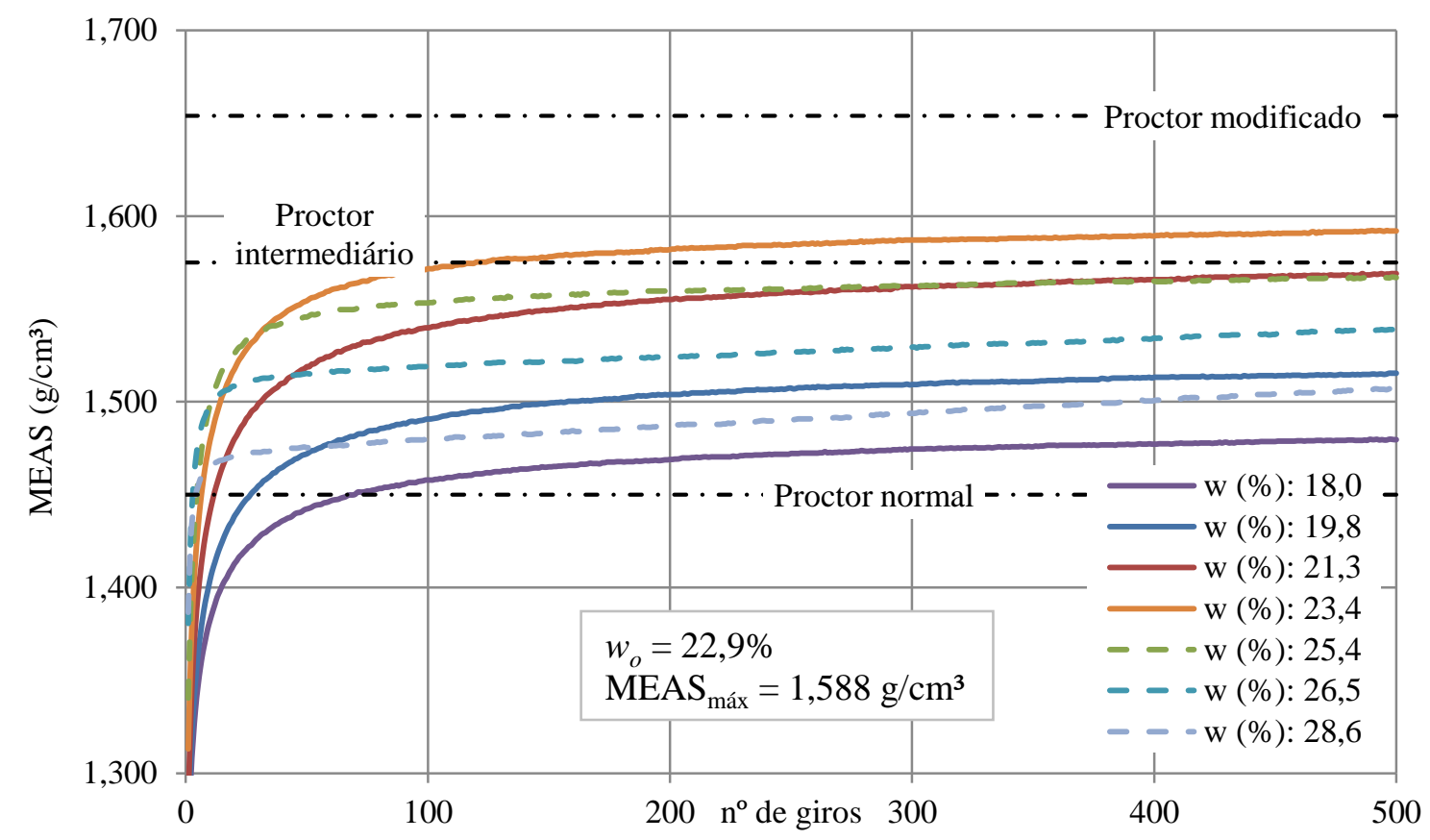

Figura 4.11 - MEAS versus número de giros para CPs de 1000g e tensão normal de $400 \mathrm{kPa}$

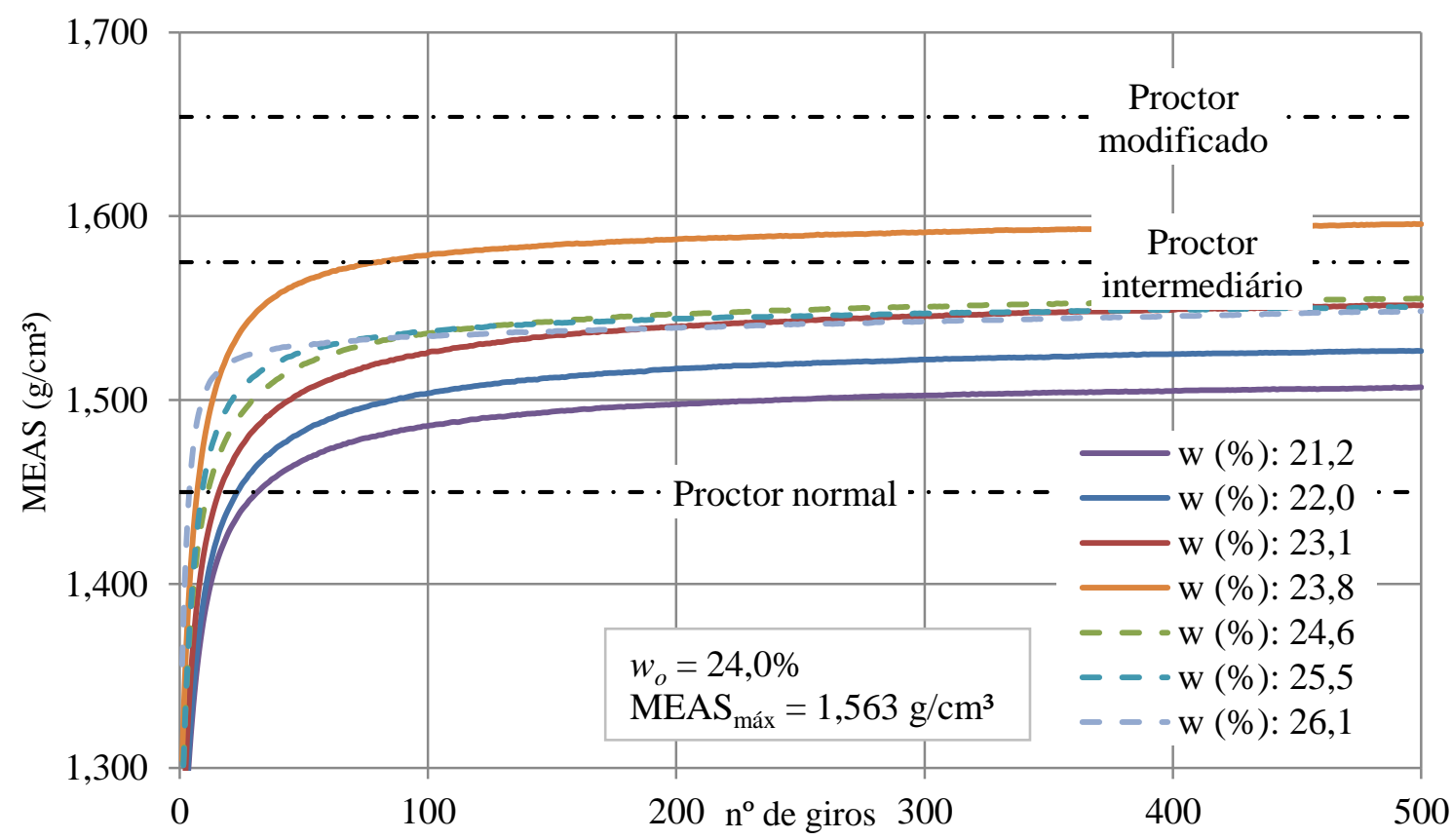

Figura 4.12 - MEAS versus número de giros para CPs de $1800 \mathrm{~g}$ e tensão normal de $400 \mathrm{kPa}$ 
Assim como ocorrido com os ensaios executados com tensão normal de $200 \mathrm{kPa}$, observa-se nas Figuras 4.11 e 4.12 que as curvas referentes aos CPs com umidades acima da $w_{o}$ estabilizaram-se mais rapidamente. Na Figura 4.11, nota-se que as curvas relativas às umidades de $25,4 \%, 26,2 \%$ e 28,6\% iniciam o processo de estabilização em um número menor de giros e por isso interceptam alguma das curvas dos CPs com umidade abaixo da $w_{o}$. A curva relativa ao $\mathrm{CP}$ com umidade de $23,4 \%$, apesar de ser acima da $w_{o}$, não tem o mesmo comportamento das três curvas acima da $w_{o}$, provavelmente por ser um ponto ainda muito próximo da $w_{o}$.

$\mathrm{Na}$ Figura 4.12, as curvas referentes ao CPs com umidade de 24,6\%, 25,5\% e $26,1 \%$ necessitaram de um número menor de giros para iniciar o processo de estabilização da MEAS. Pode ser observado também que essas curvas interceptam as curvas referentes aos CPs com umidade abaixo da $w_{o}$.

$\mathrm{O}$ argumento novamente para as curvas que possuem umidade acima da ótima estabilizarem-se em um número menor de giros é a quantidade de água nesses pontos, pois pelo fato de estar acima da $w_{o}$, a água existente entre os vazios do solo passa a absorver parte do esforço de compactação e assim há uma redução da taxa de compactação.

Ainda sobre as Figuras 4.11 e 4.12, vale ressaltar que, distintamente do acontecido para tensão de $200 \mathrm{kPa}$, algumas das curvas conseguiram alcançar o valor de MEASmáx do Proctor Intermediário. Isso pode ser observado para as curvas com umidades mais próximas da $w_{o}$, como na Figura 4.11 para a curva de umidade $23,4 \%$ e na Figura 4.12, umidade de $23,8 \%$.

As curvas MEAS versus número de giros dos ensaios de compactação realizados com tensão normal de $600 \mathrm{kPa}$ e corpos de prova de 1000 e 1800 gramas são exibidos, respectivamente, nas Figuras 4.13 e 4.14. 


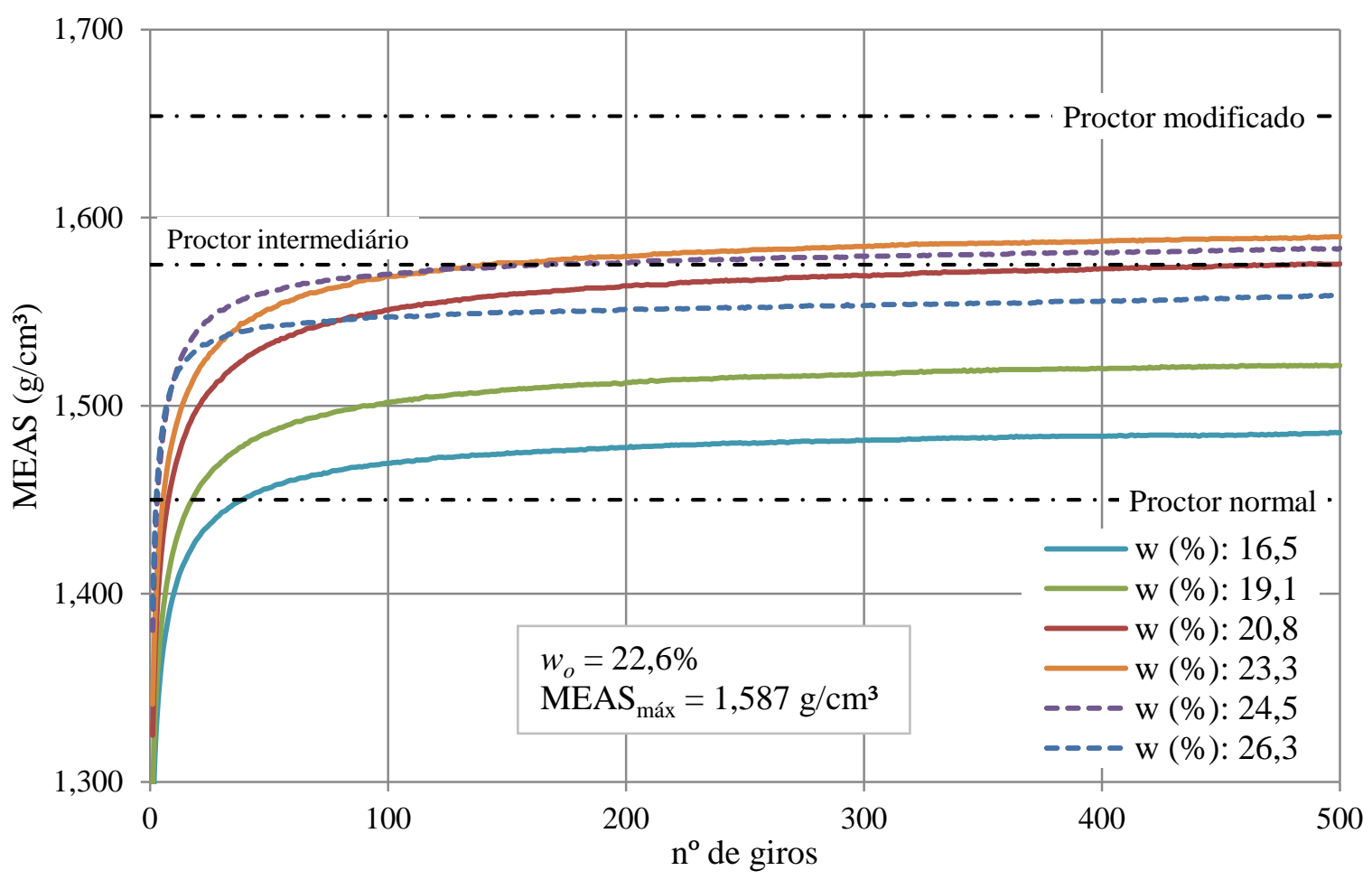

Figura 4.13 - MEAS versus número de giros para CPs de 1000g e tensão normal de $600 \mathrm{kPa}$

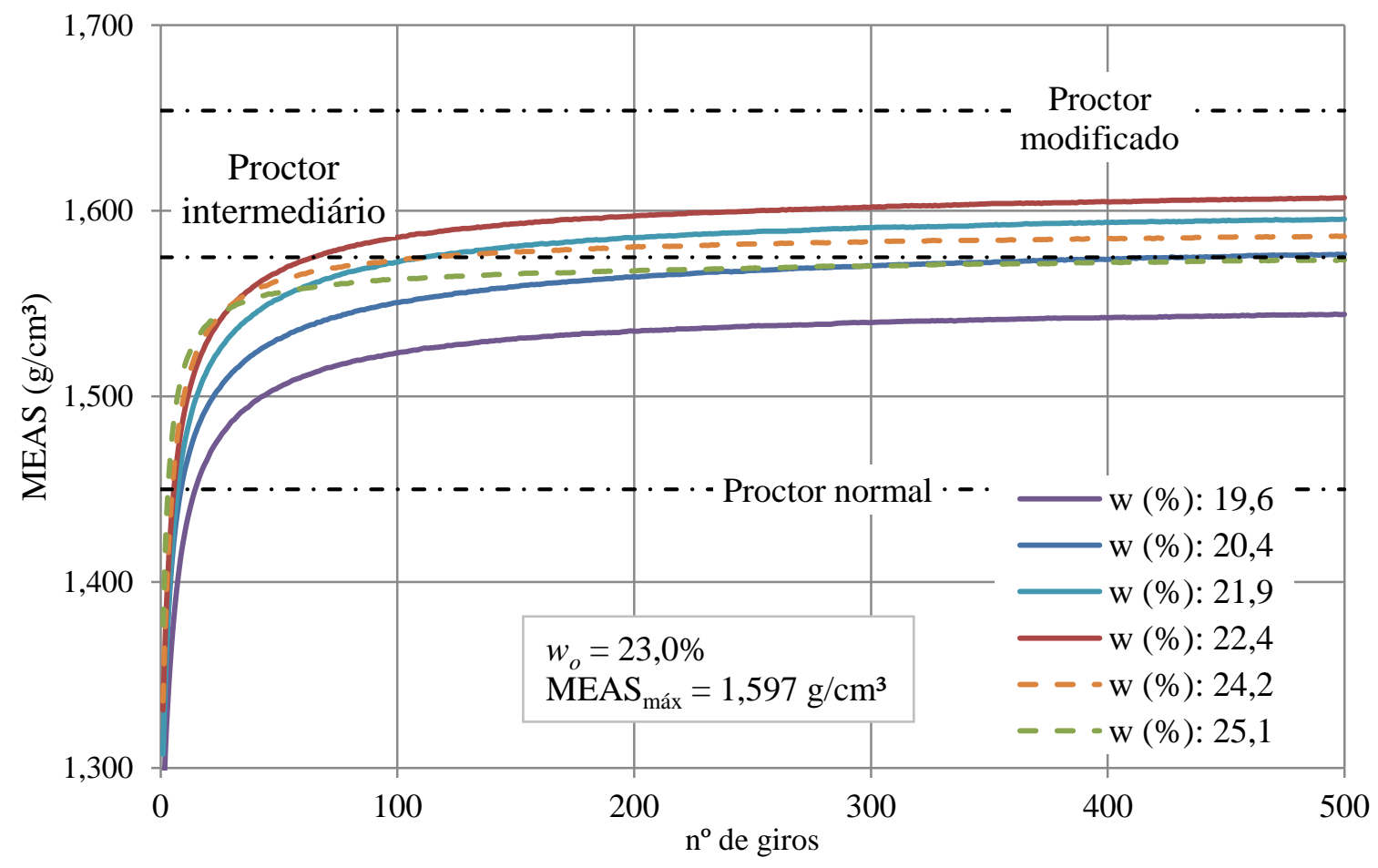

Figura 4.14 - MEAS versus número de giros para CPs de $1800 \mathrm{~g}$ e tensão normal de $600 \mathrm{kPa}$ 
Ao examinar as Figuras 4.13 e 4.14, observa-se que mesmo com o uso de $600 \mathrm{kPa}$ como tensão normal, os corpos de prova não conseguiram alcançar a $\mathrm{MEAS}_{\text {máx }}$ do Proctor Modificado. Contudo, verifica-se que diferente do ocorrido para tensão de $400 \mathrm{kPa}$, mais de um CP atingiu o valor de $\mathrm{MEAS}_{\text {máx }}$ do Proctor Intermediário. Na Figura 4.13, as curvas referentes às umidades 23,3\% e 24,5\% alcançaram a MEAS ${ }_{\text {máx }}$ do Proctor Intermediário e, na Figura 4.14, foram as curvas relativas aos CPs de umidade 21,9\%, 22,4\% e 24,2\%.

A estabilização das curvas, em ambas as figuras, ocorre mais rapidamente para as curvas relativas aos CPs com umidade acima da $w_{o}$. A exceção se faz na Figura 4.13, em que a curva do CP com umidade de 23,3\% teve comportamento equivalente às curvas dos CPs que ainda estão no ramo seco da curva de compactação, possivelmente pelo fato de neste ponto a água ainda não estar absorvendo parte do esforço de compactação.

\subsubsection{Ajuste da curva massa específica versus número de giros}

Na tentativa de melhor compreender o comportamento do solo no processo de compactação no CGS, foi utilizado o recurso de modelagem da curva MEAS versus número de giros, por meio do software matemático SciDAVis 0.2.4. O ajuste das curvas utilizou a função matemática mostrada na Equação 4.1.

$$
f(x)=a \cdot \ln (x)+b x+c
$$

Em que,

$$
\begin{aligned}
& f(x)=\text { MEAS } \\
& x=\text { número de giros } \\
& a, b \text { e } c=\text { parâmetros pertencentes ao conjunto dos números reais }
\end{aligned}
$$


O objetivo de ajustar as curvas MEAS versus número de giros para uma função matemática foi obter a taxa de variação das curvas e assim estabelecer um critério de parada da compactação. A partir das curvas geradas e observando-se as curvas MEAS versus número de giros, ficou evidente que a MEAS após certo número de giros passava a ter um ganho muito discreto. Assim, o próximo passo foi definir o momento em que o aumento na MEAS poderia ser desconsiderado.

Após o ajuste das curvas, calculou-se a taxa de variação para todos os 500 giros. O valor da taxa de variação escolhido para avaliar o incremento da MEAS foi de 0,001. Decidiu-se por esse valor porque a ordem de grandeza da MEAS é de $10^{-3}$, assim se a taxa de variação da MEAS em função do número de giros fosse menor que 0,001, os incrementos já poderiam ser desprezados. O número de giros crítico, n', foi considerado como o $1^{\circ}$ giro em que a taxa de variação foi menor que 0,001. O ajuste das curvas foi feito por meio da avaliação do melhor coeficiente de determinação $\left(\mathrm{R}^{2}\right)$, que para as curvas desta pesquisa, foi em média superior a 0,93 .

A Tabela 4.7 apresenta o número de giros crítico (n’) dos CPs dos ensaios de compactação com tensão normal de $200 \mathrm{kPa}$ e 500 giros.

Tabela 4.7 - Valores de n' para ensaios de compactação com 200kPa e 500 giros

\begin{tabular}{|c|c|c|c|c|c|c|c|}
\hline $\begin{array}{l}\text { Ensaios de } \\
\text { compactação }\end{array}$ & $w(\%)$ & n' (giros) & $\begin{array}{l}\% \text { MEAS } \\
\text { (500 giros) }\end{array}$ & $\begin{array}{l}\mathrm{n}_{\text {médio }} \\
\text { (giros) }\end{array}$ & $\begin{array}{l}\text { Desvio } \\
\text { padrão }\end{array}$ & $\begin{array}{c}\text { Desvio/média } \\
(\%)\end{array}$ & $\begin{array}{c}\text { Condição } \\
\text { do CP }\end{array}$ \\
\hline \multirow{6}{*}{$\begin{array}{c}\text { CPs de } 1000 \mathrm{~g} \\
w_{o}=26,0 \%\end{array}$} & 20,2 & 33 & 96,3 & \multirow{4}{*}{40} & \multirow{4}{*}{5,5} & \multirow{4}{*}{13,7} & \multirow{4}{*}{ pré-wo } \\
\hline & 22,1 & 39 & 96,2 & & & & \\
\hline & 24,5 & 45 & 95,8 & & & & \\
\hline & 26,0 & 44 & 96,6 & & & & \\
\hline & 27,8 & 28 & 98,2 & \multirow{2}{*}{22} & \multirow{2}{*}{9,2} & \multirow{2}{*}{42,8} & \multirow{2}{*}{ pós- $w_{o}$} \\
\hline & 29,3 & 15 & 98,2 & & & & \\
\hline \multirow{4}{*}{$\begin{array}{c}\text { CPs de } 1800 \mathrm{~g} \\
w_{o}=26,7 \%\end{array}$} & 23,8 & 45 & 96,9 & \multirow{3}{*}{48} & \multirow{3}{*}{3,1} & \multirow{3}{*}{6,3} & \multirow{3}{*}{ pré- $w_{o}$} \\
\hline & 24,9 & 49 & 96,8 & & & & \\
\hline & 26,0 & 51 & 96,9 & & & & \\
\hline & 29,3 & 14 & 98,1 & 24 & - & - & pós-wo \\
\hline
\end{tabular}


Examinando a Tabela 4.7, observa-se que as curvas MEAS versus número de giros dos CPs com umidade acima da $w_{o}$ estabilizaram-se mais rapidamente do que aquelas dos CPs abaixo da $w_{o}$. Em média, para os CPS com umidade acima da $w_{o}$, o CGS necessitou efetuar um número de giros, em média, $50 \%$ menor que o número de giros para os CPs do ramo seco da curva de compactação.

Para ambos os ensaios mostrados na Tabela 4.7, verificou-se que menos de 50 giros foram suficientes para a estabilização da MEAS. Contudo, a porcentagem da MEAS atingida nos valores de n' foram diferentes do ramo seco para o ramo úmido. Observou-se que no ramo seco do ensaio com CPs de 1000g, a MEAS no n' ocorreu, em média, na condição de 96,2\% da MEAS do final do ensaio (500 giros). No ramo úmido, observou-se que no n' a MEAS foi, em média, de 98,1\% da MEAS do final do ensaio.

A Tabela 4.8, apresenta os valores de n’ para os dois ensaios de compactação realizados com tensão normal de $400 \mathrm{kPa}$ e 500 giros, onde se nota a diferença nos valores de n' entre os corpos de prova do ramo seco e do ramo úmido.

Tabela 4.8 - Valores de n' para ensaios de compactação com 400kPa e 500 giros

\begin{tabular}{|c|c|c|c|c|c|c|c|}
\hline $\begin{array}{c}\text { Ensaios de } \\
\text { compactação }\end{array}$ & $w(\%)$ & n' (giros) & $\begin{array}{l}\% \text { MEAS } \\
\text { (500 giros) }\end{array}$ & $\begin{array}{l}\mathrm{n}^{\prime} \text { médio } \\
\text { (giros) }\end{array}$ & $\begin{array}{l}\text { Desvio } \\
\text { padrão }\end{array}$ & $\begin{array}{c}\text { Desvio/média } \\
(\%)\end{array}$ & $\begin{array}{l}\text { Condição } \\
\text { do CP }\end{array}$ \\
\hline \multirow{7}{*}{$\begin{array}{c}\text { CPs de } 1000 \mathrm{~g} \\
w_{o}=22,9 \%\end{array}$} & 18,0 & 34 & 96,7 & \multirow{4}{*}{39} & \multirow{4}{*}{3,8} & \multirow{4}{*}{9,7} & \multirow{4}{*}{ pré- $w_{o}$} \\
\hline & 19,8 & 38 & 96,6 & & & & \\
\hline & 21,3 & 43 & 96,4 & & & & \\
\hline & 23,4 & 40 & 97,2 & & & & \\
\hline & 25,4 & 28 & 98,0 & \multirow{3}{*}{17} & \multirow{3}{*}{9,8} & \multirow{3}{*}{57,9} & \multirow{3}{*}{ pós- $w_{o}$} \\
\hline & 26,5 & 14 & 97,7 & & & & \\
\hline & 28,6 & 9 & 97,1 & & & & \\
\hline \multirow{7}{*}{$\begin{array}{c}\text { CPs de } 1800 \mathrm{~g} \\
w_{o}=24,0 \%\end{array}$} & 21,2 & 43 & 97,0 & \multirow{4}{*}{44} & \multirow{4}{*}{2,1} & \multirow{4}{*}{4,7} & \multirow{4}{*}{ pré-wo } \\
\hline & 22,0 & 46 & 97,0 & & & & \\
\hline & 23,1 & 46 & 96,8 & & & & \\
\hline & 23,8 & 42 & 97,7 & & & & \\
\hline & 24,6 & 41 & 97,3 & \multirow{3}{*}{33} & \multirow{3}{*}{10,6} & \multirow{3}{*}{32,1} & \multirow{3}{*}{ pós- $w_{o}$} \\
\hline & 25,5 & 37 & 98,0 & & & & \\
\hline & 26,1 & 21 & 98,3 & & & & \\
\hline
\end{tabular}


Na Tabela 4.8, assim como ocorreu nos ensaios com tensão de $200 \mathrm{kPa}$, constatase que os valores de n' dos CPs situados no ramo seco foram maiores que os valores de n' dos CPs do ramo úmido. No ensaio com CPs de 1000g, o n'médio do ramo seco foi $130 \%$ maior que o do ramo úmido, indicando uma maior dificuldade do CGS em compactar os CPs abaixo da $w_{o}$. No caso do ensaio com CPs de $1800 \mathrm{~g}$, o n' médio do ramo seco foi pouco mais de $30 \%$ maior que o do ramo úmido. Essas observações a respeito do n' médio devem ser consideradas com ressalvas, pois para os ramos úmidos o desvio padrão do n' foi muito elevado, prejudicando a análise comparativa.

Entretanto, a respeito dos ramos úmidos dos ensaios da Tabela 4.8, pode-se afirmar que conforme os CPs ficavam mais úmidos, seus valores de n' decresciam muito. Também pode ser observado na Tabela 4.8 que quando o n' foi alcançado no ramo seco dos dois ensaios, mais de $97 \%$ da MEAS do final do ensaio tinha sido atingida. No caso do ramo úmido dos dois ensaios, foi um pouco maior, da ordem de $98 \%$ da MEAS do final do ensaio.

A Tabela 4.9 mostra os valores de n' para os ensaios de compactação executados com tensão de 600 kPa e 500 giros.

Tabela 4.9 - Valores de LP para ensaios de compactação com 600kPa e 500 giros

\begin{tabular}{|c|c|c|c|c|c|c|c|}
\hline $\begin{array}{l}\text { Ensaios de } \\
\text { compactação }\end{array}$ & $w(\%)$ & n' (giros) & $\begin{array}{l}\% \text { MEAS } \\
\text { (500 giros) }\end{array}$ & $\begin{array}{l}\mathrm{n}_{\text {médio }} \\
\text { (giros) }\end{array}$ & $\begin{array}{l}\text { Desvio } \\
\text { padrão }\end{array}$ & $\begin{array}{c}\text { Desvio/média } \\
(\%)\end{array}$ & $\begin{array}{c}\text { Condição } \\
\text { do CP }\end{array}$ \\
\hline \multirow{6}{*}{$\begin{array}{c}\text { CPs de } 1000 \mathrm{~g} \\
w_{o}=22,6 \%\end{array}$} & 16,5 & 31 & 97,1 & \multirow{3}{*}{35} & \multirow{3}{*}{3,5} & \multirow{3}{*}{10,1} & \multirow{3}{*}{ pré-wo } \\
\hline & 19,1 & 35 & 97,0 & & & & \\
\hline & 20,8 & 38 & 96,7 & & & & \\
\hline & 23,3 & 37 & 97,0 & \multirow{3}{*}{28} & \multirow{3}{*}{9,0} & \multirow{3}{*}{32,6} & \multirow{3}{*}{ pós- $w_{o}$} \\
\hline & 24,5 & 27 & 97,8 & & & & \\
\hline & 26,3 & 19 & 98,1 & & & & \\
\hline \multirow{6}{*}{$\begin{array}{c}\text { CPs de } 1800 \mathrm{~g} \\
w_{o}=23,0 \%\end{array}$} & 19,5 & 42 & 97,1 & \multirow{4}{*}{42} & \multirow{4}{*}{1,0} & \multirow{4}{*}{2,3} & \multirow{4}{*}{ pré-wo } \\
\hline & 20,4 & 41 & 96,7 & & & & \\
\hline & 21,9 & 43 & 97,0 & & & & \\
\hline & 22,4 & 41 & 97,1 & & & & \\
\hline & 24,2 & 34 & 97,9 & \multirow{2}{*}{30} & \multirow{2}{*}{6,4} & \multirow{2}{*}{21,6} & \multirow{2}{*}{ pós-wo } \\
\hline & 25,1 & 25 & 98,2 & & & & \\
\hline
\end{tabular}


Ao observar a Tabela 4.9, verifica-se que a diferença entre o n'médio do ramo seco e do ramo úmido foi menor que nos ensaios com tensão de 200 e $400 \mathrm{kPa}$, indicando que a tensão de $600 \mathrm{kPa}$ facilitou a compactação do corpos de prova acima da $w_{o}$. Os valores de n'médio tanto do ramo seco, quanto do ramo úmido, mostram que o uso de 500 giros é exagerado, pois pode-se notar que quando o n' foi alcançado mais de 97\% da MEAS do final do ensaio já havia sido atingida.

Para facilitar a avaliação dos valores de n' para os ensaios de compactação realizados com as três tensões normais e as duas massas úmidas por corpo de prova, a Tabela 4.10 apresenta um resumo dos valores de n'médio encontrados nos ensaios. Deve-se destacar que os valores de n'médio para os ramos úmidos de todos os ensaios tiveram dispersão muito elevada.

Tabela 4.10 - Resumo dos valores de n' ${ }_{\text {médio }}$ dos ensaios de compactação

\begin{tabular}{|c|c|c|c|c|}
\hline \multirow[b]{2}{*}{$\begin{array}{l}\text { Ensaios de } \\
\text { compactação }\end{array}$} & \multicolumn{3}{|c|}{ n'médio (giros) } & \multirow[b]{2}{*}{$\begin{array}{c}\text { Condição } \\
\text { do CP }\end{array}$} \\
\hline & $200 \mathrm{kPa}$ & $400 \mathrm{kPa}$ & $600 \mathrm{kPa}$ & \\
\hline \multirow{2}{*}{ CPs de $1000 \mathrm{~g}$} & 40 & 39 & 35 & pré- $w_{o}$ \\
\hline & 22 & 17 & 28 & pós- $w_{o}$ \\
\hline \multirow{2}{*}{ CPs de $1800 \mathrm{~g}$} & 48 & 44 & 42 & pré- $w_{o}$ \\
\hline & 24 & 33 & 30 & pós-wo \\
\hline
\end{tabular}

Examinando a Tabela 4.10, nota-se claramente que a utilização de 500 giros para execução dos ensaios foi uma escolha exagerada, pois nenhum dos valores de n'médio ultrapassou os 50 giros. Além disso, percebe-se também que o aumento de tensão conduziu a uma redução do n' médio nos ramos secos, sendo ela mais acentuada, quando considerado o aumento de 200 para $600 \mathrm{kPa}$, onde se constata um decréscimo de cerca de $14 \%$ em ambos os ensaios.

Quanto aos ramos úmidos, a dispersão elevada dos valores de n' possivelmente explica o comportamento observado na Tabela 4.10, pois quando houve aumento de tensão normal, os valores de n' aumentaram igualmente. 
Sendo assim, pode-se dizer que o uso de 500 giros para realização do ensaio de compactação mostrou-se excessivo, segundo a análise da estabilização da densificação dos CPs por meio das curvas de MEAS versus número de giros. Todas as curvas de MEAS versus número de giros estabilizaram-se abaixo de 50 giros, como mostrado nas Tabelas 4.7, 4.8 e 4.9. Portanto, pode-se afirmar que, se os ensaios de compactação no CGS tivessem sido realizados com apenas 75 giros, os valores de $\mathrm{MEAS}_{\text {máx }}$ e umidade ótima para as três tensões normais seriam praticamente os mesmos dos ensaios realizados com 500 giros.

\subsubsection{Locking Point}

O conceito do Locking Point foi utilizado nesta pesquisa como uma forma de se estudar a estabilização da densificação dos corpos de prova no CGS, na tentativa de se estabelecer um critério de parada do processo de compactação.

A Tabela 4.11 apresenta os valores de LP dos CPs dos dois ensaios de compactação realizados com tensão normal de $200 \mathrm{kPa}$ e 500 giros, sendo a tabela dividida em CPs abaixo e acima da $w_{o}$. Observa-se, nos dois ensaios, que os valores de $\mathrm{LP}_{\text {médio }}$ entre o ramo seco e o ramo úmido foram muito diferentes entre si,.

Tabela 4.11 - Valores de LP para ensaios de compactação com 200kPa e 500 giros

\begin{tabular}{|c|c|c|c|c|c|c|c|}
\hline $\begin{array}{l}\text { Ensaios de } \\
\text { compactação }\end{array}$ & $w(\%)$ & $\begin{array}{c}\text { LP } \\
\text { (giros) }\end{array}$ & $\begin{array}{l}\% \text { MEAS } \\
\text { (500 giros) }\end{array}$ & $\begin{array}{l}\mathrm{LP}_{\text {médio }} \\
\text { (giros) }\end{array}$ & $\begin{array}{l}\text { Desvio } \\
\text { padrão }\end{array}$ & $\begin{array}{c}\text { Desvio/média } \\
(\%)\end{array}$ & $\begin{array}{l}\text { Condição } \\
\text { do CP }\end{array}$ \\
\hline \multirow{6}{*}{$\begin{array}{c}\text { CPs de } 1000 \mathrm{~g} \\
w_{o}=26,0 \%\end{array}$} & 20,2 & 41 & 96,7 & \multirow{4}{*}{46} & \multirow{4}{*}{4,6} & \multirow{4}{*}{10,0} & \multirow{4}{*}{ pré-wo } \\
\hline & 22,1 & 43 & 96,5 & & & & \\
\hline & 24,5 & 51 & 96,2 & & & & \\
\hline & 26,0 & 48 & 96,8 & & & & \\
\hline & 27,8 & 25 & 98,0 & \multirow{2}{*}{22} & \multirow{2}{*}{4,9} & \multirow{2}{*}{23,0} & \multirow{2}{*}{ pós- $w_{o}$} \\
\hline & 29,3 & 18 & 98,4 & & & & \\
\hline \multirow{4}{*}{$\begin{array}{c}\text { CPs de } 1800 \mathrm{~g} \\
w_{o}=26,7 \%\end{array}$} & 23,8 & 66 & 97,8 & \multirow{3}{*}{69} & \multirow{3}{*}{3,0} & \multirow{3}{*}{4,3} & \multirow{3}{*}{ pré- $w_{o}$} \\
\hline & 24,9 & 72 & 97,8 & & & & \\
\hline & 26,0 & 69 & 97,6 & & & & \\
\hline & 29,3 & 24 & 98,4 & 24 & - & - & pós- $w_{o}$ \\
\hline
\end{tabular}


Examinando a Tabela 4.11, observa-se que a diferença entre o $\mathrm{LP}_{\text {médio }}$ do ramo seco e do ramo úmido foi mais acentuada no ensaio com CPs de $1800 \mathrm{~g}$, onde $\mathrm{LP}_{\text {médio }}$ do ramo seco foi cerca de $185 \%$ maior que o do ramo úmido; no ensaio com CPs de $1000 \mathrm{~g}$, a diferença ficou em torno de $110 \%$.

Essa diferença tão elevada entre o valores de $\mathrm{LP}_{\text {médio }}$ dos ramos secos e úmidos pode indicar que o CGS encontrou uma maior dificuldade em compactar os CPs com umidade abaixo da $w_{o}$ devido aos vazios do solo ainda não estarem preenchidos por água ou pode indicar que os CPs acima da $w_{o}$ já estavam muito úmidos e assim com a resistência prejudicada.

Ainda na Tabela 4.11, observa-se, nos CPs do ramo seco de ambos ensaios, que quando o LP foi alcançado a MEAS era, em média, 97\% da MEAS do final do ensaio, nos 500 giros. Nos ramos úmidos, percebe-se que a MEAS era, em média, 98,2\% da MEAS dos 500 giros. Essas observações indicam que o grande número de giros efetuados após o LP não proporcionou ganho expressivo na MEAS, corroborando o conceito de Locking Point.

Ao comparar os ramos secos dos dois ensaios exibidos na Tabela 4.11, observa-se que para alcançar o LP o CGS necessitou aplicar nos CPs de 1800g um número de giros, em média, 50\% maior que a média de giros nos CPs de 1000g. Essa observação indica que possivelmente a quantidade de solo no molde tenha levado o CGS a ter maiores dificuldades em compactar e, assim, alcançar o LP. Nos ramos úmidos dos ensaios com CPs de 1000 e $1800 \mathrm{~g}$, o LP ${ }_{\text {médio }}$ entre eles foi praticamente igual.

A Tabela 4.12 apresenta os valores de LP para os CPs compactados no CGS a 500 giros e tensão normal de $400 \mathrm{kPa}$. 
Tabela 4.12 - Valores de LP para ensaios de compactação com 400kPa e 500 giros

\begin{tabular}{|c|c|c|c|c|c|c|c|}
\hline $\begin{array}{c}\text { Ensaios de } \\
\text { compactação }\end{array}$ & $w(\%)$ & $\begin{array}{l}\text { LP } \\
\text { (giros) }\end{array}$ & $\begin{array}{l}\% \text { MEAS } \\
\text { (500 giros) }\end{array}$ & $\begin{array}{l}\mathrm{LP}_{\text {médio }} \\
\text { (giros) }\end{array}$ & $\begin{array}{l}\text { Desvio } \\
\text { padrão }\end{array}$ & $\begin{array}{c}\text { Desvio/média } \\
(\%)\end{array}$ & $\begin{array}{c}\text { Condição } \\
\text { do CP }\end{array}$ \\
\hline \multirow{7}{*}{$\begin{array}{c}\text { CPs de } 1000 \mathrm{~g} \\
w_{o}=22,9 \%\end{array}$} & 18,0 & 40 & 97,0 & \multirow{4}{*}{41} & \multirow{4}{*}{4,1} & \multirow{4}{*}{10,0} & \multirow{4}{*}{ pré-wo } \\
\hline & 19,8 & 47 & 97,0 & & & & \\
\hline & 21,3 & 39 & 96,2 & & & & \\
\hline & 23,4 & 38 & 97,1 & & & & \\
\hline & 25,4 & 27 & 97,9 & \multirow{3}{*}{20} & \multirow{3}{*}{7,5} & \multirow{3}{*}{37,7} & \multirow{3}{*}{ pós-wo } \\
\hline & 26,5 & 21 & 98,0 & & & & \\
\hline & 28,6 & 12 & 97,3 & & & & \\
\hline \multirow{7}{*}{$\begin{array}{c}\text { CPs de } 1800 \mathrm{~g} \\
w_{o}=24,0 \%\end{array}$} & 21,2 & 59 & 97,7 & \multirow{4}{*}{58} & \multirow{4}{*}{4,7} & \multirow{4}{*}{8,1} & \multirow{4}{*}{ pré- $w_{o}$} \\
\hline & 22,0 & 56 & 97,4 & & & & \\
\hline & 23,1 & 63 & 97,5 & & & & \\
\hline & 23,8 & 52 & 98,1 & & & & \\
\hline & 24,6 & 54 & 97,8 & \multirow{3}{*}{45} & \multirow{3}{*}{16,2} & \multirow{3}{*}{36,2} & \multirow{3}{*}{ pós-wo } \\
\hline & 25,5 & 54 & 98,5 & & & & \\
\hline & 26,1 & 26 & 98,4 & & & & \\
\hline
\end{tabular}

Assim como ocorreu com a tensão de $200 \mathrm{kPa}$, observa-se, na, que o $\mathrm{LP}_{\text {médio }}$ do ramo seco é maior que o do ramo úmido nos dois ensaios de compactação mostrados. Essa diferença pode ser explicada a partir da própria teoria de compactação de solos de Proctor, que explica que quando a quantidade de água entre os vazios de um solo é insuficiente, devese aplicar uma quantidade maior de energia para que se alcancem níveis mais altos de massa específica. Sendo assim, no caso do CGS, pode-se dizer que mais energia implica maior número de giros para se atingir o LP.

Ainda na Tabela 4.12, nota-se que a variação entre o $\mathrm{LP}_{\text {médio }}$ do ramo seco e do ramo úmido foi bem distinta nos dois ensaios de compactação executados. No ensaio com CPs de $1000 \mathrm{~g}$, a diferença foi de $105 \%$ e no ensaio com CPs de $1800 \mathrm{~g}$, a diferença foi de apenas cerca de $30 \%$.

Contudo, convém ressaltar que o $\mathrm{LP}_{\text {médio }}$ do ramo úmido do ensaio com $\mathrm{CPs}$ de $1800 \mathrm{~g}$ pode não ser representativo do ensaio, pois os corpos de prova com umidades de $24,6 \%$ e 25,5\% tiveram valores de LP muito semelhantes àqueles apresentados pelos CPs do ramo seco, além do elevado desvio padrão apresentado. Essa suspeita acerca de qual ramo 
esses corpos de prova pertencem pode acontecer devido a subjetividade que ocorre no processo de determinação da curva de compactação.

Também verifica-se que, quando foi alcançado o LP, praticamente em todos os pontos a MEAS era igual ou maior que $97 \%$ da MEAS do final do ensaio, mostrando mais uma vez que o uso de 500 giros para realização do ensaio de compactação foi muito maior que o necessário.

A Tabela 4.13 mostra os valores de LP dos ensaios de compactação realizados com tensão normal de $600 \mathrm{kPa}$ e 500 giros. Pode-se ver que novamente houve uma distinção evidente entre o $\mathrm{LP}_{\text {médio }}$ do ramo seco e do ramo úmido em ambos ensaios.

Tabela 4.13 - Valores de LP para ensaios de compactação com 600kPa e 500 giros

\begin{tabular}{|c|c|c|c|c|c|c|c|}
\hline $\begin{array}{c}\text { Ensaios de } \\
\text { compactação }\end{array}$ & $w(\%)$ & $\begin{array}{c}\text { LP } \\
\text { (giros) }\end{array}$ & $\begin{array}{l}\% \text { MEAS } \\
\text { (500 giros) }\end{array}$ & $\begin{array}{l}\mathrm{LP}_{\text {médio }} \\
\text { (giros) }\end{array}$ & $\begin{array}{l}\text { Desvio } \\
\text { padrão }\end{array}$ & $\begin{array}{c}\text { Desvio/média } \\
(\%)\end{array}$ & $\begin{array}{c}\text { Condição } \\
\text { do CP }\end{array}$ \\
\hline \multirow{6}{*}{$\begin{array}{c}\text { CPs de } 1000 \mathrm{~g} \\
w_{o}=22,6 \%\end{array}$} & 16,5 & 36 & 97,5 & \multirow{3}{*}{36} & \multirow{3}{*}{2,0} & \multirow{3}{*}{5,6} & \multirow{3}{*}{ pré- $w_{o}$} \\
\hline & 19,1 & 34 & 96,9 & & & & \\
\hline & 20,8 & 38 & 96,7 & & & & \\
\hline & 23,3 & 35 & 96,9 & \multirow{3}{*}{27} & \multirow{3}{*}{8,0} & \multirow{3}{*}{30,1} & \multirow{3}{*}{ pós-wo } \\
\hline & 24,5 & 26 & 97,7 & & & & \\
\hline & 26,3 & 19 & 98,1 & & & & \\
\hline \multirow{6}{*}{$\begin{array}{c}\text { CPs de } 1800 \mathrm{~g} \\
w_{o}=23,0 \%\end{array}$} & 19,5 & 57 & 97,7 & \multirow{4}{*}{57} & \multirow{4}{*}{2,2} & \multirow{4}{*}{3,8} & \multirow{4}{*}{ pré-wo } \\
\hline & 20,4 & 60 & 97,5 & & & & \\
\hline & 21,9 & 56 & 97,6 & & & & \\
\hline & 22,4 & 55 & 97,7 & & & & \\
\hline & 24,2 & 43 & 98,3 & \multirow{2}{*}{38} & \multirow{2}{*}{7,1} & \multirow{2}{*}{18,6} & \multirow{2}{*}{ pós-wo } \\
\hline & 25,1 & 33 & 98,5 & & & & \\
\hline
\end{tabular}

A Tabela 4.13 mostra que os ensaios com tensão normal de $600 \mathrm{kPa}$ apresentaram comportamento semelhante ao ocorrido nos ensaios com $400 \mathrm{kPa}$. Nota-se que LP médio $_{\text {dos }}$ ramos secos foi maior que o dos ramos úmidos, onde no ensaio com CPs de $1000 \mathrm{~g}$ a diferença foi de cerca de $33 \%$ e no ensaio com CPs de $1800 \mathrm{~g}$, foi de $50 \%$. 
Assim como ocorrido nos ensaios de compactação com 200 e 400 kPa, observa-se na Tabela 4.13 que a maioria dos CPs alcançou o LP com mais de 97\% da MEAS do final do ensaio.

Para facilitar a avaliação dos valores de LP para os ensaios de compactação realizados com as três tensões normais e as duas massas úmidas por corpo de prova, a Tabela 4.14 apresenta um resumo dos valores de $\mathrm{LP}_{\text {médio }}$ encontrados nos ensaios.

Tabela 4.14 - Resumo dos valores de LP dos ensaios de compactação no CGS

\begin{tabular}{ccccc}
\hline \multirow{2}{*}{$\begin{array}{c}\text { Ensaios de } \\
\text { compactação }\end{array}$} & $200 \mathrm{kPa}$ & $400 \mathrm{kPa}$ & $600 \mathrm{kPa}$ & $\begin{array}{c}\text { LP } \\
\text { Condição } \\
\text { CP }\end{array}$ \\
\hline CPs de 1000g & 46 & 41 & 36 & pré- $w_{o}$ \\
\hline CPs de 1800g & 22 & 20 & 27 & pós- $w_{o}$ \\
\hline
\end{tabular}

Ao analisar a Tabela 4.14, constata-se que a utilização de 500 giros para execução dos ensaios foi uma escolha exagerada, assim como ocorrido na avaliação do n'. Observa-se que a maioria dos $\mathrm{LP}_{\text {médio }}$ ficou abaixo de 50 giros. Mais uma vez, pode-se notar que o aumento de tensão leva reduções no LP, principalmente, quando a tensão é aumentada de 200 para $600 \mathrm{kPa}$. 


\subsection{CURVAS DE COMPACTAÇÃO PROCTOR VERSUS CURVAS DE COMPACTAÇÃO DO CGS}

A Figura 4.15 mostra as curvas de compactação obtidas para os ensaios de compactação Proctor e os ensaios desenvolvidos com o CGS para CPs de 1000g.

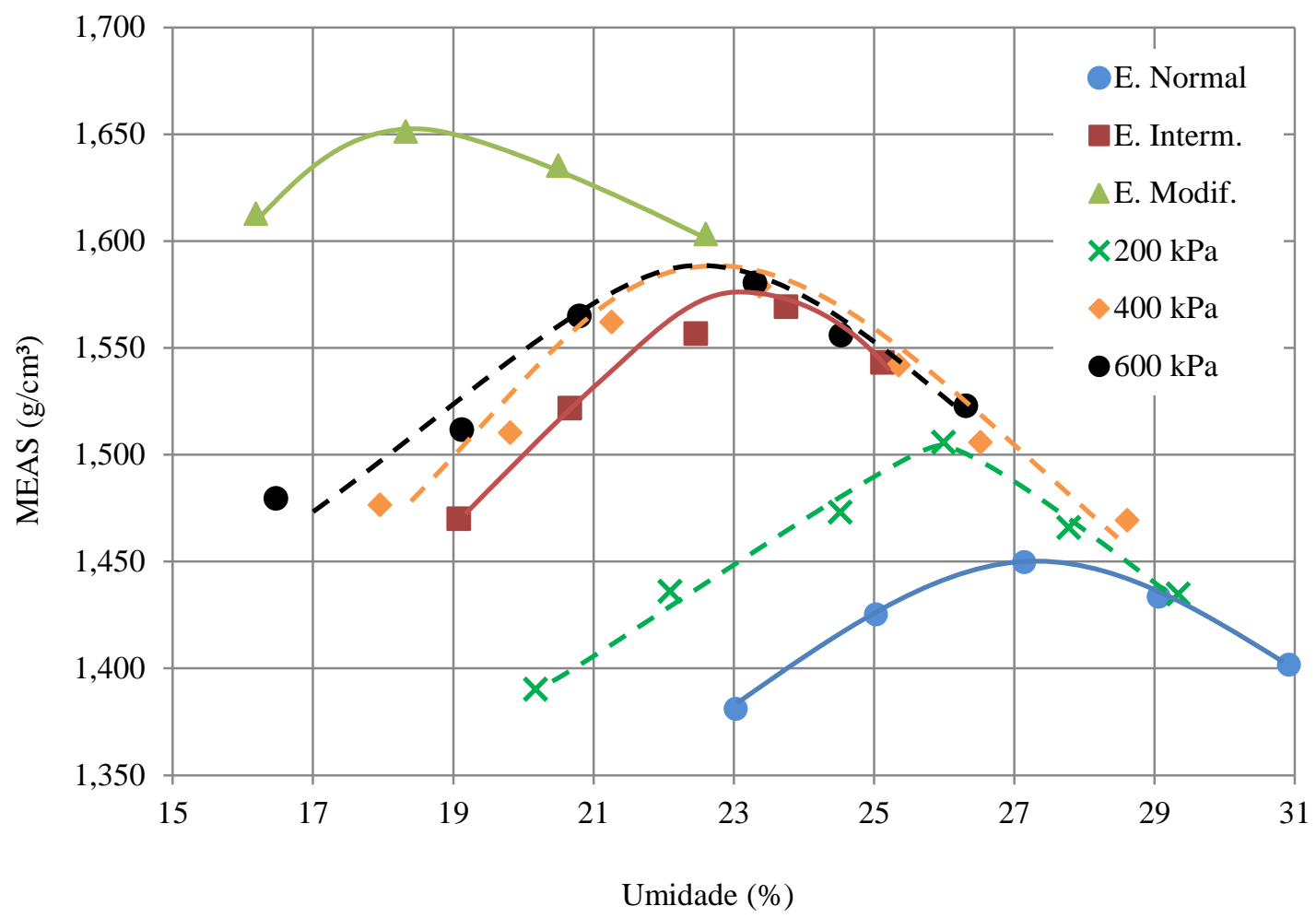

Figura 4.15 - Curvas de compactação Proctor e CGS a 500 giros (CPs de 1000g)

Analisando a Figura 4.15, verifica-se que nenhum dos ensaios executados com CGS conseguiu alcançar os níveis de massa específica seca do Proctor Modificado. O ensaio com tensão de $200 \mathrm{kPa}$ alcançou níveis de massa específica seca maiores que o Proctor Normal, entretanto, menores que o Proctor Intermediário.

As curvas referentes aos ensaios com tensões normais de 400 e $600 \mathrm{kPa}$ tiveram aspectos muito semelhantes, apesar do aumento de 50\% no nível de tensão aplicada. Essas curvas ficaram praticamente iguais a curva do Proctor Intermediário, mostrando uma diferença muito pequena entre seus respectivos valores de massa específica seca máxima. 
A Figura 4.16 apresenta as curvas de compactação Proctor e as curvas obtidas com o CGS para corpos de prova de $1800 \mathrm{~g}$ e três tensões normais.

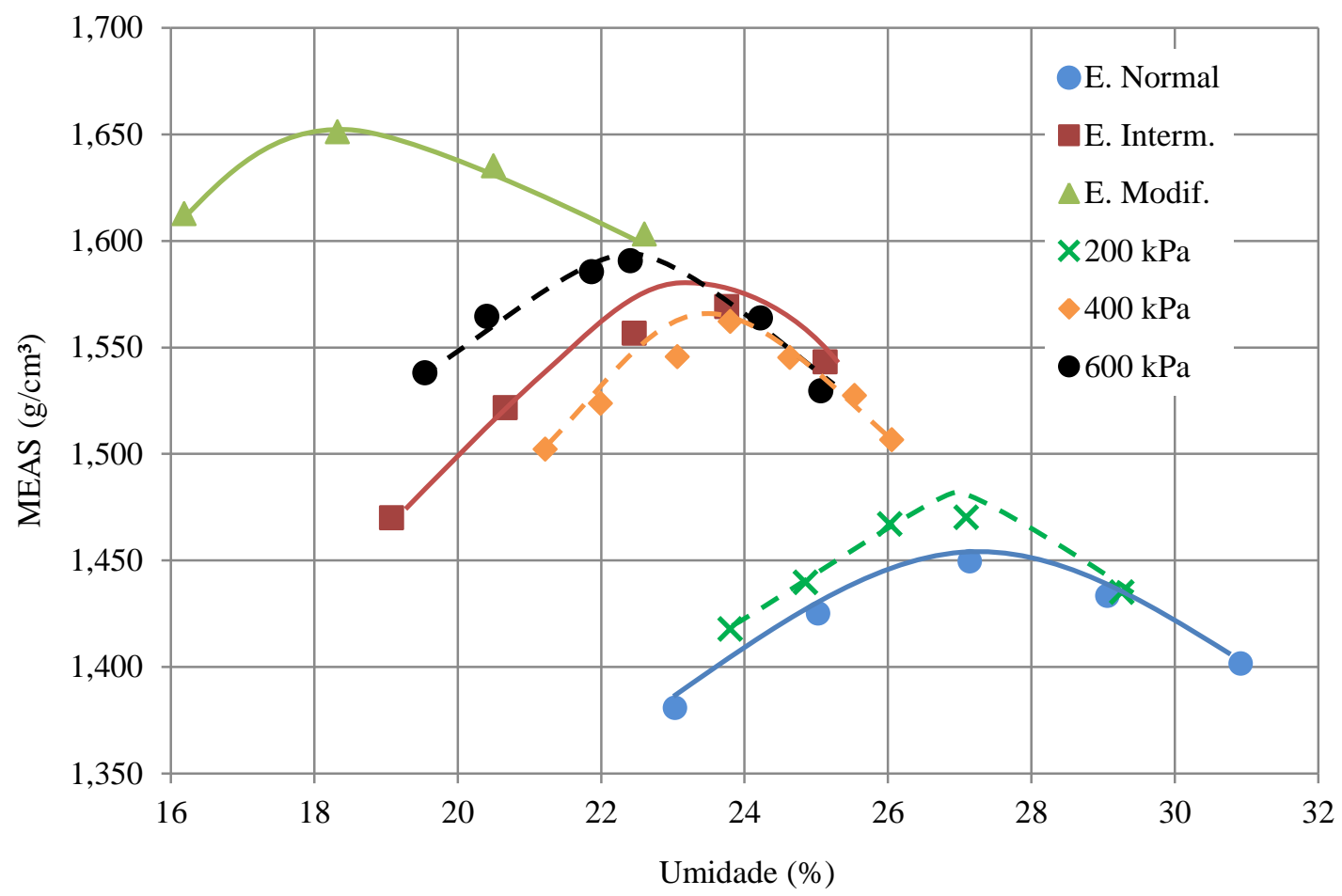

Figura 4.16 - Curvas de compactação Proctor e CGS a 500 giros (CPs de 1800g)

Examinando a Figura 4.16, observa-se que as curvas de compactação com uso do CGS para CPs de $1800 \mathrm{~g}$ tiveram aspectos bastante semelhantes àquelas apresentadas na Figura 4.15. Nota-se uma maior diferença entre as curvas com 400 e $600 \mathrm{kPa}$, porém seus valores de massa específica seca máxima ainda foram muito semelhantes entre si. Assim como na, verifica-se na Figura 4.16 que as curvas para 400 e $600 \mathrm{kPa}$ ficaram muito próximas a do Proctor Intermediário, entretanto, não atingiram os níveis de massa específica seca do Proctor Modificado.

As diferenças apresentadas nos valores de massa específica seca máxima entre as curvas de compactação Proctor e as do CGS podem ser melhor visualizadas na Tabela 4.15 e na Figura 4.17. 
Tabela 4.15 - MEAS $_{\text {máx }}$ dos ensaios Proctor e CGS a 500 giros

\begin{tabular}{l|c|cc}
\hline \multirow{2}{*}{ CGS } & & \multicolumn{2}{c}{ MEAS $_{\text {máx }}\left(\mathrm{g} / \mathrm{cm}^{3}\right)$} \\
\cline { 3 - 4 } & & CPs de 1000g & CPs de 1800g \\
\hline \multirow{4}{*}{ Proctor } & $200 \mathrm{kPa}$ & 1,506 & 1,473 \\
& $400 \mathrm{kPa}$ & 1,588 & 1,563 \\
& $600 \mathrm{kPa}$ & 1,587 & 1,597 \\
& E. Normal & \multicolumn{2}{|c}{1,450} \\
& E. Interm. & \multicolumn{2}{|c}{1,575} \\
& E. Modif. & \multicolumn{2}{|c}{1,654} \\
\hline
\end{tabular}

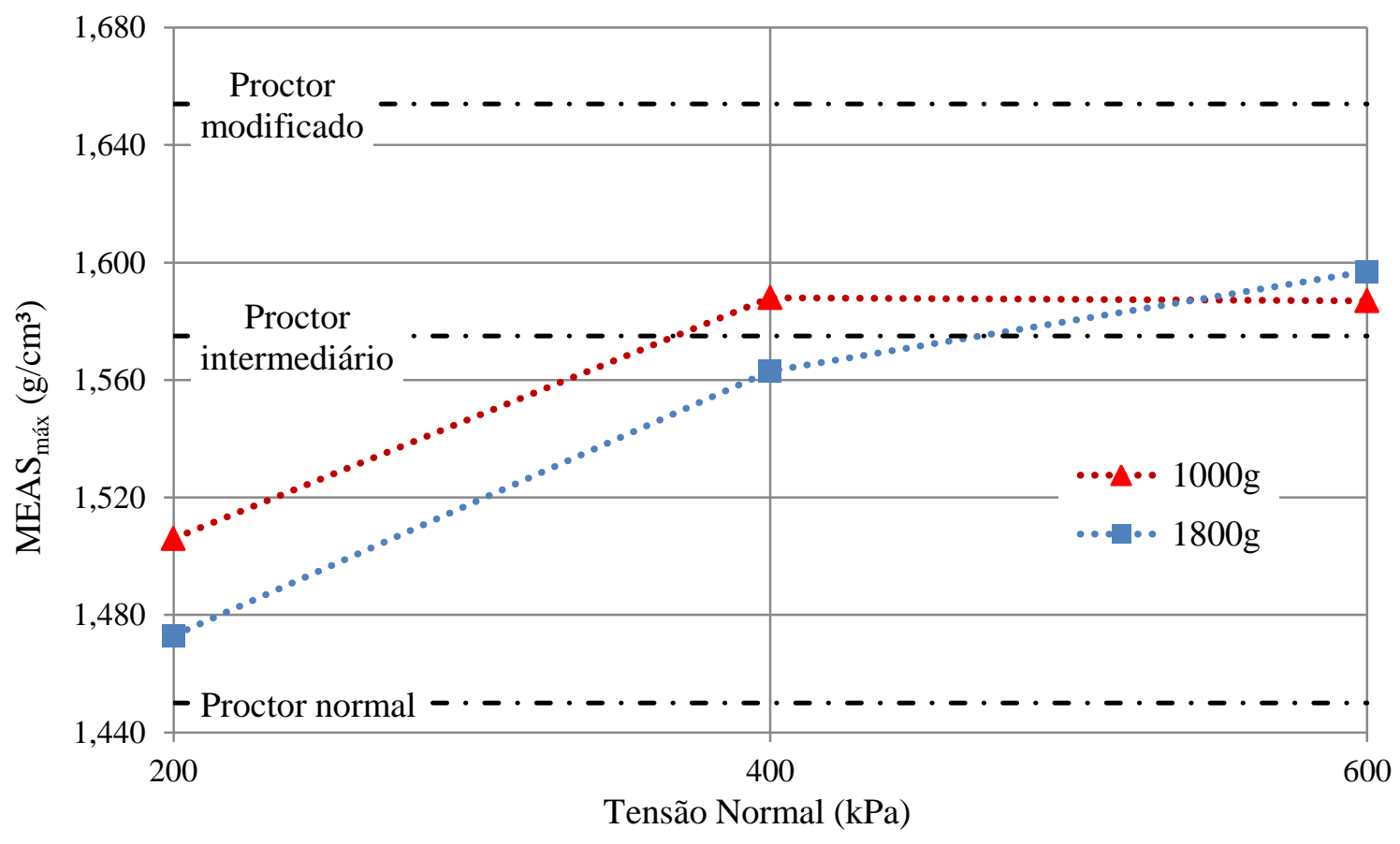

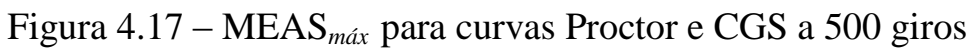

Examinando os resultados da Tabela 4.15 e a Figura 4.17, evidencia-se que os valores de massa específica seca máxima dos ensaios com 400 e $600 \mathrm{kPa}$ ficaram muito abaixo do Proctor Modificado, alcançando apenas a massa específica seca máxima do Proctor Intermediário. A diferença percentual da $\mathrm{MEAS}_{\text {máx }}$ do Proctor Modificado para a dos ensaios com tensão normal de $600 \mathrm{kPa}$ e $400 \mathrm{kPa}$ foi da ordem de $4 \%$ e $5 \%$, respectivamente. A 
MEAS $_{\text {máx }}$ dos ensaios com tensão normal de $200 \mathrm{kPa}$ só conseguiram alcançar a do Proctor Normal, ficando, em média, cerca de $6 \%$ menor que a MEAS $S_{\text {máx }}$ do Proctor Intermediário.

As considerações feitas nesse tópico devem ser examinadas com prudência, pois apesar das $\mathrm{MEAS}_{\text {máx }}$ dos ensaios de compactação realizados com CGS terem sido menores que as do Proctor Modificado, deve-se ressaltar as diferenças nas condições de compactação. No ensaio Proctor, os CPs foram compactados em três ou cinco camadas, enquanto que no CGS os CPs foram compactados em camada única. Assim, conclusões mais oportunas podem ser extraídas dos resultados dos ensaios mecânicos, que se comentam no item 4.5.

\subsection{ENSAIOS MECÂNICOS}

\subsubsection{Ensaio de Compressão Simples}

Os ensaios de compressão simples foram executados com a finalidade de se obter a tensão de ruptura (RCS) de cada corpo de prova para os dois diferentes tipos de moldagem: estático e no CGS. Vale relembrar que os CPs preparados na prensa estática foram moldados em cinco camadas nas dimensões $100 \mathrm{~mm}$ de diâmetro e 200mm de altura e os CPs do CGS foram moldados em camada única, de acordo com o que foi apresentado no Capítulo 3, item 3.4 .

Em relação ao critério de aceitação dos corpos de prova, definiu-se que aqueles que tivessem RCS dentro da $\operatorname{RCS}_{\text {média }} \pm 2$ vezes o desvio padrão seriam utilizados, se houvesse um ou mais fora dessa faixa, os mesmos eram retirados e uma nova $\mathrm{RCS}_{\text {média }}$ era calculada.

A Figura 4.18 apresenta a imagem de um dos corpos de prova ensaiados à compressão simples após sua ruptura. 


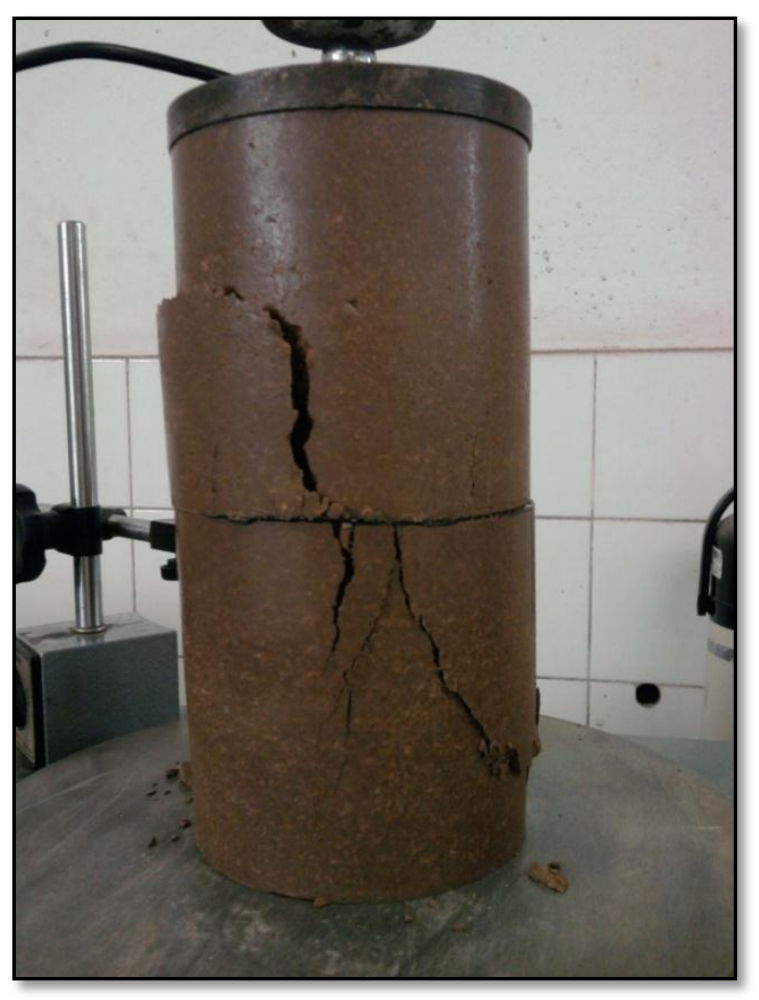

Figura 4.18 - Corpo de prova após ensaio de Compressão Simples

A Tabela 4.16 mostra os valores de RCS para corpos de prova moldados estaticamente e no CGS, na umidade ótima e massa específica seca máxima do Proctor Normal.

Tabela 4.16 - RCS para CPs moldados estaticamente e no CGS, na energia do Proctor Normal

\begin{tabular}{|c|c|c|}
\hline & \multicolumn{2}{|c|}{$\mathrm{RCS}(\mathrm{kPa})$} \\
\hline & Estático & CGS \\
\hline \multirow{3}{*}{$\mathrm{CPs}$} & 112,6 & 129,6 \\
\hline & 89,2 & 131,6 \\
\hline & 104,1 & 120,0 \\
\hline Média & 102,0 & 127,1 \\
\hline Desvio padrão & 11,8 & 6,2 \\
\hline Desvio/média (\%) & 11,6 & 4,9 \\
\hline
\end{tabular}


Analisando a Tabela 4.16, observa-se primeiramente os valores similares de RCS apresentados pelos CPs moldados no CGS, destacando-se que o desvio padrão dos valores de RCS dos CPs moldados estaticamente é mais que o dobro do apresentado para os CPs moldados no CGS.

Possivelmente, esse melhor desempenho na repetibilidade dos ensaios apresentados por CPs moldados no CGS seja causado pelo processo de moldagem, pois os CPs do CGS foram moldados em uma única camada e os CPs moldados estaticamente foram em cinco. Acredita-se que a moldagem dos CPs em cinco camadas conduza a maiores discrepâncias, haja vista características peculiares da moldagem, como uma boa ligação entre as camadas e a umidade final do CP.

Além disso, ressalta-se que o valor de RCS igual a 89,2 kPa na Tabela 4.16 pode ter sido influenciado pelo valor da umidade do CP que foi maior que $w_{o} \pm 0,3$. Portanto, a Tabela 4.17 representa a Tabela 4.16 sem o valor de 89,2 .

Tabela 4.17 - RCS para CPs moldados estaticamente e no CGS, na energia do Proctor Normal

\begin{tabular}{c|cc}
\hline \multirow{2}{*}{} & \multicolumn{2}{c}{ RCS (kPa) } \\
\cline { 2 - 3 } CPs & Estático & CGS \\
\hline \multirow{2}{*}{ Média } & 112,6 & 129,6 \\
& 104,1 & 131,6 \\
Desvio padrão & 108,4 & 120,0 \\
\hline Desvio/média (\%) & 6,0 & 6,2 \\
\hline
\end{tabular}

Analisando agora a Tabela 4.17, observa-se uma redução em quase 50\% no desvio padrão para a RCS dos CPs moldados estaticamente. Como os desvios padrões dos dois grupos foram menores que $7 \%$, pode-se dizer que a variação de $17 \%$ entre a $\mathrm{RCS}_{\text {média }}$ do estático e do CGS seja efeito da diferença do tipo de compactação. 
A Tabela 4.18 mostra os valores de RCS obtidos para os CPs moldados estaticamente e no CGS na energia intermediária do Proctor.

Tabela 4.18 - RCS para CPs moldados estaticamente e no CGS, na energia do Proctor Intermediário

\begin{tabular}{c|cc}
\hline \multirow{2}{*}{ CPs } & \multicolumn{2}{c}{ RCS (kPa) } \\
\cline { 2 - 3 } & 237,8 & CGS \\
\hline \multirow{2}{*}{ Médico } & 151,8 & 221,9 \\
& 508,7 & 215,6 \\
\hline Desvio padrão & 299,4 & 218,0 \\
Desvio/média (\%) & 186,3 & 3,4 \\
\hline
\end{tabular}

A Tabela 4.18 mostra que houve uma dispersão muito alta entre os valores de RCS dos CPs moldados estaticamente, pois o desvio padrão foi de 186,3, representando mais de $60 \%$ da média. Assim, comparações diretas entre a $\mathrm{RCS}_{\text {média }}$ dos dois processos de moldagem de corpos de prova não é adequada.

Contudo, ainda vale ressaltar mais uma vez a boa repetibilidade dos valores de RCS para corpos de prova moldados no CGS, apresentando um desvio padrão muito baixo de apenas 3,4, que representa apenas $1,6 \%$ da $\operatorname{RCS}_{\text {média. }}$

Para efeito comparativo, decidiu-se descartar o valor de RCS igual 508,7 $\mathrm{kPa}$ mostrado na Tabela 4.18, e assim, o desvio padrão da RCS para CPs moldados estaticamente reduziu de 186,3 para 60,8. Sendo assim, a Figura 4.19 apresenta os valores de RCSmédia para os CPs moldados estaticamente e no CGS, tanto para Energia Normal, quanto para Intermediária do Proctor.

Na Figura 4.19, pode-se observar uma tendência de aumento no valor da RCS quando os corpos de prova foram moldados no CGS em comparação àqueles moldados estaticamente. Contudo, vale relembrar que a $\mathrm{RCS}_{\text {média }}$ para moldagem estática e energia intermediária teve um desvio padrão da ordem de 60. 


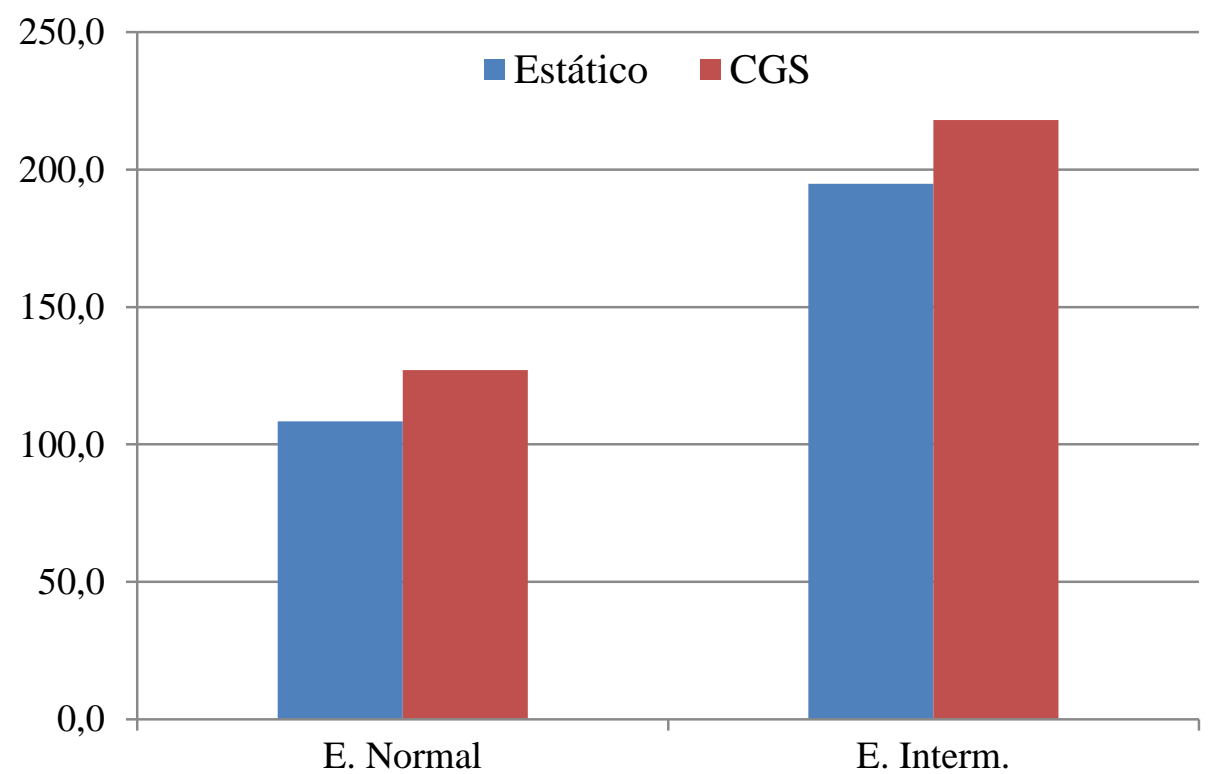

Figura 4.19 - RCS $_{\text {média }}$ para CPs moldados estaticamente e no CGS

\subsubsection{Ensaio de Compressão Diametral}

Os ensaios de compressão diametral foram realizados para se obter os valores de resistência à tração por compressão diametral (RTCD) para corpos de prova moldados estaticamente e com uso do CGS.

Os CPs que obtiveram RTCD maiores que RTCDmédia $\pm 20 \%$ foram descartados e uma nova média foi calculada. A Tabela 4.19 mostra os resultados de RTCD para CPs moldados na prensa estática e no CGS na energia normal do Proctor. 
Tabela 4.19 - RTCD para CPS moldados estaticamente e no CGS, na energia do Proctor Normal

\begin{tabular}{ccc}
\hline \multirow{2}{*}{} & \multicolumn{2}{c}{ RTCD $(\mathrm{kPa})$} \\
\cline { 2 - 3 } CPs & Estático & CGS \\
\hline \multirow{2}{*}{ Média } & 18,7 & 10,3 \\
& 25,7 & 9,6 \\
Desvio padrão & 22,2 & 10,2 \\
\hline Desvio/média (\%) & 4,9 & 0,4 \\
\hline
\end{tabular}

Com base nos resultados mostrados na Tabela 4.18 verifica-se que, assim como ocorreu nos ensaios de RCS, a repetibilidade dos ensaios realizados com CPs moldados no CGS foi muito boa, apresentando um desvio padrão de apenas 0,4 , representado apenas 1,6\% da média.

Já os CPs moldados estaticamente apresentaram uma dispersão elevada dos valores de RTCD, com um desvio padrão de 4,9 , que representa cerca de $22 \%$ da média. Por isso, que análise comparativa entre $\mathrm{RTCD}_{\text {média }}$ do $\mathrm{CPs}$ moldados no estático com aqueles moldados no CGS ficou comprometida.

Diferentemente do que foi levantado nos ensaios de RCS como possível causa para dispersão tão elevada nos CPs moldados estaticamente, para a RTCD, a moldagem não é elemento preponderante nos resultados, pois tanto os CPs moldados estaticamente quanto os moldados no CGS foram compactados em camada única.

A Tabela 4.20 mostra os resultados de RTCD para CPs moldados na prensa estática e no CGS, na energia do Proctor Intermediário. 
Tabela 4.20 - RTCD para CPS moldados estaticamente e no CGS, na energia do Proctor Intermediário

\begin{tabular}{ccc}
\hline \multirow{2}{*}{ CPs } & \multicolumn{2}{c}{ RTCD $(\mathrm{kPa})$} \\
\cline { 2 - 3 } & 24,1 & 35,5 \\
& & 36,2 \\
& 28,0 & 32,4 \\
\hline \multirow{2}{*}{ Médiático } & 26,1 & 34,7 \\
Desvio padrão & 2,7 & 2,0 \\
Desvio/média (\%) & 10,5 & 5,8 \\
\hline
\end{tabular}

Mais uma vez verifica-se uma dispersão muito baixa para os resultados dos CPs moldados no CGS, sendo que o desvio padrão representa cerca de $6 \%$ da média, mostrando novamente a boa repetibilidade dos ensaios mecânicos desenvolvidos a partir de CPs moldados no CGS.

Para a energia intermediária, a dispersão dos resultados de RTCD para os CPs moldados estaticamente foi menor do que o verificado na energia normal. Sendo assim, comparando-se a $\mathrm{RTCD}_{\text {média }}$ dos dois diferentes tipo de moldagem, verifica-se um aumento da ordem de $33 \% \mathrm{RTCD}_{\text {média }}$ do estático para o CGS.

A Figura 4.20 mostra os valores de $\mathrm{RTCD}_{\text {médio }}$ para os ensaios desenvolvidos com CPs moldados nos dois métodos e nas duas energias. Verifica-se o melhor desempenho dos CPs moldados no CGS na energia intermediária, enquanto que na normal, o desempenho foi melhor para os CPs moldados estaticamente. Entretanto, deve-se lembrar que o desvio padrão para os valores de RTCD dos CPs moldados estaticamente na energia normal representou mais de $20 \%$ do $\mathrm{RTCD}_{\text {médio }}$ e talvez a análise esteja comprometida. 


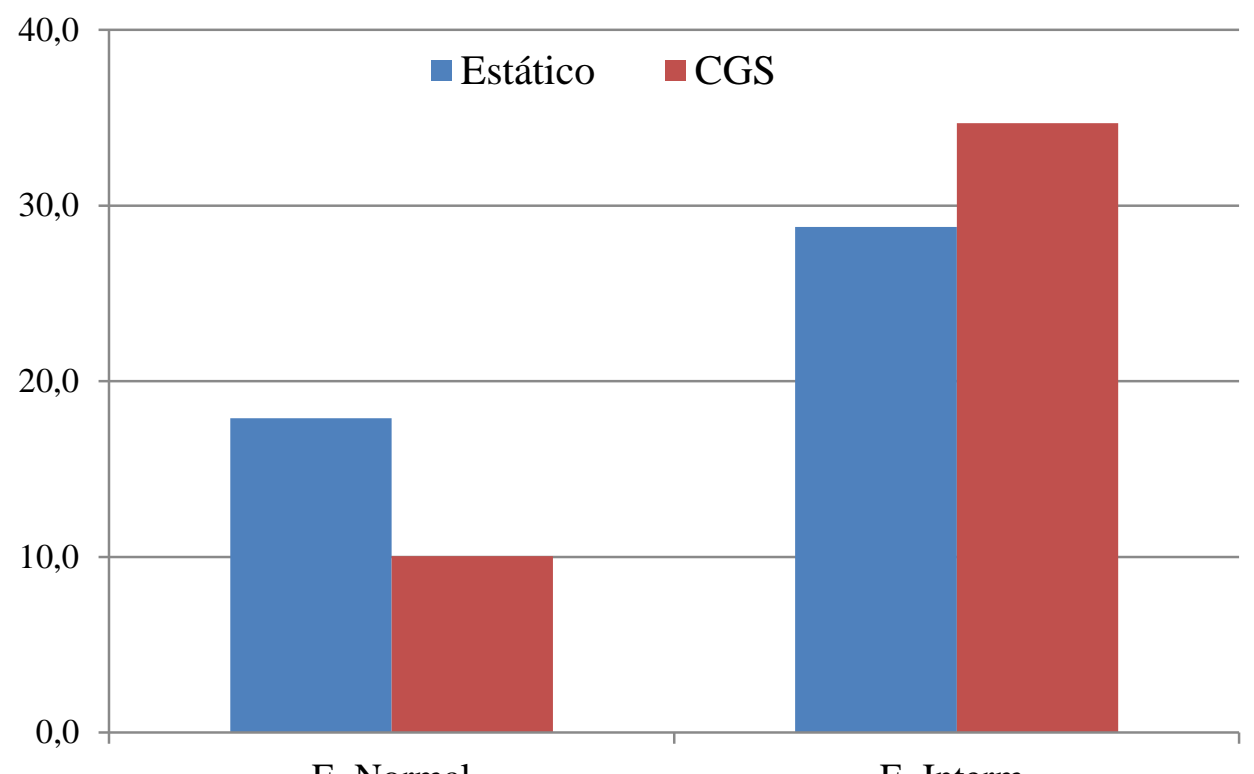

E. Normal

E. Interm.

Figura 4.20 - RTCD média $_{\text {para }}$ CPs moldados estaticamente e no CGS

\subsubsection{Ensaio Trixial Cíclico}

\subsubsection{Calibração do modelo matemático}

Os ensaios trixiais cíclicos foram executados visando a obtenção dos módulos de resiliência (MR) dos corpos de prova e assim fazer uma comparação entre os processos de moldagem estático e com uso do CGS.

Para obtenção dos MRs de cada corpo de prova, foi necessário proceder a calibração dos quatro modelos matemáticos a partir do coeficiente de determinação $\left(\mathrm{R}^{2}\right)$. A Tabela 4.21 mostra os quatro modelos avaliados, os quais estão em função da tensão desvio $\left(\sigma_{\mathrm{d}}\right)$, tensão confinante $\left(\sigma_{3}\right)$, primeiro invariante de tensões $(\theta)$ e da tensão cisalhante octaédrica $\left(\tau_{\text {oct }}\right)$. 
Tabela 4.21 - Modelos avaliados na representação do MR em função do estado de tensões

\begin{tabular}{|c|c|c|}
\hline Modelo & Modelagem matemática & Equação \\
\hline Modelo em Função da Tensão Desvio & $M R=k_{1} \sigma_{d}^{k_{2}}$ & $(5.1)$ \\
\hline Modelo em Função da Tensão de Confinamento & $M R=k_{1} \sigma_{3}^{k_{2}}$ & $(5.2)$ \\
\hline Modelo Composto & $M R=k_{1} \sigma_{d}^{k_{2}} \sigma_{3}^{k_{3}}$ & $(5.3)$ \\
\hline Modelo Universal da AASHTO & $M R=k_{1} p_{a}\left(\frac{\theta}{p_{a}}\right)^{k_{2}} \cdot\left(\frac{\tau_{o c t}}{p_{a}}+1\right)$ & (5.4) \\
\hline
\end{tabular}

Em que,

$\mathrm{M}_{\mathrm{R}}$ : módulo de resiliência

$\sigma_{d}$ : tensão desvio

$\sigma_{3}:$ tensão de confinamento

$\theta$ : primeiro invariante de tensões

$\tau_{o c t}:$ tensão cisalhante octaédrica

$p_{a}$ : pressão atmosférica

$k_{1}, k_{2}$ e $k_{3}:$ constantes

Os quatro modelos matemáticos apresentados na tabela anterior foram calibrados por meio de um programa computacional desenvolvido em plataforma LabView pelo Prof. Dr. Glauco Tulio Pessa Fabbri do Departamento de Engenharia de Transportes da EESCUSP. A Figura 4.21 ilustra uma imagem do referido programa. 


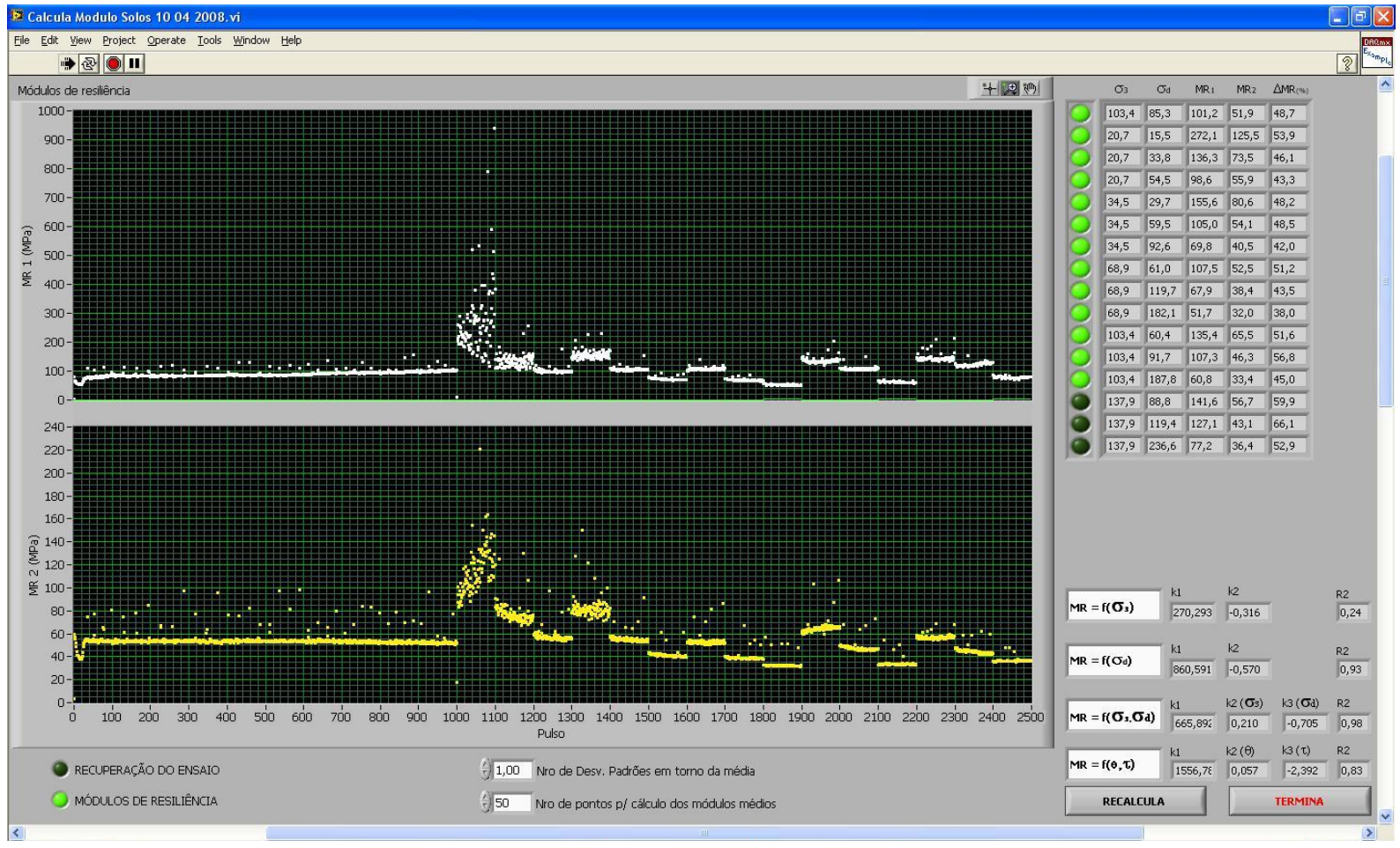

Figura 4.21 - Tela do programa empregado para a calibração dos modelos matemáticos de Módulo de Resiliência

As regressões matemáticas foram calculadas para os ensaios que obtiveram um número mínimo de doze pontos referentes a doze estágios de tensões e com um número mínimo de duas réplicas por tipo de ensaio. A Tabela 4.22 apresenta os coeficientes de determinação médios $\left(\mathrm{R}^{2}\right)$ para os quatro modelos matemáticos empregados segundo os tipos de moldagem dos corpos de prova e as energias empregadas. 
Tabela 4.22 - Coeficientes de determinação médios $\left(\mathrm{R}^{2}\right)$ dos modelos matemáticos para o MR

\begin{tabular}{c|ccccc}
\hline $\begin{array}{c}\text { Tipo de } \\
\text { Moldagem }\end{array}$ & Energia & $\begin{array}{c}\text { Função da } \\
\text { Tensão Desvio }\end{array}$ & $\begin{array}{c}\text { Função da } \\
\text { Tensão de } \\
\text { Confinamento }\end{array}$ & $\begin{array}{c}\text { Modelo } \\
\text { Composto }\end{array}$ & $\begin{array}{c}\text { Modelo } \\
\text { Universal da } \\
\text { AASHTO }\end{array}$ \\
\hline & Normal & 0,94 & 0,27 & 0,98 & 0,84 \\
\cline { 2 - 6 } Estática & Intermediária & 0,99 & 0,60 & 0,99 & 0,96 \\
\hline \multirow{2}{*}{ CGS } & Normal & 0,84 & 0,11 & 0,92 & 0,85 \\
& Intermediária & 0,98 & 0,63 & 0,98 & 0,93 \\
\hline
\end{tabular}

De maneira geral, verifica-se na Tabela 4.22 que os Modelos Composto e em Função da Tensão Desvio obtiveram melhor desempenho para o solo utilizado. Segundo a literatura estudada, esperava-se esse tipo de comportamento, pois os solos argilosos dependem muito mais da tensão desvio do que da tensão de confinamento, e por isso, o modelo em Função da Tensão de Confinamento foi aquele que obteve valores médios de $\mathrm{R}^{2}$ mais baixos.

Convém ressaltar que o Modelo Universal da AASHTO também teve um bom desempenho, contudo seus coeficientes de determinação médios ainda foram menores que aqueles encontrados para o Modelo Composto e o Modelo em Função da Tensão Desvio.

Portanto, embora a diferença entre os Modelos Composto e em Função da Tensão Desvio tenha sido discreta em termos de coeficiente de determinação, os cálculos dos valores de módulo de resiliência para um estado de tensão específico serão efetuados com o Modelo Composto, seguindo tendência observada em pesquisas no Brasil com solos argilosos. 


\subsubsection{Módulo de resiliência para um estado de tensão específico}

Com o objetivo de fazer uma melhor comparação entre os resultados obtidos no ensaio Triaxial Cíclico para cada corpo de prova, foram calculados os módulos de resiliência de cada CP a partir do modelo Composto, utilizando um dos 15 pares de tensões empregados no próprio ensaio triaxial cíclico. No Capítulo 3, no item 3.4.4, foi apresentada a tabela com os 15 pares de tensões que são empregados para realização do ensaio segundo a norma AASHTO T 307-99.

Para o cálculo dos MRs, foi escolhido um dos pares de tensão aplicados no próprio ensaio, com o objetivo de avaliar o desempenho de CPs compactados de maneiras distintas. Como não é objetivo desta pesquisa verificar a viabilidade do uso do solo utilizado em camadas de pavimentos flexíveis, não serão feitas maiores discussões acerca da escolha do par de tensões para realização dos cálculos de MRs.

A Tabela 4.23 apresenta os valores de MR calculados a partir do modelo composto, empregando um par de tensões do próprio ensaio triaxial cíclico.

Tabela 4.23 - MRs para o modelo composto e tensões de $\sigma_{3}=34,5 \mathrm{kPa}$ e $\sigma_{\mathrm{d}}=93,1 \mathrm{kPa}$

\begin{tabular}{|c|c|c|c|c|c|c|c|c|}
\hline $\begin{array}{c}\text { Tipo de } \\
\text { moldagem }\end{array}$ & Energia & $\mathrm{k}_{1}$ & $\mathrm{k}_{2}$ & $\mathrm{k}_{3}$ & $\begin{array}{c}\mathrm{MR} \\
(\mathrm{MPa})\end{array}$ & $\begin{array}{l}\text { Média } \\
(\mathrm{MPa})\end{array}$ & $\begin{array}{l}\text { Desvio } \\
\text { Padrão }\end{array}$ & $\begin{array}{c}\text { Desvio/média } \\
(\%)\end{array}$ \\
\hline \multirow{4}{*}{ Estático } & \multirow{2}{*}{ Normal } & 663,6963 & 0,2277 & $-0,7183$ & 146 & \multirow{2}{*}{164} & \multirow{2}{*}{25} & \multirow{2}{*}{15} \\
\hline & & 1160,2466 & 0,1420 & $-0,7061$ & 181 & & & \\
\hline & \multirow{2}{*}{ Interm. } & 5595,4381 & $-0,0721$ & $-0,6066$ & 471 & \multirow{2}{*}{394} & \multirow{2}{*}{109} & \multirow{2}{*}{28} \\
\hline & & 3861,0393 & $-0,0262$ & $-0,6729$ & 316 & & & \\
\hline \multirow{4}{*}{ CGS } & \multirow{2}{*}{ Normal } & 417,4793 & 0,2080 & $-0,6988$ & 90 & \multirow{2}{*}{88} & \multirow{2}{*}{3} & \multirow{2}{*}{4} \\
\hline & & 371,2431 & 0,1581 & $-0,6160$ & 86 & & & \\
\hline & \multirow{2}{*}{ Interm. } & 1488,4599 & 0,0144 & $-0,5833$ & 201 & \multirow{2}{*}{233} & \multirow{2}{*}{44} & \multirow{2}{*}{19} \\
\hline & & 2008,9439 & $-0,0216$ & $-0,5458$ & 264 & & & \\
\hline
\end{tabular}


Examinando a Tabela 4.23, verifica-se que os valores de MR tiveram uma dispersão muito alta, à exceção dos MRs dos CPs moldados no CGS na energia normal que tiveram desvio padrão de $3 \%$, correspondendo a apenas $4 \%$ da média.

Por causa da boa repetibilidade ocorrida nos ensaios de RCS e RTCD com CPs moldados no CGS, acredita-se que o valor elevado de desvio padrão apresentado nos MRs dos CPs moldados no CGS na energia intermediária seja consequência de algum erro na execução do ensaio triaxial ou a própria dispersão do ensaio.

Observando a Tabela 4.23, verifica-se que os CPs moldados estaticamente tiveram valores de desvio padrão muito altos, dificultando muito a comparação entre os métodos de moldagem. Contudo, para efeito comparativo, observa-se uma indicação de que os MRs obtidos de CPs moldados estaticamente são maiores que aqueles apresentados pelos CPs moldados no CGS. Se for observado os CPs moldados na energia normal do Proctor, pois foram os que obtiveram os menores desvios em relação a média, observa-se que o $\mathrm{MR}_{\text {médio }}$ dos CPs moldados estaticamente foi cerca de $85 \%$ maior que o $\mathrm{MR}_{\text {médio }}$ dos CPs moldados no CGS.

Acredita-se que os valores mais elevados de MR para os CPs moldados estaticamente estejam relacionados ao processo de moldagem, pois enquanto os CPs no CGS foram moldados em camada única, no estático, os CPs foram moldados em cinco camadas. 


\section{CONCLUSÕES E RECOMENDAÇÕES}

\subsection{ENSAIO DE COMPACTAÇÃO NO CGS}

Essa pesquisa apresenta um estudo de viabilidade do uso do compactador giratório Superpave na execução de ensaios de compactação de um solo argiloso.

A partir dos ensaios de compactação realizados com o CGS foi possível chegar a algumas conclusões acerca das características de execução do ensaio, como massa úmida por corpo de prova, tensão normal aplicada e número de giros.

A massa úmida por $C P$ mostrou-se um parâmetro de pouca influência nos valores de MEAS, mesmo que no geral os ensaios de compactação com CPs de $1000 \mathrm{~g}$ tenham apresentado valores de $\mathrm{MEAS}_{\text {máx }}$ um pouco maiores, quando comparados aos ensaios com CPs de $1800 \mathrm{~g}$. O maior impacto da massa úmida por $\mathrm{CP}$ nos valores de $\mathrm{MEAS}_{\text {máx }}$ foi registrado nos ensaios de compactação com tensão de $200 \mathrm{kPa}$, onde foi possível verificar que

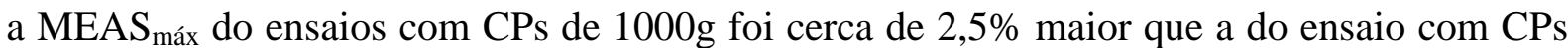
de $1800 \mathrm{~g}$.

Ping et al. (2003b) já haviam chegado à conclusão semelhante, mostrando que a combinação de grande volumes de material e baixas tensões pode ser prejudicial à eficiência do processo de compactação no CGS. Em função disso e para garantir maior reprodutibilidade, sugere-se que o ensaio de compactação de solos no CGS seja executado com CPs de 1000g de massa úmida. 
Quanto à tensão normal aplicada pelo CGS, foi constatado nesta pesquisa que entre as tensões de 400 e $600 \mathrm{kPa}$ a diferença na $\mathrm{MEAS}_{\text {máx }}$ foi muito pequena nos ensaios com CPs de $1000 \mathrm{~g}$ e nos ensaios com CPs de $1800 \mathrm{~g}$ a diferença foi de $2 \%$. Com relação à tensão de $200 \mathrm{kPa}$, seu desempenho foi muito aquém do observado para as outras duas tensões, mostrando que este valor de tensão não foi suficiente para alcançar valores superiores de MEAS $_{\text {máx }}$

Desta forma, a tensão de $600 \mathrm{kPa}$ mostrou-se a melhor para execução do ensaio de compactação de solos no CGS, pois, apesar da diferença para a de $400 \mathrm{kPa}$ ter sido pequena, o valor de 600 conduziu a resultados um pouco maiores de $M_{E A S}$ máx.

Em relação ao número de giros utilizado nos ensaios de compactação, o número de 500 giros mostrou-se um valor muito elevado para sua execução. As curvas MEAS versus número de giros de todos os ensaios apresentaram comportamento assintótico após 75 giros, indicando incrementos muito discretos na MEAS.

O uso do conceito do Locking Point (LP) de Vavrik e Carpenter (1998) foi importante para se justificar que o uso de 500 giros foi exagerado. No LP, os CPs já haviam alcançado pelo menos $97 \%$ da MEAS do final do ensaio (500 giros). Os valores médios de LP foram muito diferentes para o ramo seco e o ramo úmido das curvas de compactação. Em média, observou-se que foi necessário dobrar o número de giros para que os CPs do ramo seco atingissem o LP. Contudo, verificou-se que mesmo sendo maior o número de giros para atingir o LP nos CPs do ramo seco, esses valores não foram maiores que 50 giros.

O ajuste das curvas de MEAS versus número de giros dos ensaios de compactação e a análise das suas taxas de variação também possibilitaram verificar que o número de 500 giros foi excessivo para execução dos ensaios de compactação. Como ocorrido no LP, observou-se que o incremento na MEAS tornou-se muito pequeno, em média, a partir dos 50 giros.

O estudo das curvas MEAS versus número de giros por meio do Locking Point e da Taxa de Variação também possibilitou corroborar a conclusão acerca do uso da tensão de $600 \mathrm{kPa}$ na execução dos ensaios de compactação, uma vez que foi nessa tensão que se necessitou de um número de giros menor para se alcançar o LP e o incremento mínimo na MEAS. 


\subsection{COMPACTAÇÃO PROCTOR VERSUS COMPACTAÇÃO NO CGS}

A comparação entre valores de $\mathrm{MEAS}_{\text {máx }}$ dos ensaios de compactação realizados pelo método Proctor e no CGS mostrou que o método Proctor teve valores mais elevados de MEAS, apesar de ter sido utilizado 500 giros no CGS.

Os valores de $\mathrm{MEAS}_{\text {máx }}$ para os ensaios desenvolvidos com tensão normal de $400 \mathrm{kPa}$ e $600 \mathrm{kPa}$ ficaram abaixo da MEAS ${ }_{\text {máx }}$ do Proctor Modificado, apresentando uma diferença média de 5,5\%. As $\mathrm{MEAS}_{\text {máx }}$ dos ensaios com tensão normal de $200 \mathrm{kPa}$ só alcançaram a $\mathrm{MEAS}_{\text {máx }}$ do Proctor Normal, ficando bem abaixo do Proctor Intermediário.

É provável que os valores mais elevados de MEAS apresentados pelo ensaio Proctor quando comparados àqueles do CGS podem ter sido influenciados pelo número de camadas dos corpos de prova, pois enquanto no Proctor os CPs foram moldados em 3 ou 5 camadas, no CGS os CPs foram moldados em camada única. Assim, acredita-se que o fato de se fazer mais de uma camada na moldagem dos CPs possivelmente conduza a valores mais elevados de MEAS.

Quanto aos ensaios mecânicos, os corpos de prova moldados no CGS apresentaram, de maneira geral, melhores resultados de resistência à compressão simples e resistência a tração por compressão diametral que os CPs moldados estaticamente.

Na RCS foi observado que os CPs moldados no CGS tiveram valores de RCS, em média, 17\% maiores que os CPs moldados estaticamente. No ensaio de RTCD, observou-se que os CPs moldados no CGS tiveram valores RTCD 33\% maiores que os CPs moldados na prensa estática.

Para o módulo de resiliência, a dispersão apresentada pelos resultados dificultou a comparação, contudo, foi possível notar uma tendência de melhor desempenho dos CPs moldados estaticamente. 


\subsection{PROCEDIMENTO PARA ENSAIO DE COMPACTAÇÃO NO CGS COM SOLO ARGILOSO}

Com base nas conclusões apresentadas, pode-se sugerir um procedimento para realização do ensaio de compactação empregando-se o CGS. Todavia, deve-se ressaltar que as conclusões são baseadas nos ensaios realizados nessa pesquisa com um único solo, de características argilosas e, portanto, para se emitir conclusões mais gerais acerca da compactação de solos no CGS, pesquisas adicionais devem ser realizadas.

Assim, pode-se dizer que para se fazer o ensaio de compactação no CGS, deve-se optar por uma massa úmida do CP constante e igual a $1000 \mathrm{~g}$, tensão normal de $600 \mathrm{kPa}$ e um número de giros igual a 75 e após a compactação de cada $\mathrm{CP}$ verificar com os dados de saída do CGS se o CP alcançou o LP. Quanto aos outros parâmetros, recomenda-se frequência de 30 rpm e ângulo de giro de $1,25^{\circ}$.

\subsection{SUGESTÕES PARA PESQUISAS FUTURAS}

Com o propósito de ampliar os conhecimentos a respeito do uso do CGS na compactação de solos e assim auxiliar em uma possível normatização do procedimento, sugere-se:

- fazer ensaios de compactação no CGS utilizando outros tipos de solos, como solos arenosos e solos lateríticos;

- realizar ensaios de compactação no CGS utilizando corpos de prova com volume fixo e, assim, averiguar os níveis de energia que o CGS alcança;

- avaliar ensaio de compactação no CGS, moldando os corpos de prova em mais de uma camada;

- comparar as MEAS de ensaios de compactação realizados no CGS com as MEAS in situ; 
- avaliar o que acontece com a granulometria dos CPs moldados no CGS;

- analisar o coeficiente de permeabilidade a partir de moldagem de CPs no CGS;

- executar ensaio de compactação no CGS, variando valores de frequência e ângulo de giro, para avaliar a influência desses parâmetros em solos brasileiros, e;

- investigar o desempenho de ensaios de compactação realizados no CGS com cilindro de $15 \mathrm{~cm}$ de diâmetro. 


\section{REFERÊNCIAS}

AMERICAN ASSOCIATION OF STATE HIGHWAY AND TRANSPORTATION OFFICIALS. (2004). AASHTO M-145-91. Standard Specification for Classification of Soils and Soil-Aggregate Mixtures for Highway Construction Purposes. Washington, EUA.

. (2007). AASHTO T 307-99. Standard Method of Test for Determing the Resilient Modulus of Soils and Aggregate Materials. Washington, EUA.

AMERICAN SOCIETY FOR TESTING AND MATERIALS. (2011). ASTM D2487 - 11. Standard Practice for Classification of Soils for Engineering Purposes (Unified Soil Classification System). Pensilvânia, EUA.

ASSOCIAÇÃO BRASILEIRA DE NORMAS TÉCNICAS (1984). NBR 6459. Solo Determinação do limite de liquidez. Rio de Janeiro,

. (1984). NBR 6508. Grãos de solos que passam na peneira de 4,8 mm Determinação da massa específica e os procedimentos para determinação do Limite de Plasticidade e Limite de Liquidez. Rio de Janeiro.

. (1984). NBR 7180. Solo - Determinação do limite de plasticidade. Rio de Janeiro.

. (1984). NBR 7181. Solo-Análise granulométrica. Rio de Janeiro.

. (1986). NBR 7182. Solo - Ensaio de compactação. Rio de Janeiro.

. (1992). NBR 12770. Solo coesivo - Determinação da resistência à compressão não confinada. Rio de Janeiro.

Browne, M. (2006). Feasibility of Using a Gyratory Compactor to Determine Compaction Characteristics of Soil. Dissertação de Mestrado, Departamento de Engenharia Civil, Universidade do Estado de Montana, Bozeman, Montana.

Butcher, M. (1998). Determining Gyratory Compaction Characteristics Using Servopac Gyratory Compactor.Transportation research record 1630, $\mathrm{n}^{\circ}$ 98-0114.

DEPARTAMENTO NACIONAL DE ESTRADAS E RODAGEM. DNER - ME 228/94 (1994). Solos - Compactação em equipamento miniatura. Rio de Janeiro.

DNER - ME 256/94 (1994). Solos compactados com equipamento miniatura Determinação da perda de massa por imersão. Rio de Janeiro.

DNER - ME 258/94 (1994). Solos compactados em equipamento miniatura Mini-MCV. Rio de Janeiro. 
DNER-CLA 259-96 (1996). Classificação de solos tropicais para finalidades rodoviárias utilizando corpos de prova compactados em equipamento miniatura. Rio de Janeiro.

DNIT - DEPARTAMENTO NACIONAL DE INFRA-ESTRUTURA DE TRANSPORTES. Manual de Pavimentação. Diretoria de Planejamento e Pesquisa, Coordenação Geral de Estudos e Pesquisa, Instituto de Pesquisas Rodoviárias, IPR - Publicação 719. Rio de Janeiro, 2006, 274p.

George, K. P. (1992). Resilient Testing of Soils Using Gyratory Testing Machine. Transportation Research Record 1369, Transportation Research Board, NationalResearch Council, Washington, D.C., p. 63-72.

Harman, T., Bukowski, J. R., Moutier, F., Huber, G. e MCG Sennis, R. (2002). History and Future Challenges of Gyratory Compaction - 1939 to 2001. Transportation Research Record 1789.

Huber, G. (1996). Development of the Superpave Gyratory Compactor. Heritage Research. Indianapolis, Indiana.

Milberger, L. L., and Dunlap, W. A. (1966). A gyratory Compactor for Molding Large Diameter Triaxial Specimens of Granular materials. Instituto de Transportes do Texas, Universidade A\&M, Texas.

Mokwa, R., Cuelho, E. e Browne, M. (2008). Laboratory Testing of Soil Using the Superpave Gyratory Compactor. Transportation Research Board, Washington D.C., Janeiro 14-17.

Nogami, J. S.; Villibor, D. F. (1995). Pavimentação de baixo custo com solos lateríticos. São Paulo.

Ping, W. V., Leonard, M., e Yang, Z. (2003a). Laboratory Simulationof Field Compaction Characteristics (Phase I).Departamento de Engenharia Civil e Ambiental, Universidade do Estado da Florida. Tallahassee, Florida.

Ping, W. V., Xing, G., Leonard, M., e Yang, Z. (2003b).Evaluation of Laboratory Compaction Techniques for Simulating Field Compaction (Phase II). Departamento de Engenharia Civil e Ambiental, Universidade do Estado da Florida. Tallahassee, Florida.

Ping, W., Yang, Z., Leonard, M. e Putcha, S. (2002).Laboratory Simulation of Field Compaction Characteristics on Sandy Soils. Transportation Research Board, Washington D.C., Janeiro 13-17.

Takeda, M. C. (2006). A influência da variação da umidade pós-compactação no comportamento mecânico de solos de rodovias do interior paulista. Tese de Doutorado, Escola de Engenharia de São Carlos (EESC), Universidade de São Paulo, São Carlos, SP.

Vargas, M. (1977). Introdução à mecânica dos solos. São Paulo: MCGSraw-Hill do Brasil, 509 p. 
Venkatarama Reddy, B. V. e Jagadaish, K. S. (1993). The static compaction of soils. Géotechnique 43, n², 337-341.

Vavrik, W. R.; Carpenter, S. H. (1998). Calculating Air Voids at Specified Numbers of Gyrations in Superpave Gyratory Compactor. In: Transportation Research Record 1630: Asphalt Mixtures: Stiffness Characterization, Variables, and Performance, Transportation Research Board, National Research Council, Washington, D.C., EUA. 


\section{ANEXO A - CÁlCULO DA ENERGIA APLICADA PELO CGS}

O cálculo da energia aplicada pelo CGS foi realizado com base nas considerações apresentadas no trabalho de Ping et al. (2003b), no qual os autores dividiram a energia aplicada pelo compactador em duas parcelas: uma advinda da tensão normal e outra da tensão cisalhante.

A parcela da energia composta pela tensão normal é o trabalho exercido pela força vertical do pistão de compactação, que é constante durante todo o ensaio, e foi obtida segundo a Equação A.1.

$$
E \sigma_{N}=P . A . \Delta H
$$

Onde:

$E \sigma_{N}$ : energia aplicada pela tensão normal $(J)$

$P$ : tensão normal $(P a)$

$A$ : área da seção transversal da amostra de solo $\left(m^{2}\right)$

$\Delta H:$ a diferença entre a altura final e inicial do corpo de prova $(m)$

Já a parcela da energia decorrida da tensão cisalhante foi obtida segundo a Equação A.2.

$$
E \tau=4 . H . \theta . \tau . A \quad(\mathrm{~A} .2)
$$


Onde:

$E \tau$ : energia aplicada pela tensão cisalhante $(J)$

$H$ : altura do $\mathrm{CP}(m)$

$\theta$ : ângulo de giro $(\mathrm{rad})$

$\tau:$ tensão cisalhante aplicada $(P a)$

$A$ : área da seção transversal do corpo de prova $\left(m^{2}\right)$

O cálculo da energia foi feito de forma sequencial, isto é, em cada giro efetuado foi avaliada a parcela de energia aplicada pela tensão normal e a parcela da tensão cisalhante. Por conseguinte, foi possível considerar a energia empregada pelo CGS durante todo o ensaio de compactação, ou seja, para todos os 500 giros. Desta forma, para se entender o nível de energia que o CGS alcançou na compactação dos CPs de solo, calculou-se a energia total empregada no ensaio com CGS por unidade de volume e por unidade de massa.

A energia do ensaio Proctor é usualmente calculada por unidade de volume, visto que o volume dos CPs no ensaio é constante; contudo, os ensaios de compactação realizados no CGS foram feitos com massa constante e, por isso, a energia empregada no CGS também foi calculada por unidade de massa.

A Tabela A.1 apresenta as energias empregadas nos ensaios Proctor por unidade de volume e por unidade de massa, sendo que esta última é uma média do que foi apresentado nos ensaios de compactação.

Tabela A.1 - Valores de energia do ensaio Proctor (NBR 7182/1986)

\begin{tabular}{ccc}
\hline Ensaio & $\begin{array}{c}\text { Energia por } \\
\text { volume }\left(\mathrm{J} / \mathrm{cm}^{3}\right)\end{array}$ & $\begin{array}{c}\text { Energia por } \\
\text { massa }(\mathrm{J} / \mathrm{g})\end{array}$ \\
\hline Normal & 0,59 & 0,33 \\
Intermediária & 1,30 & 0,68 \\
Modificada & 2,78 & 1,39 \\
\hline
\end{tabular}


As Tabelas A.2 e A.3 apresentam o número de giros no CGS necessários para atingir as energias do ensaio Proctor por unidade de volume e por unidade de massa, para os ensaios de compactação com tensão normal de $200 \mathrm{kPa}$ e corpos de prova $1000 \mathrm{~g}$ e $1800 \mathrm{~g}$, respectivamente.

Tabela A.2 - Número de giros necessários para atingir energias do Proctor no ensaio com tensão de $200 \mathrm{kPa}$ e CPs de $1000 \mathrm{~g}$

\begin{tabular}{|c|c|c|c|c|c|c|c|}
\hline \multirow[b]{2}{*}{$\mathrm{CP}$} & \multirow[b]{2}{*}{$\mathrm{w}(\%)$} & \multicolumn{2}{|c|}{ Energia Normal } & \multicolumn{2}{|c|}{ Energia Intermediária } & \multicolumn{2}{|c|}{ Energia Modificada } \\
\hline & & $\begin{array}{c}\mathrm{n}^{\circ} \text { de giros } \\
\left(\mathrm{J} / \mathrm{cm}^{3}\right)\end{array}$ & $\mathrm{n}^{\mathrm{o}} \underset{(\mathrm{J} / \mathrm{g})}{ }$ & $\begin{array}{c}\mathrm{n}^{\mathrm{o}} \text { de giros } \\
\left(\mathrm{J} / \mathrm{cm}^{3}\right)\end{array}$ & $\mathrm{n}^{\mathrm{o}} \underset{(\mathrm{J} / \mathrm{g})}{\text { de giros }}$ & $\begin{array}{c}\mathrm{n}^{\mathrm{o}} \text { de giros } \\
\left(\mathrm{J} / \mathrm{cm}^{3}\right)\end{array}$ & $\mathrm{n}^{\mathrm{o}} \underset{(\mathrm{J} / \mathrm{g})}{\operatorname{siros}}$ \\
\hline 180 & 20,18 & 117 & 106 & 246 & 214 & - & 429 \\
\hline 181 & 22,10 & 105 & 99 & 227 & 206 & 482 & 420 \\
\hline 182 & 24,52 & 96 & 96 & 213 & 204 & 455 & 418 \\
\hline 183 & 26,00 & 98 & 102 & 216 & 215 & 474 & 448 \\
\hline 184 & 27,78 & 112 & 117 & 253 & 252 & - & - \\
\hline \multirow[t]{3}{*}{185} & 29,34 & 127 & 133 & 284 & 281 & - & - \\
\hline & média & 109 & 240 & 470 & 229 & 470 & 429 \\
\hline & desvio padrão & 11,9 & 26,9 & 13,9 & 31,0 & 13,9 & 13,7 \\
\hline \multicolumn{2}{|c|}{ desvio/média (\%) } & 10,9 & 11,2 & 2,9 & 13,6 & 2,9 & 3,2 \\
\hline
\end{tabular}

Tabela A.3 - Número de giros necessários para atingir energias do Proctor no ensaio com tensão de $200 \mathrm{kPa}$ e CPs de $1800 \mathrm{~g}$

\begin{tabular}{|c|c|c|c|c|c|c|c|}
\hline \multirow[b]{2}{*}{$\mathrm{CP}$} & \multirow[b]{2}{*}{$\mathrm{w}(\%)$} & \multicolumn{2}{|c|}{ Energia Normal } & \multicolumn{2}{|c|}{ Energia Intermediária } & \multicolumn{2}{|c|}{ Energia Modificada } \\
\hline & & $\begin{array}{c}\mathrm{n}^{\mathrm{o}} \text { de giros } \\
\left(\mathrm{J} / \mathrm{cm}^{3}\right)\end{array}$ & $\begin{array}{c}\mathrm{n}^{\mathrm{o}} \text { de giros } \\
(\mathrm{J} / \mathrm{g})\end{array}$ & $\begin{array}{c}\mathrm{n}^{\mathrm{o}} \text { de giros } \\
\left(\mathrm{J} / \mathrm{cm}^{3}\right)\end{array}$ & $\mathrm{n}^{\mathrm{o}} \underset{(\mathrm{J} / \mathrm{g})}{ }$ & $\begin{array}{c}\mathrm{n}^{\mathrm{o}} \text { de giros } \\
\left(\mathrm{J} / \mathrm{cm}^{3}\right)\end{array}$ & $\mathrm{n}^{\mathrm{o}} \underset{(\mathrm{J} / \mathrm{g})}{ }$ \\
\hline 114 & 23,80 & 161 & 154 & 356 & 325 & - & - \\
\hline 115 & 24,86 & 157 & 154 & 348 & 326 & - & - \\
\hline 116 & 26,03 & 157 & 159 & 353 & 342 & - & - \\
\hline 126 & 27,10 & - & 222 & - & 475 & - & - \\
\hline \multirow[t]{3}{*}{127} & 29,26 & 231 & 242 & - & - & - & - \\
\hline & média & 177 & 186 & 352 & 367 & 470 & 429 \\
\hline & desvio padrão & 36,4 & 42,5 & 4,0 & 72,4 & 13,9 & 13,7 \\
\hline \multicolumn{2}{|c|}{ desvio/média (\%) } & 20,6 & 22,8 & 1,1 & 19,7 & 2,9 & 3,2 \\
\hline
\end{tabular}


As Tabelas A.4 e A.5 apresentam o número de giros no CGS necessários para alcançar as energias do ensaio Proctor, tanto por unidade de volume, como por unidade de massa, para os ensaios de compactação com tensão normal de $400 \mathrm{kPa}$ e corpos de prova $1000 \mathrm{~g}$ e $1800 \mathrm{~g}$, respectivamente.

Tabela A.4 - Número de giros necessários para atingir energias do Proctor no ensaio com tensão de $400 \mathrm{kPa}$ e CPs de $1000 \mathrm{~g}$

\begin{tabular}{|c|c|c|c|c|c|c|c|}
\hline \multirow[b]{2}{*}{$\mathrm{CP}$} & \multirow[b]{2}{*}{$\mathrm{w}(\%)$} & \multicolumn{2}{|c|}{ Energia Normal } & \multicolumn{2}{|c|}{ Energia Intermediária } & \multicolumn{2}{|c|}{ Energia Modificada } \\
\hline & & $\begin{array}{c}\mathrm{n}^{\mathrm{o}} \text { de giros } \\
\left(\mathrm{J} / \mathrm{cm}^{3}\right)\end{array}$ & $\begin{array}{c}\mathrm{n}^{\circ} \text { de giros } \\
(\mathrm{J} / \mathrm{g})\end{array}$ & $\begin{array}{c}\mathrm{n}^{\mathrm{o}} \text { de giros } \\
\left(\mathrm{J} / \mathrm{cm}^{3}\right)\end{array}$ & $\begin{array}{c}\mathrm{n}^{\mathrm{o}} \text { de giros } \\
(\mathrm{J} / \mathrm{g})\end{array}$ & $\begin{array}{c}\mathrm{n}^{\mathrm{o}} \text { de giros } \\
\left(\mathrm{J} / \mathrm{cm}^{3}\right)\end{array}$ & $\begin{array}{c}\mathrm{n}^{\circ} \text { de giros } \\
(\mathrm{J} / \mathrm{g})\end{array}$ \\
\hline 186 & 17,96 & 65 & 61 & 142 & 128 & 299 & 259 \\
\hline 187 & 19,82 & 63 & 61 & 136 & 128 & 293 & 264 \\
\hline 188 & 21,26 & 58 & 60 & 129 & 127 & 280 & 263 \\
\hline 189 & 23,37 & 59 & 62 & 135 & 138 & 299 & 290 \\
\hline 190 & 25,35 & 69 & 74 & 165 & 170 & 374 & 364 \\
\hline 191 & 26,52 & 95 & 101 & 219 & 221 & 488 & 471 \\
\hline \multirow[t]{3}{*}{192} & 28,61 & 109 & 115 & 241 & 242 & - & 500 \\
\hline & média & 76 & 79 & 171 & 171 & 347 & 359 \\
\hline & desvio padrão & 21,4 & 23,6 & 48,0 & 49,8 & 87,1 & 105,3 \\
\hline \multicolumn{2}{|c|}{ desvio/média (\%) } & 28,3 & 29,9 & 28,1 & 29,1 & 25,1 & 29,4 \\
\hline
\end{tabular}

Tabela A.5 - Número de giros necessários para atingir energias do Proctor no ensaio com tensão de $400 \mathrm{kPa}$ e CPs de $1800 \mathrm{~g}$

\begin{tabular}{|c|c|c|c|c|c|c|c|}
\hline \multirow[b]{2}{*}{$\mathrm{CP}$} & \multirow[b]{2}{*}{$\mathrm{w}(\%)$} & \multicolumn{2}{|c|}{ Energia Normal } & \multicolumn{2}{|c|}{ Energia Intermediária } & \multicolumn{2}{|c|}{ Energia Modificada } \\
\hline & & $\begin{array}{c}\mathrm{n}^{\mathrm{o}} \text { de giros } \\
\left(\mathrm{J} / \mathrm{cm}^{3}\right)\end{array}$ & $\begin{array}{c}\mathrm{n}^{\mathrm{o}} \text { de giros } \\
(\mathrm{J} / \mathrm{g})\end{array}$ & $\begin{array}{c}\mathrm{n}^{\mathrm{o}} \text { de giros } \\
\left(\mathrm{J} / \mathrm{cm}^{3}\right)\end{array}$ & $\begin{array}{c}\mathrm{n}^{\mathrm{o}} \text { de giros } \\
(\mathrm{J} / \mathrm{g})\end{array}$ & $\begin{array}{l}\mathrm{n}^{\mathrm{o}} \text { de giros } \\
\left(\mathrm{J} / \mathrm{cm}^{3}\right)\end{array}$ & $\begin{array}{c}\mathrm{n}^{\mathrm{o}} \text { de giros } \\
(\mathrm{J} / \mathrm{g})\end{array}$ \\
\hline 121 & 21,22 & 97 & 97 & 222 & 211 & - & 441 \\
\hline 122 & 22,00 & 98 & 99 & 221 & 215 & - & 449 \\
\hline 123 & 23,07 & 101 & 105 & 230 & 229 & - & 477 \\
\hline 128 & 23,80 & 110 & 120 & 267 & 276 & - & - \\
\hline 124 & 24,64 & 108 & 115 & 248 & 251 & - & - \\
\hline 125 & 25,54 & 107 & 114 & 252 & 256 & - & - \\
\hline \multirow[t]{3}{*}{129} & 26,06 & 158 & 170 & 367 & 374 & - & - \\
\hline & média & 114 & 121 & 264 & 267 & - & 463 \\
\hline & desvio padrão & 22,2 & 25,4 & 53,0 & 56,7 & - & 19,8 \\
\hline \multicolumn{2}{|c|}{ desvio/média (\%) } & 19,5 & 21,1 & 20,0 & 21,2 & - & 3,2 \\
\hline
\end{tabular}


As Tabelas A.6 e A.7 apresentam o número de giros no CGS necessários para atingir as energias do ensaio Proctor, tanto por unidade de volume, como por unidade de massa, para os ensaios de compactação com tensão normal de $600 \mathrm{kPa}$ e corpos de prova $1000 \mathrm{~g}$ e $1800 \mathrm{~g}$, respectivamente.

Tabela A.6 - Número de giros necessários para atingir energias do Proctor no ensaio com tensão de $600 \mathrm{kPa}$ e CPs de $1000 \mathrm{~g}$

\begin{tabular}{|c|c|c|c|c|c|c|c|}
\hline \multirow[b]{2}{*}{$\mathrm{CP}$} & \multirow[b]{2}{*}{$\mathrm{w}(\%)$} & \multicolumn{2}{|c|}{ Energia Normal } & \multicolumn{2}{|c|}{ Energia Intermediária } & \multicolumn{2}{|c|}{ Energia Modificada } \\
\hline & & $\begin{array}{c}\mathrm{n}^{\mathrm{o}} \text { de giros } \\
\left(\mathrm{J} / \mathrm{cm}^{3}\right)\end{array}$ & 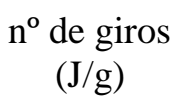 & $\begin{array}{c}\mathrm{n}^{\mathrm{o}} \text { de giros } \\
\left(\mathrm{J} / \mathrm{cm}^{3}\right)\end{array}$ & $\begin{array}{c}\mathrm{n}^{\mathrm{o}} \text { de giros } \\
(\mathrm{J} / \mathrm{g})\end{array}$ & $\begin{array}{c}\mathrm{n}^{\mathrm{o}} \text { de giros } \\
\left(\mathrm{J} / \mathrm{cm}^{3}\right)\end{array}$ & $\mathrm{n}^{\mathrm{o}} \underset{(\mathrm{J} / \mathrm{g})}{\mathrm{ge} \text { giros }}$ \\
\hline 148 & 19,1 & 15 & 14 & 32 & 29 & 66 & 59 \\
\hline 149 & 20,8 & 14 & 14 & 30 & 28 & 62 & 57 \\
\hline 150 & 23,3 & 14 & 14 & 30 & 29 & 63 & 60 \\
\hline 151 & 24,5 & 14 & 15 & 32 & 32 & 68 & 68 \\
\hline \multirow[t]{3}{*}{152} & 26,3 & 15 & 17 & 37 & 37 & 83 & 80 \\
\hline & média & 14 & 15 & 32 & 31 & 68 & 65 \\
\hline & desvio padrão & 0,5 & 1,3 & 2,9 & 3,7 & 8,5 & 9,5 \\
\hline \multicolumn{2}{|c|}{ desvio/média (\%) } & 3,8 & 8,8 & 8,9 & 11,9 & 12,4 & 14,6 \\
\hline
\end{tabular}

Tabela A.7 - Número de giros necessários para atingir energias do Proctor no ensaio com tensão de $600 \mathrm{kPa}$ e CPs de $1800 \mathrm{~g}$

\begin{tabular}{|c|c|c|c|c|c|c|c|}
\hline \multirow[b]{2}{*}{$\mathrm{CP}$} & \multirow[b]{2}{*}{$\mathrm{w}(\%)$} & \multicolumn{2}{|c|}{ Energia Normal } & \multicolumn{2}{|c|}{ Energia Intermediária } & \multicolumn{2}{|c|}{ Energia Modificada } \\
\hline & & $\begin{array}{c}\mathrm{n}^{\mathrm{o}} \text { de giros } \\
\left(\mathrm{J} / \mathrm{cm}^{3}\right)\end{array}$ & $\mathrm{n}_{(\mathrm{J} / \mathrm{g})}$ de giros & $\begin{array}{c}\mathrm{n}^{\mathrm{o}} \text { de giros } \\
\left(\mathrm{J} / \mathrm{cm}^{3}\right)\end{array}$ & $\mathrm{n}^{\mathrm{o}} \underset{(\mathrm{J} / \mathrm{g})}{\mathrm{ge} \text { giros }}$ & $\begin{array}{c}\mathrm{n}^{\mathrm{o}} \text { de giros } \\
\left(\mathrm{J} / \mathrm{cm}^{3}\right)\end{array}$ & $\mathrm{n}^{\mathrm{o}} \underset{(\mathrm{J} / \mathrm{g})}{\mathrm{de}^{2} \text { giros }}$ \\
\hline 106 & 19,55 & 21 & 21 & 45 & 42 & 94 & 85 \\
\hline 7 & 20,41 & 24 & 24 & 52 & 50 & 110 & 103 \\
\hline 107 & 21,87 & 21 & 21 & 46 & 46 & 100 & 95 \\
\hline $8 \mathrm{a}$ & 22,41 & 23 & 24 & 51 & 51 & 109 & 105 \\
\hline 108 & 24,22 & 21 & 22 & 48 & 49 & 106 & 102 \\
\hline 9 & 25,07 & 26 & 28 & 62 & 63 & 141 & 137 \\
\hline & média & 23 & 23 & 51 & 50 & 110 & 105 \\
\hline & desvio padrão & 2,1 & 2,7 & 6,2 & 7,1 & 16,3 & 17,5 \\
\hline \multicolumn{2}{|c|}{ desvio/média (\%) } & 9,1 & 11,4 & 12,2 & 14,1 & 14,8 & 16,8 \\
\hline
\end{tabular}

